\title{
The Mid-Ocean Dynamics Experiment
}

\author{
THE MODE GrouP*
}

\author{
(Received 25 July 1977; in revised form 20 December 1977; accepted 15 January 1978)
}

\begin{abstract}
The Mid-Ocean Dynamics Experiment (MODE-1) was designed to investigate mid-ocean mesoscale eddies. An intensive and extensive program of measurements in three spatial dimensions and time was undertaken in an area southwest of Bermuda from March through mid-July 1973. Principal components of the experiment were an array of moored current meters and temperature-pressure recorders, hydrographic stations, drifting neutrally buoyant floats at $1500 \mathrm{~m}$ tracked by SOFAR, and acoustic and elect romagnetic profilers. During MODE- 1 a smaller scale survey relying on ship-tracked neutrally buoyant floats, a conductivity-temperature (CTD) survey, and a moored current meter array, MINIMODE, wascarried out. The experiment was preceded by MODE- 0 , consisting of measurements by a series of moored current meters and other instruments in the general area selected for MODE-1.

MODE-1 observations were generally within a $300-\mathrm{km}$ radius circle centered at $26^{\circ} \mathrm{N}, 69^{\circ} 40^{\prime} \mathrm{W}$, with a greater concentration of observations in the interior of the circle. The region covers varied topography, with a flat abyssal plain sloping upward to thecontinental rise in the western half and rough topography in the eastern half.

Descriptive, dynamical, numerical results of the experiment are presented. It is concluded that midocean eddies are part of an energetic and structured variability field superimposed on the weaker gyrescale mean circulation. In the western North Atlantic there is a band of eddy variability of around 100 day period and 70-km scale in which currents are horizontally nearly isot ropic; vertical scales are of the order of the depth. The experiment provided conclusive evidence of the existence of mid-ocean eddies and serves as the basis for future experiments, such as POLYMODE, to extend our knowledge of these systems.
\end{abstract}

DURING the past decade, physical oceanographers have directed a considerable effort to exploring and modeling mid-ocean mesoscale 'eddies', which are fluctuating current cells extending throughout the water column. Eddies occur irregularly throughout the World's oceans. They have swirl speeds of 5 to $50 \mathrm{~cm} \mathrm{~s}^{-1}$, and space-time scales of tens to hundreds of kilometers and weeks to months. Associated with the horizontal currents are fluctuating vertical displacements of up to several hundred meters in the main thermocline. Eddies, where they exist, usually dominate the mid-ocean flow.

Understanding the eddies and their role in the general circulation has emerged as a central problem in ocean circulation dynamics. Moreover, understanding eddy dynamics is a prerequisite for both valid modeling of large-scale exchanges of momentum and energy, heat and salt, geochemicals, nutrients and other passive solutes, and for realistic coupled ocean-atmospheric models necessary for longer range weather prediction and climate modeling.

This paper treats the summary findings of one particular eddy experiment, the United States-United Kingdom Mid-Ocean Dynamics Experiment-One (MODE-1), including preliminary and following experiments (MODE-0 and post-MODE) and related eddy

* The 'MODE Group', listed at the end, includes authors of this paper and principal scientific contributors to the MODE experiment. Current addresses are available through the MODE Executive Office, Department of Meteorology, Massachusetts Institute of Technology, Cambridge, MA 02139, U.S.A. The paper was drafted by W. Simmons. 
results deriving from supplementary data sets such as those in the National Oceanographic Data Center (NODC), from numerical experiments, and preliminary U.S. results from POLYMODE. It is arranged so as to set the context for edd y studies (Section 1); to review what actually occurred in the field during MODE (Section 2); to describe briefly the resulting data base and its kinematic and statistical interpretation (Section 3); to discuss and interrelate analytical and numerical interpretations todate and review theories of eddy dynamics (Section 4), and to present the scientific conclusions (Section 5).

There are now well over 100 scientific papers and technical reports on the specific results of MODE-1. These are referred to throughout the text. A few of these papers are introductions, literature reviews, or summaries intended for laymen or non-specialists. These include the articles by Hammond (1974), BretherTon (1975), RoBinson (1975), Holland (1977a), Rhines (1977), Richman, Wunsch and Hogg (1977), and the entire third issue of the nineteenth volume of Oceanus. In addition, there are three MODE internal reports* from fall and winter 1974 to 1975 which (i) summarize the data set in atlas form (MODE-1 SyNOPTIC ATLAS Group, 1974), (ii) present dynamical analyses of the data set (MODE-1 Dynamics Group, 1975), and (iii) review MODE-1 instrument performance and intercomparisons (MODE-1 INTERCOMPARISON GROUP, 1974). The first, intended to be only a preliminary working draft, has undergone revision and extension and been published as the 'Atlas of the Mid-Ocean Dynamics Experiment (MODE-1)' (MODE-1 AtLas Group, 1977).

The latest summary report on theoretical and numerical eddy research is the proceedings of the August 1976 POLYMODE Theoretical Summer Institute held in Yalta (Academy of Sciences of the Ukrainian S.S.R. 1977).

Although MODE was gratifyingly successful in achieving its stated objectives and going beyond them in many cases, it has not 'solved' the eddy problem. Indeed, the authors of this paper are not always unanimous in their support of the conclusions stated. MODE was an eddy experiment at one small place for one short period, and considerable additional data and analysis will be necessary before decisive answers to all the important questions of eddy dynamics and statistics can be found. Plans for the next major eddy experiment, POLYMODE (U.S. POLYMODE ORGanizing CommitTEe, 1976) are noted throughout this paper.

\section{MESOSCALE VARIABILITY PHENOMENA}

Unequivocal discovery of the mid-ocean mesoscale phenomenon occurred in 1959 concurrently with the development of instruments capable of long-term direct measurements of deep velocities. Neutrally buoyant Swallow floats tracked from a nearby vessel at $41^{\circ} \mathrm{N}, 14^{\circ} \mathrm{W}$ in 1958 and near Bermuda in 1959 and 1960 revealed the existence of energetic $\left(10 \mathrm{~cm} \mathrm{~s}^{-1}\right)$ eddies about $200 \mathrm{~km}$ in diameter drifting westward at $2 \mathrm{~cm} \mathrm{~s}^{-1}$ and occupying the entire water column (CREASE, 1962; Swallow, 1961; Swallow, 1971). The work also revealed that oceanographic instrumentation in use at the time was disappointingly inadequate for effective measurements of such motions. More than a decade was necessary to develop and perfect new instrumentation for long-term arrays of direct current measurements and high resolution in situ density measurements. In the interim, oceanographers had little choice but to plan and where possible to search for and try to understand eddies from the few data at hand.

*Available through the MODE Executive Office. 
It is apparent now that eddy signals exist almost everywhere in the World's oceans. The familiar $36^{\circ} \mathrm{N}$ temperature section (FIG. 1) by FUGLISTER (1960) is a particularly striking example of eddy aliasing in a classical hydrographic section. Large amplitude variability throughout the water column is clearly apparent east of $60^{\circ} \mathrm{W}$ but unresolved by the $150-\mathrm{km}$ station spacing. More recently, SEAVER (1975) was able to resolve the eddy signal in the same region over the upper $750 \mathrm{~m}$ by sampling underway with expendable bathythermographs at a $15-\mathrm{km}$ sampling interval (Fig. 2). Other definitive North Atlantic eddy identifications include the 1970 U.S.S.R. POLYGON at $16^{\circ} 30^{\prime} \mathrm{N}$, $33^{\circ} 30^{\prime}$ W (BREKHOVSKIKH, FedOROV, Fomin, KoshLYAKOV and YAMPOLSKY, 1971) and the MODE experiments at $28^{\circ} \mathrm{N}, 69^{\circ} 40^{\prime} \mathrm{W}$ discussed here. Eddies have also been found in the North Pacific (Bernstein and White, 1974; Wilson and Dugan, 1977), the South Pacific (Patzert and Bernstein, 1976), the East Australia Current (ANDrews and SCully-Power, 1976), the Southern Ocean (EltaNIN RePORTs, 1974), the northwest Indian Ocean (Caston and Swallow, 1972), the South Atlantic (DunCan, 1968), and the Arctic (HUNkins, 1974). A thorough discussion of mesoscale current observations is given by SWALLOW (1976).

Not all mesoscale variabilities are alike. The literature on western boundary currents such as the Gulf Stream or Kuroshio abounds with terms like 'meander', 'convoluted', 'bifurcated', 'filamentous', and other descriptors of a well-documented variability now known to be in the mesoscale range (RoBInson, LUYTEN and FugLiSTER, 1974, for example). These mesoscale variabilities are excluded from the class of MODE eddies by virtue of their connection with the instigating currents. 'Mid-ocean' is thus taken to mean several internal deformation radii gyreward from boundary or free-stream effects, sufficiently removed to be in the far field of such forcings.

For the same reason, 'rings', which are spawned from the Gulf Stream and other similar currents, do not qualify, at least not at the time of their formation. Rings form when the sides of elongated meanders coalesce and pinch off from the main current, entrapping in the center water from the opposite side of the current-a useful clue in identifying them (Fuglister, 1972; ChenY, Gemmill, SHAnk, Richardson and WebB, 1976). Vertical displacements and currents in newly formed rings are those of the stream itself, namely, $500 \mathrm{~m}$, and knots in the thermocline. Sargasso Sea rings, which must be cyclonic, form in the Gulf Stream from $75^{\circ}$ to about $60^{\circ} \mathrm{W}$. However, after formation they usually [but not always (RIChardson, Cheny and MANTINI, 1977)] move southwesterly, rejoining the stream as much as 2 to 3 years later (CHENEY and RiCHARDSON, 1976; LAI and RICHARDSON, 1977). During transit, many rings truly qualify as mid-ocean mesoscale variabilities. However, we will distinguish them from 'eddies' because their source is known, they are discernible through their water mass properties, and their life cycle is more or less known.

One other class of ring-like features has been identified. They are less intense by half but broader by about twice than rings and are probably formed further to the east in the North Atlantic (Gould, 1976). A recent study including deep hydrographic stations, current meters, and water sampling (MCCARTNEY, WORTHINGTON and SCHMITZ, 1977) suggests a possible formation zone near $40^{\circ} \mathrm{W}$ with cold North Atlantic water being entrapped. These features reach the bottom and can be tilted in the vertical. One was observed to reverse its sense of rotation below $2000 \mathrm{~m}$. The $34^{\circ} 30^{\prime} \mathrm{N}$ section of Fig. 2 shows a ring centered near $60^{\circ} \mathrm{W}$, and one of the ring-like features centered near $48^{\circ} \mathrm{W}$ with possibly two additional ring-like features further to the east.

We will reserve the term eddy for features such as those on the $29^{\circ} 30^{\prime} \mathrm{N}$ section of 
Fig. 2. They have no obvious distinctive or anomalous water mass properties but rather appear to be energetic cyclonic and/or anticyclonic undulations of mid-ocean ambient isopycnal surfaces, much like the atmospheric synoptic scale, or possibly the variability one might expect from a random field of Rossby waves or two-dimensional turbulence. An unambiguous source(s) or sink(s) of eddy energy has not been suggested in the data. Moreover, it is not certain whether eddy crests and troughs are conserved during propagation, although it appears likely they are not. The physical and dynamical properties of mid-ocean eddies are the principal subjects of the remaining sections of this paper.

Variability is an ocean-wide phenomenon, at least in the North Atlantic. To substantiate that point, all expendable bathythermograph (XBT) traces plus selected hydrographic stations on file at the U.S. National Oceanographic Data Center were analyzed statistically by DANTZLER (1977) for a large part of the North Atlantic. The amplitude of r.m.s. deviations of the $15^{\circ} \mathrm{C}$ isotherm normalized by half the local mean squared buoyancy frequency (i.e. local potential energy per unit mass of the variability), were compared to the mean topography of the $15^{\circ} \mathrm{C}$ isotherm (Fig. 3) and indicated that upper layer variability could follow the major current systems over the gyre. Greatest intensities occurred in and around the Gulf Stream system, and intermediate intensities occurred in the North Atlantic Current, continuing south of the Azores, the Canary Current, and the North Equatorial Current west of the Mid-Atlantic Ridge. This variability could, of course, be associated with the mean currents themselves and not represent what we have called eddy motion. Other areas, some having sparse data coverage, are of comparatively low intensity, particularly the central region of the gyre centered along $28^{\circ} \mathrm{N}$. These results are in good agreement with an independent analysis of surface currents by WYRTKI, MAGAARD and HAGER (1976), in which mean and fluctuating surface kinetic energies are computed by 5-degree squares based on several million merchant ship reports of ship's set. Their results suggest that the ratio of mean to eddy kinetic energy may be as high as one or two in the major current systems of the World's oceans and as low as $1 / 20$ or $1 / 40$ in the central regions of the major gyres.

\section{MID-OCEAN DYNAMICS EXPERIMENT}

MODE-1 was a large-scale cooperative experiment derived from the collaborative and mutual efforts of many theoretical, experimental, numerical, and instrumentally-oriented investigators from many institutions, primarily in the U.S. and U.K. Principal goals of the experiment were to determine the kinematic properties of the eddy field, to map the field in varying degrees of accuracy so as to gain information on the dynamics, and to establish preliminary statistical estimates. This work was to go hand-in-hand with theoretical efforts to model eddy phenomena and study their dynamical properties numerically. There were secondary goals as well, some held in reserve in the event of fortuitous success, others natural out-growths of the number of ships and workers and the amount and diversity of instrumentation in use.

The experimental work to be discussed can be subdivided into four distinct experiments that were nearly continuous in time and in the same general location, as follows (see also Fig. 4): (i) 'MODE-0' included preliminary mooring and hydrographic work from fall 1971 through winter 1972. (ii) The period of intensive experimentation and maximum instrumentation and collaboration in the same region, called 'MODE-1', extended from March through mid-July of 1973. (iii) SOFAR floats in a somewhat larger region and site moorings 


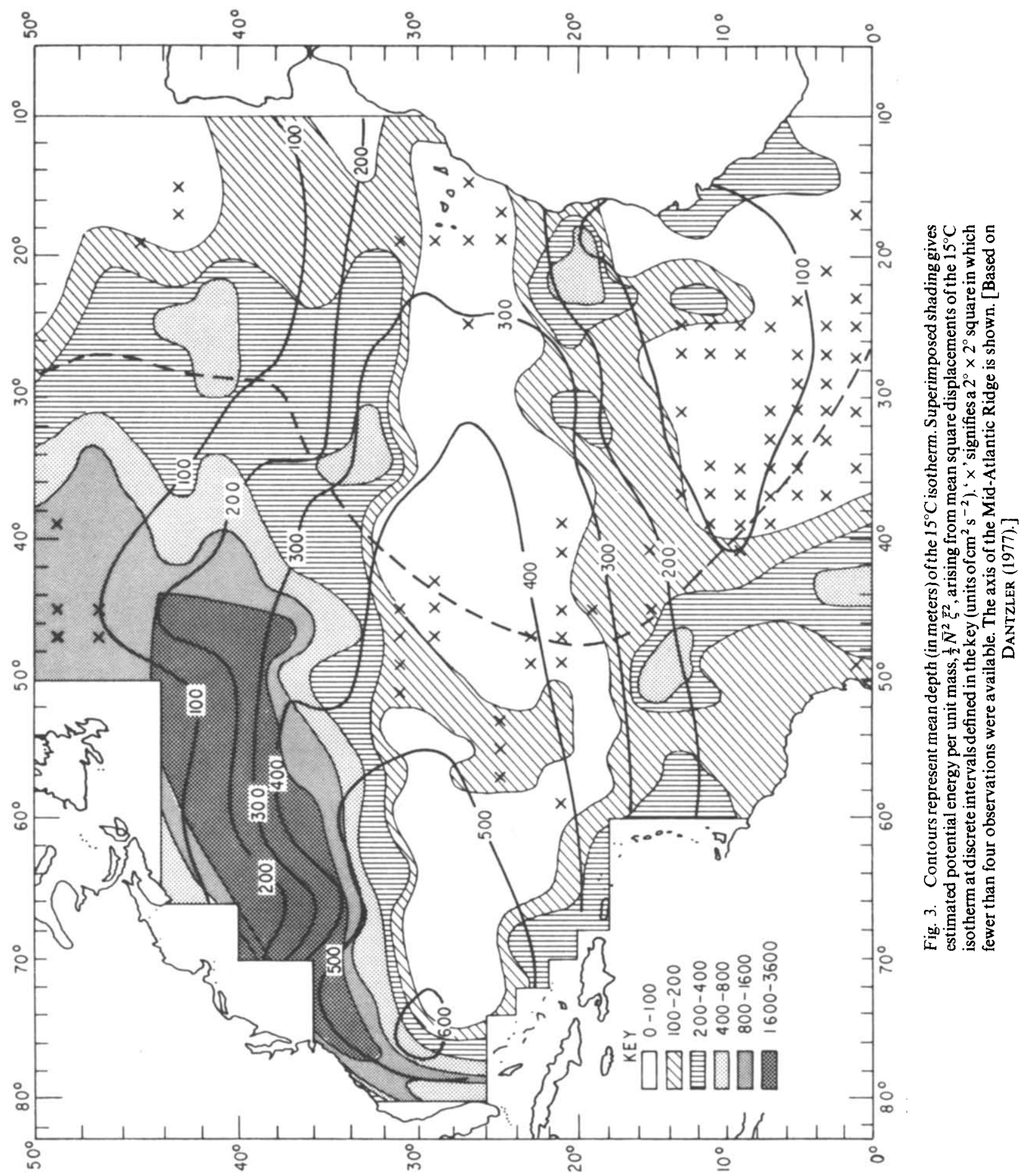




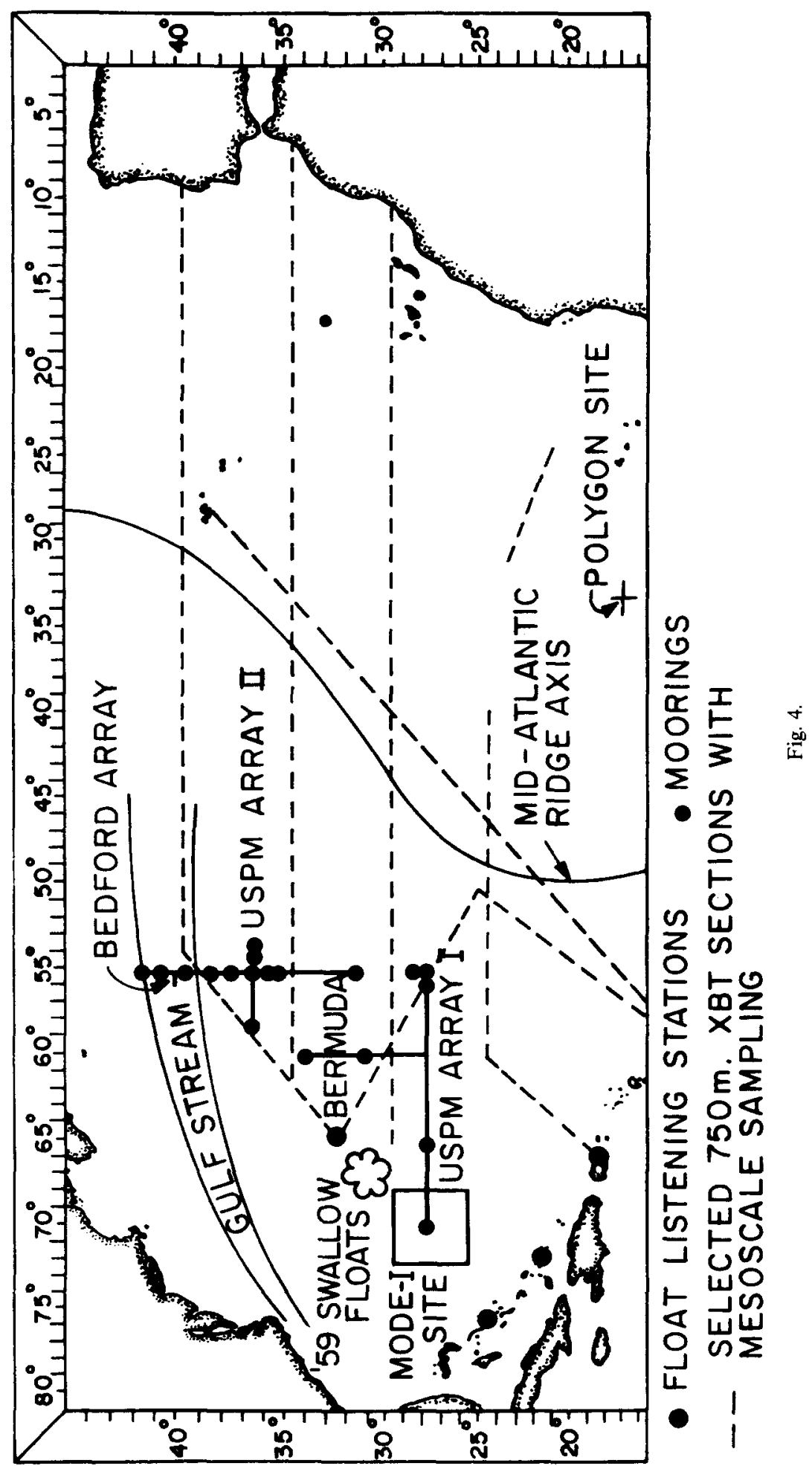



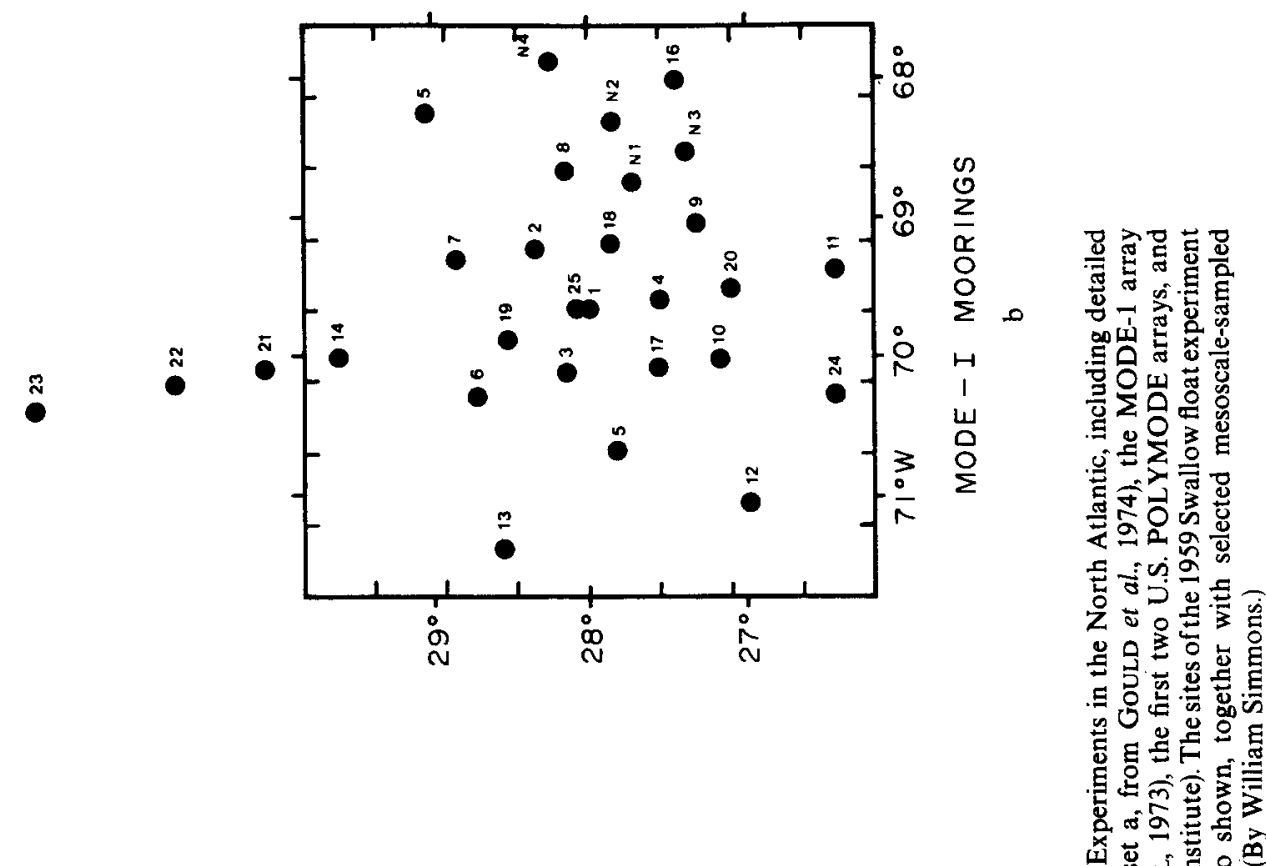

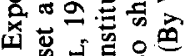

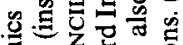

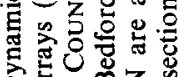

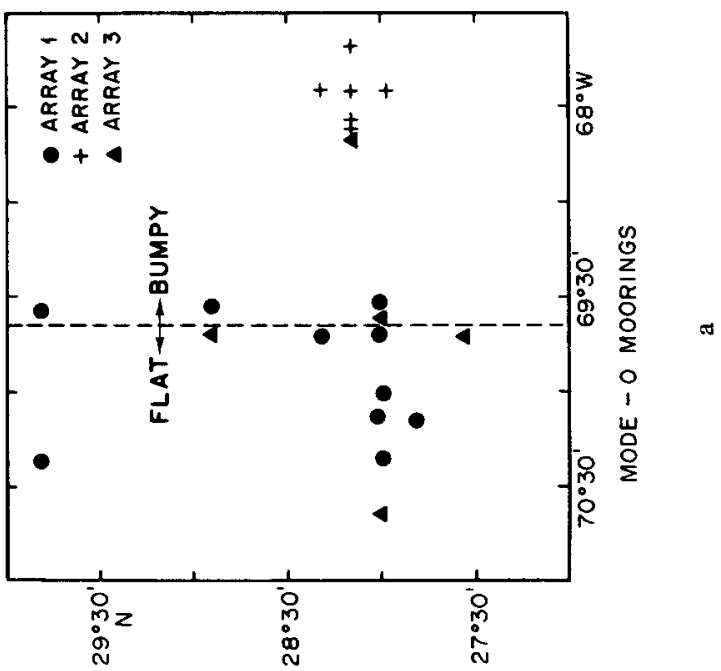

a

둘돌

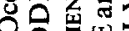

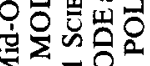

政为

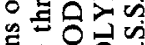

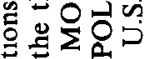

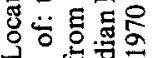

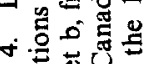

量导导焉 
maintained from MODE-1 until January 1977 and July 1974, respectively, comprise most of the 'MODE-1 extension', or 'post-MODE'. (iv) As the last MODE mooring was retrieved, the first U.S. POLYMODE moorings were set within and to the east and north of the MODE-1 area to be maintained until July 1977 . These settings plus various closely spaced XBT sections, preliminary XBT surveys and SOFAR float work, and reexamination of existing historical data for eddies are included here as a fourth component, although in reality they are elements of a successor experiment to MODE-1. The remainder of this section outlines these four experiments in greater detail.

\section{A. MODE-0}

Large-scale experimentation began with the three moored arrays set in the 2-degree square centered on $28^{\circ} 30^{\prime} \mathrm{N}, 69^{\circ} 30^{\prime} \mathrm{W}$ (Fig. 4). It was intended to test proposed MODE-1 sites and to determine spatial scales required for MODE-1 sampling (Gould, SCHMITZ and Wunsch, 1974). Eight moorings from November 1971 to February 1972 (Array 1) were followed by two site moorings, replaced by the six moorings of Array 2 from March 1972 to May 1972, and then five moorings of Array 3 from May 1972 to November 1972. The instruments were set at 1500 and $4000 \mathrm{~m}$ with additional instruments at $500 \mathrm{~m}$ in Array 3 . They were primarily current meters including the new vector averaging current meters (VACMs) and a few temperature-pressure sensors. Both subsurface and surface buoyancy was used, the latter for the last time in MODE because of the serious amplification it induced in current records at all depths (Gould et al., 1974; SCOR WORKING GrouP 21, 1974). A preliminary grid of STD stations was also occupied thoughout MODE-0. After analysis and much discussion of the MODE-0 data, the site finally chosen for the MODE-1 experiment was a compromise based on dynamical, instrumental, and logistic considerations. It was centered at $28^{\circ} \mathrm{N}, 69^{\circ} 40^{\circ} \mathrm{W}$, with an overall radius of $300 \mathrm{~km}$, but with instrumentation more densely spaced toward the centerthus most of the hydrographic station work and mooring array was inside the $200-\mathrm{km}$ radius (MODE SCIENTIFIC CounCIL, 1973). The topography of the eastern half of this area is characterized by the abyssal hills of the Bermuda Rise, that of the western half by the Hatteras Abyssal Plain, and far to the west there is the continental slope leading up to the Blake Plateau (BusH, 1976, and Fig. 5). The region is well outside the Gulf Stream's path and in that sense is 'mid-ocean'.

\section{B. $M O D E-1$}

MODE-1 occurred during March through mid-July 1973 (year days 60 to 200) but many of the elements were deployed for only part of this period. For example, the above period includes the launching and recovery of the instrumentation-itself a time-consuming operation. The central mooring was actually in place between days 70 and 183, but outer moorings were in place for up to 30 days less. The ship-borne density program [of conductivity-temperature-depth (CTD) lowerings] extended from day 71 to 192 . The SOFAR floats were tracked throughout MODE-1 and afterwards, but they first appeared in substantial numbers at about day 97 .

The main components of the MODE- 1 experiment were:

(i) an array of moored current meters and temperature-pressure recorders (RICHMAN, 1976);

(ii) hydrographic stations (CTD, STD, Nansen bottles and other samplers) were made 


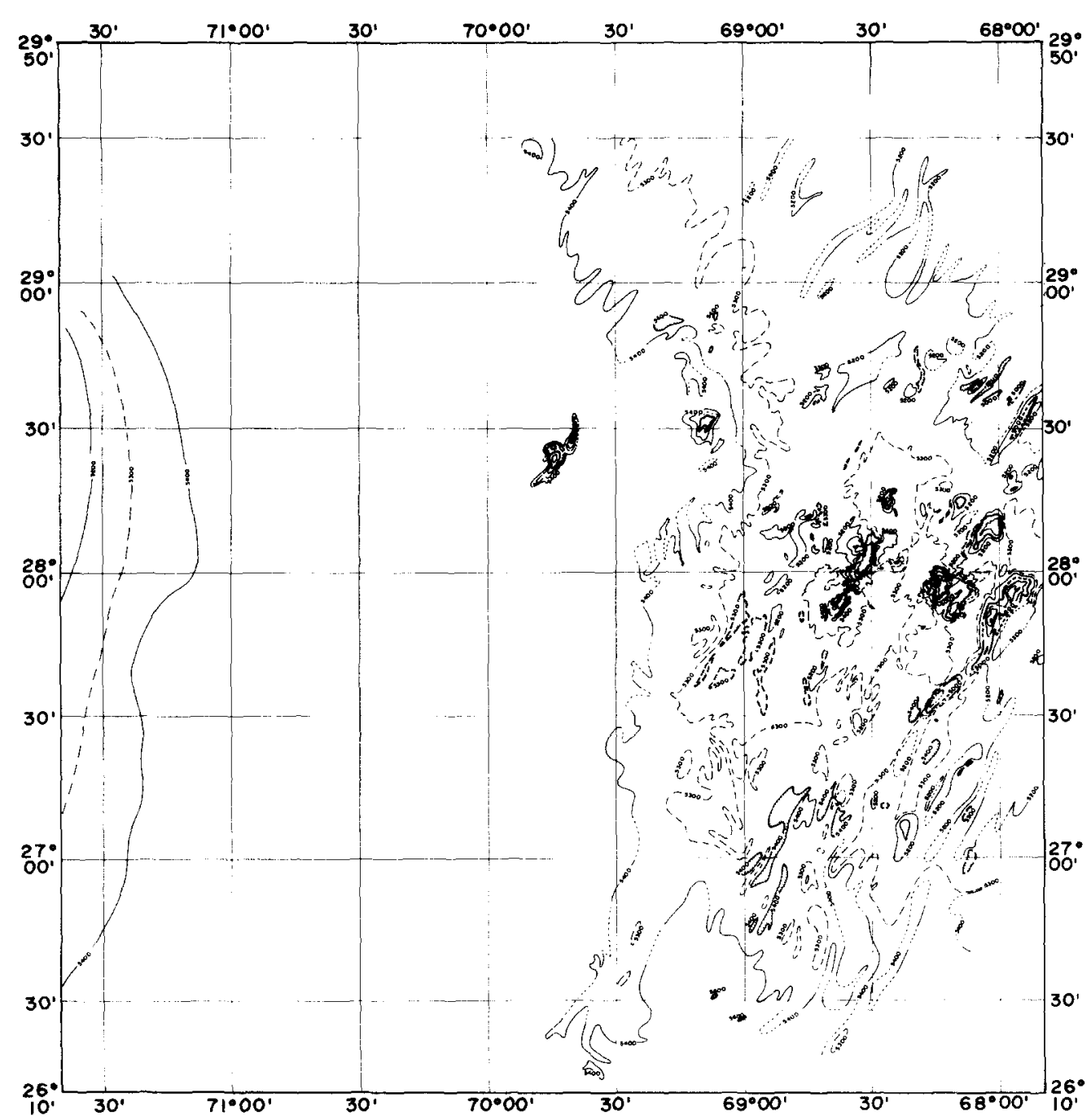

Fig. 5. Detailed bathymetry in the $400-\mathrm{km}$ square centered on MODE center. Note the rough topography to the east, flat abyssal plain to the immediate west, and continental rise to the extreme west. [From BusH (1976).]

from ships on a regular grid-from which the dynamically important density field was computed (MODE-1 ATLAS Group, 1977);

(iii) a field of drifting neutrally buoyant floats at about $1500 \mathrm{~m}$, tracked acoustically from shore-based stations using the SOFAR channel (ROSSBY, VoORHIS and WEBB, 1975). Some of the floats carried additional instrumentation and were recoverable;

(iv) acoustic (POCHAPSKY, 1976) and electromagnetic (SANFORD, 1974; SANFORD, DREVER and DUNLAP, 1978) profilers dropped from ships to obtain vertical profiles of the horizontal velocity;

(v) a smaller-scale survey using ship-tracked neutrally buoyant floats (Swallow, MCCartney and Millard, 1974) at several levels, an independent CTD survey, and a moored current meter array. This experiment, embedded within MODE-1, 
was conducted by scientists from the U.K., and was known collectively as MINIMODE (SWALLOW, 1977).

In addition to these main components of MODE-1, other programs were undertaken simultaneously:

(vi) an extensive bottom experiment involving bottom-mounted pressure and temperature recorders (BAKER, WEARN and HILL, 1973; SNODGRASs, BROWN and MUNK, 1975; Brown, Munk, SNodgrass, Mofjeld and Zetler, 1975) deep-sea tide gauges (ZeTler, Munk, Mofjeld, Brown and Dormer, 1975; Hendry, 1977), inverted echo sounders (W ATTS and RossBY, 1977), electric field recorders (POEHLS and VON HERZEN, 1976), and magnetometers (Bennett and Filloux, 1975; Cox, Filloux, Gough, Larsen, Poehls, Von Herzen and Winter, 1978);

(vii) auxiliary salinity and temperature surveys on a fine horizontal scale made by tow-fish (KATZ, 1975), XBT and (Airborne) AXBT sampling;

(viii) determination of surface current and vertically integrated current by a new 'Airdropsonde' launched from aircraft (RICHARDSON, WHITE and NEMETH, 1972);

(ix) Bathymetric mapping (BusH, 1976); and

(x) sea-surface meteorology from participating ships.

The type and amount of data from sources (i) through (v), which is the basic large-scale long-duration material describing the MODE-1 eddy and the overall eddy field are as follows:

(i) Current meter data are available from 83 recorders on 26 main moorings (SCHMITZ, 1976a, b, 1977a). The moorings that yielded data were: one at the center; five on a $50-\mathrm{km}$ radius circle about the center; seven on a $100-\mathrm{km}$ circle; nine on a $180-\mathrm{km}$ circle; and three on a line bearing $350^{\circ}$ true (northward) from the center at distances of 230,310 , and $410 \mathrm{~km}$. Three moorings yielded no data. Currents were measured at least at one level on all moorings, and at most at eight on the central mooring. There were technical difficulties with the new VACM current meters (Dexter, Milliman and Schmitz, 1975) and few records are reliably continuous over the entire period of MODE-1. Fifty temperature and pressure records were obtained using independent recorders at 16 of the moorings: one at the center; three on the $50-\mathrm{km}$ circle; six on the $100-\mathrm{km}$ circle; and six on the $180-\mathrm{km}$ circle. The central mooring yielded 10 levels of data from these recorders. Most of these records are good throughout the entire MODE-1 period and provide an independent way of mapping the temperature field (HoGG, 1977).

(ii) Approximately 800 complete CTD stations were obtained at 77 fixed grid points. About $2 / 3$ of the casts were to $3000 \mathrm{~m}$, about $1 / 3$ to the bottom, and a few to $1500 \mathrm{~m}$. The grid points were spaced roughly at $33-\mathrm{km}$ intervals within the $50-\mathrm{km}$ radius circle and at $50-\mathrm{km}$ intervals in the annulus bounded by the $100-\mathrm{km}$ and $200-\mathrm{km}$ circles. Using Research Vessels Chain, Discovery, Hunt, Researcher, and Trident, coverage of the grid was fairly uniform for mapping purposes from day 71 to day 192 ; suitable maps were drawn for the nine 12-day mean periods from days 81 to 188 depicting temperature, sigma-theta, dynamic height, etc., for various levels (MODE-1 SyNOPTIC ATLAS Group, 1974; LEETMAA, 1977d).

(iii) Trajectories of the 20 SOFAR floats at a nominal $1500-\mathrm{m}$ depth have been computed. Some floats, instrumented to sense temperature and vertical excursion, were recovered; others were reset and allowed to drift freely. Two years after MODE-1, one-third of the floats were still being tracked (FreELAND, RHINEs and RossBy, 1975). One float continued to be trackable into early 1977 . From the instrumented floats five records of temperature 
and vertical component of velocity and four of pressure were obtained, over most of the duration of MODE-1.

(iv) The vertical profiler work was done from the Chain and Eastward. Eleven acoustic profiles were obtained between days 157 and 168 at the center of the region (PoCHAPsky, 1976). The electromagnetic profiler was used on two occasions: during days 136 to 146 five drops were made at the central mooring, and during days 160 to 168 29 drops were made at the center. Sixteen additional drops were made at other points within the 200-km radius during these two intervals (SANFORD, 1975; LEAMAN and SANFORD, 1975).

(v) MINIMODE moored current meter data are included in the tabulation set forth above in (i). The four MINIMODE moorings were east-southeast of center in such a way that the $50-\mathrm{km}$ spacing was extended out over the rough topography to the $180-\mathrm{km}$ radius-for days 96 to 143 . Trajectories of neutrally buoyant Swallow floats [independent of the SOFAR floats (iii)] were obtained for limited times but at many levels in two areas: (a) a $100-\mathrm{km}$ square just west of center where the 24 trajectories are of 3 to 21 days' duration centered at day 107 and at levels from 530 to $3820 \mathrm{~m}$; and (b) a somewhat larger rectangular area extending from approximately 70 to $240 \mathrm{~km}$ east of center where the 28 trajectories were of 5 to 22 days' duration, centered at day 138 , and at levels from 530 to $4190 \mathrm{~m}$ (Swallow, 1977).

\section{MODE-1 extension}

Post-MODE data consisted mainly of:

(i) Two site moorings, one at MODE center and one almost due east of it separated by $100 \mathrm{~km}$, maintained from MODE-1 until July 1974 when the eastern mooring was retrieved. The MODE center mooring was maintained until May 1975.

(ii) The SOFAR float array, which was allowed to disperse naturally after MODE-1, was tracked as long as signals could be detected unambiguously. Battery life, migration out of the sound channel (creep-induced sinking at approximately $0.4 \mathrm{mday}^{-1}$ ) and displacement out of the range of the listening stations all contributed to the thinning of the array.

\section{POLYMODE}

The onset of U.S. POLYMODE mooring work overlapped slightly the conclusion of post-MODE. The post-MODE mooring at MODE-center was, in its last setting from August 1974 to May 1975, an element of U.S. POLYMODE Array I comprising seven moorings overall and designed to test energy levels east and north of the MODE-1 site (SCHMITZ, 1976a). U.S. POLYMODE Array II followed immediately along $55^{\circ} \mathrm{W}$ and $37^{\circ} \mathrm{N}$. It was designed to gather stable eddy statistics over a total exposure time of 27 consecutive months. This array was augmented by three deep long-term moorings set by Bedford Institute (Canada) along the axis of the Gulf Stream just upstream from Array II.

Long sections of closely-spaced XBT drops were begun on a ship-of-opportunity basis in 1974 (Figs. 2 and 4, Seaver, 1975) to explore eddy properties over the breadth of the North Atlantic (LeETMAa, 1977b).

POLYMODE SOFAR float work, with a new constant-level float that telemeters temperature and pressure in addition to being SOFAR trackable, was begun in early 1976 in the Nares Plain area south of the MODE-1 site. The array was slowly increased through 1976 and 1977 as engineering data confirmed the reliability of the new design. 


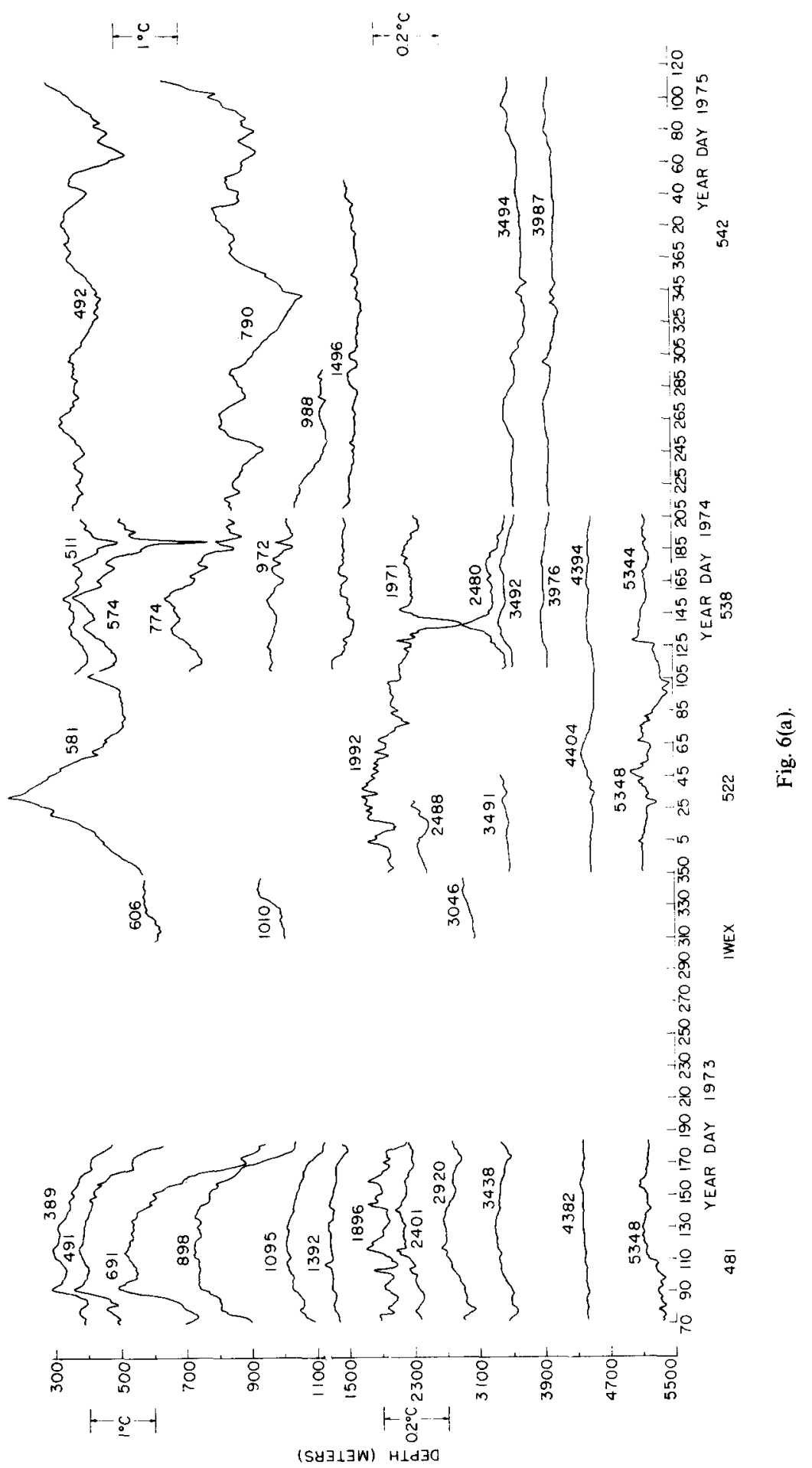




$$
\text { - ․․‥ }
$$
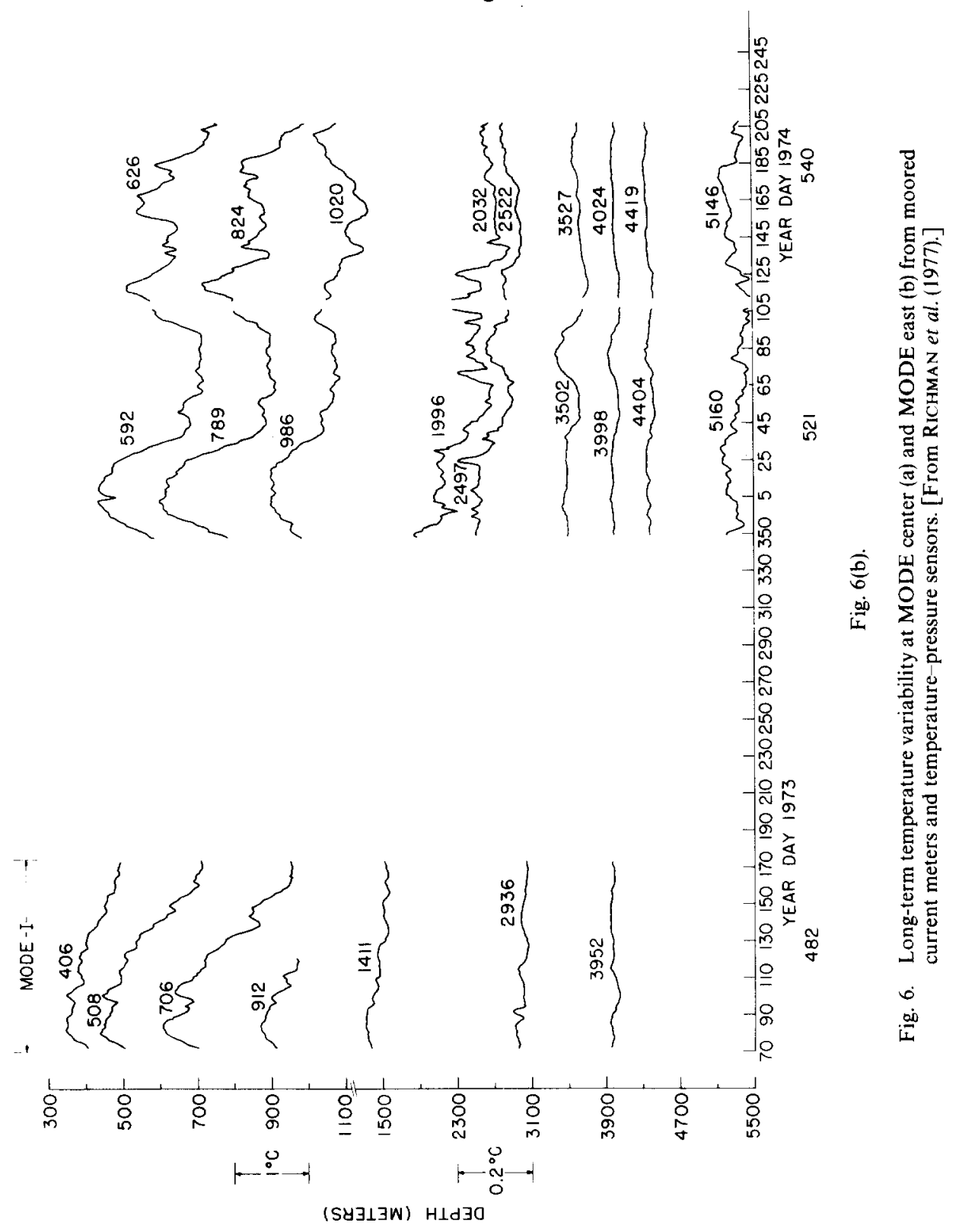


\section{DESCRIPTIVE RESULTS}

\subsection{Long-term temperature and velocity-time series}

The observed temperature variability at MODE-center and MODE-east plotted at mean sensor depth in the vertical, for the entire 2-year MODE-1 and post-MODE period is shown in Figs. 6a and 6b (from Richman et al., 1977). Many of the features of the low-frequency fluctuations in the region may be seen, including the MODE-1 eddy itself, marked by an $0\left(1^{\circ} \mathrm{C}\right)$ temperature increase in the main thermocline peaking near year day 83 (late March), 1973 at MODE east, and near day 93, 1973 at MODE center. The implied westward phase propagation is confirmed (see below) at all but the greatest depths and varied from 2 to $5 \mathrm{~km} \mathrm{day}^{-1}$. The entire water column was displaced downward by varying amounts, suggesting a low baroclinic mode. Although that displacement persisted for the entire duration of MODE-1, the initial increase in temperature was quite abrupt, requiring only about 10 days in the thermocline. The trailing edge was somewhat less abrupt. A temperature signal similar to the anticyclonic MODE-1 eddy passed through the region near day 5, 1974 at MODE-east and near day 30, 1974 at MODE-center. A mesoscale thermocline elevation, possibly of higher mode, may be seen at MODE center near day 335,1974 . Smaller-scale variability is apparent in the very deep records (over $5000 \mathrm{~m}$ ) and in the depth band 1500 to $2800 \mathrm{~m}$. Extremely energetic isolated events, including some suggesting large vertical divergences, also occur (such as near year day 135 and 190, 1974 at MODE center).

Equally long-term current meter records were obtained from the same moorings (Chausse and TARBELl, 1976). Their spectra are discussed in the section on scales. Exceedingly long-time series of eddy variability are provided by the quasi-Lagrangian SOFAR float measurements. A composite diagram of all the MODE SOFAR float tracks is shown in Fig. 7 (Dow, RossBy and SignorinI, 1977). Note the rich variety of types of path and scales of motion, and the general dispersion of the cluster to the south and west, with little spreading to the east and almost none to the north. The spreading of floats usually took place in one of two ways. In the first, lasting up to a few months, a float would drift slowly away from its launch position in a manner similar to a random walk, straying up to a few hundred kilometers from its initial position. In the second, the float would suddenly 'break away' from the MODE area toward the southwest at speeds somewhat higher than those of the MODEarea, and in a nearly translational motion with much less eddying than was typical of the MODE area. There were notable exceptions to this general behavior. One float remained within $300 \mathrm{~km}$ of its original launch for 30 months before breaking away. Two of the floats broke off to the west, crossed the Blake-Bahama Outer Ridge, and there appeared to be entrained in an eddy approximately $80 \mathrm{~km}$ in diameter with azimuthal velocities as high as $40 \mathrm{~cm} \mathrm{~s}^{-1}$. The floats continued west and entered a narrow $(\sim 60 \mathrm{~km})$ deep jet flowing south along the Blake Escarpment (RISER, FREELAND and RossBy, 1977). Two months later, a third float showed similar behavior along the Escarpment. Southward velocities of the floats in this current were as high as $52 \mathrm{~cm} \mathrm{~s}^{-1}$. The paths of these floats were closely related to the local bottom topography even though the floats were everywhere at least $3000 \mathrm{~m}$ above the bottom. Farther to the south, the floats showed little tendency to continue along the Bahamas Escarpment.

From the long-term records overall, it appears that the field of mesoscale variability is a good deal more complicated than that of a lattice-like close-packed pattern of uniformly swirling eddies. Rather, the eddies, when they do exist, may not be vertically coherent 


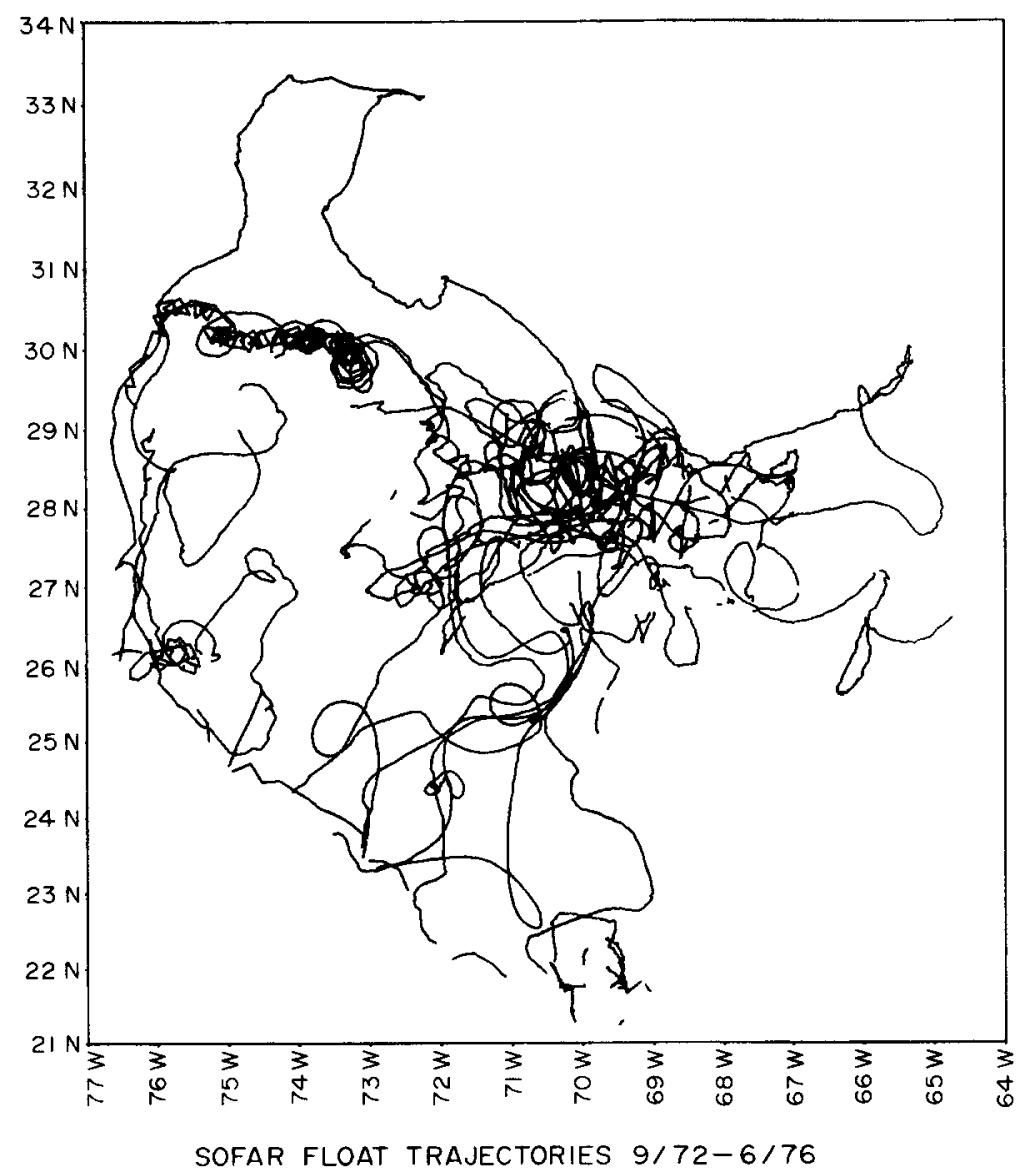

Fig. 7. The superimposed trajectories of all SOFAR floats tracked during MODE. [From Dow et al. (1977).]

throughout the water column and their overall horizontal pattern may be confused by the breadth of their range of scales and frequencies. The field may be viewed as essentially random, with a space-time continuum of scales. MODE-1-like eddies are common occurrences, but they are neither exclusive nor necessarily dominant features of the field. Extrapolation of the results of the MODE-1 dense array in either time or space may therefore produce a somewhat biased picture of mid-ocean variability.

\subsection{Maps}

One of the primary objectives of MODE-1 was to map the mesoscale temperature and current fields with high accuracy over an eddy scale and with moderate accuracy over adjoining scales. A composite map of temperature at three depths in the water column (from RICHMAN, 1976) and of current stream function (from FREELAND and GouLD, 1976) for four selected time periods spanning the dense sampling periods of MODE-1 is shown in Fig. 8. The maps were constructed by objective analysis (GANDIN, 1965; BRETHERTON, DAVIS and FANDRY, 1976). At $420 \mathrm{~m}$ a warm core double maximum eddy of 250 - to $400-\mathrm{km}$ 

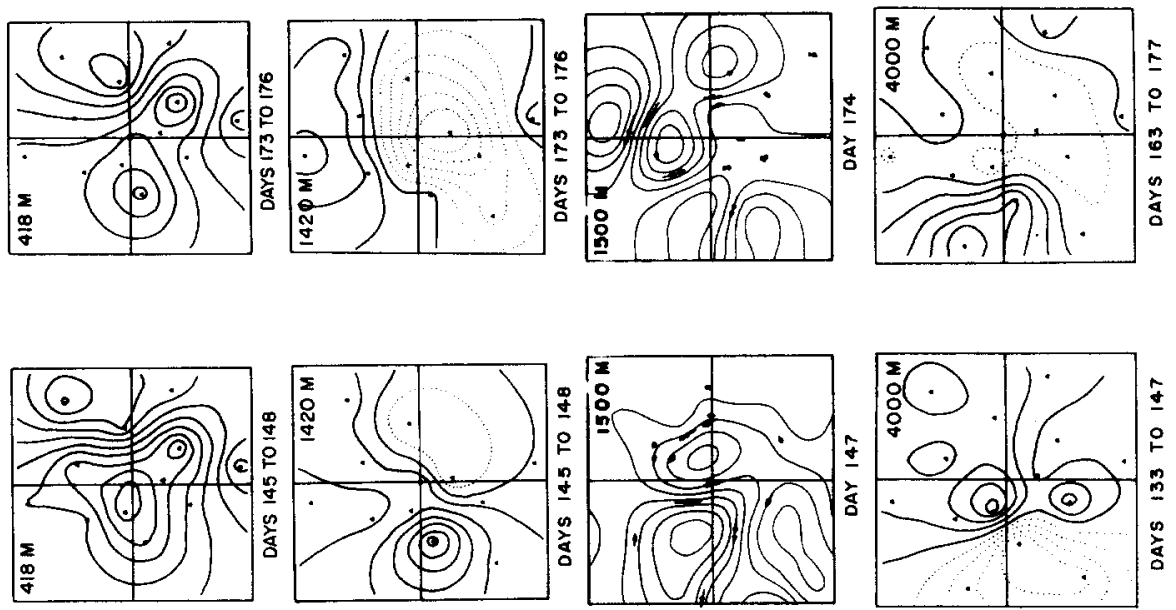

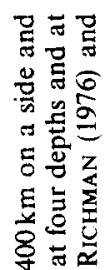
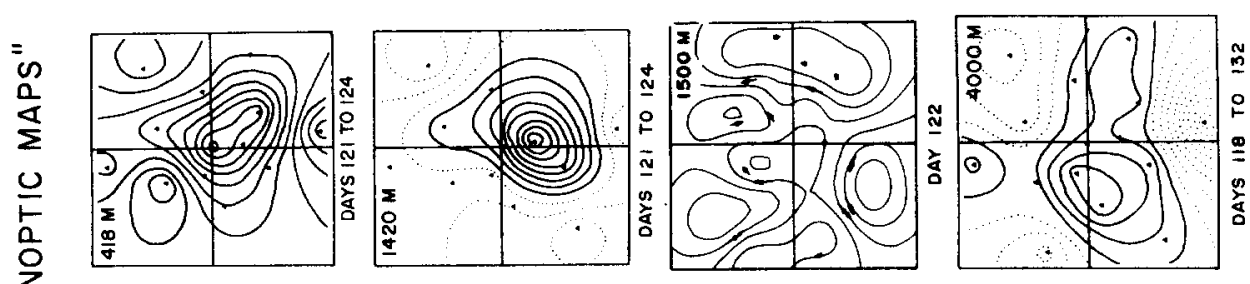

믈 훌 궁형 荘完

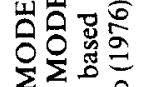
政 픙영

0
0
0
1
1
1
U
0
0
$=$
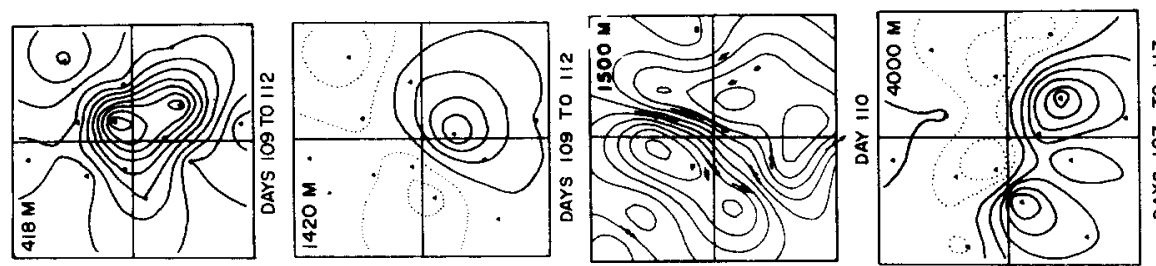

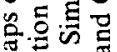
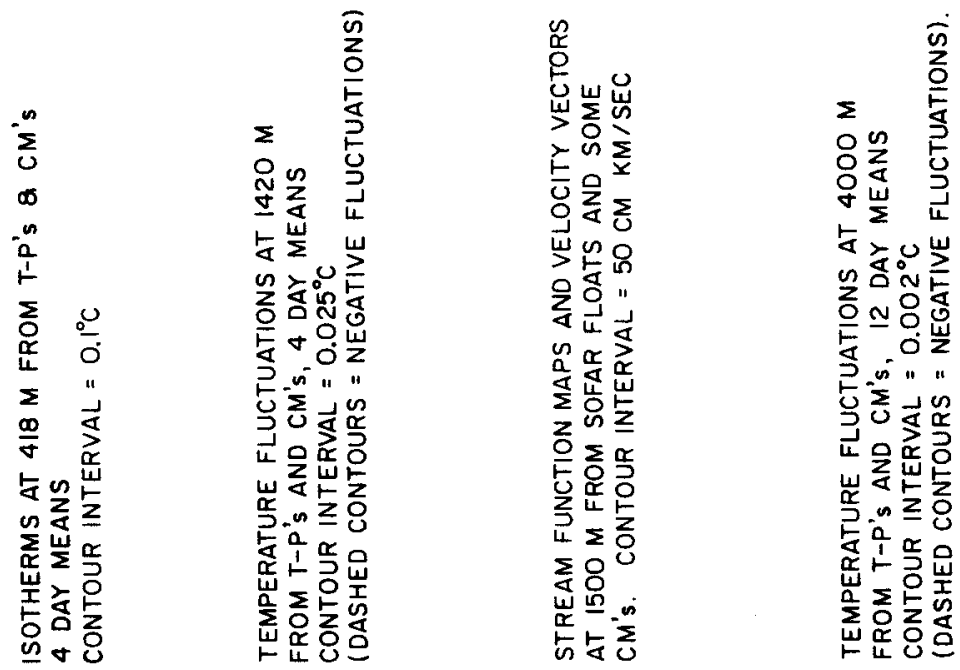
diameter initially centered east of MODE-center drifted westward at an irregular rate, weakening in amplitude and increasing somewhat in horizontal size as it did. As a by-product of objective analysis, a mean field can be estimated and subtracted out to expose fluctuations about it. At $1420 \mathrm{~m}$ a mean spatial gradient due to a north-south cold trough about twice the amplitude of the spatially averaged fluctuations obscures the patterns. Only the fluctuating field is shown. At the outset, a single maximum warm core depression appears well aligned with the $420-\mathrm{m}$ signal. It drifted westward and out of the array well before the $420-\mathrm{m}$ eddy and was replaced by a somewhat larger cold core signal. Smaller-scale features occur in the temperature maps, but these could be due to Mediterranean water $T-S$ anomalies, which would have no steric effect (HAYES, 1975).

Stream function maps were drawn at $1500 \mathrm{~m}$, the nominal depth of the SOFAR float cluster, where current data were plentiful throughout MODE-1 (FREELAND and GouLD, 1976). The current field responds to the total density field: mean, trend, and fluctuations, and thereby close correspondence to $1420-\mathrm{m}$ temperature fluctuations is not to be expected. Indeed, at day 108 a north-south jet dominated the flow inducing a double-eddy pattern. This jet, with speeds up to $12 \mathrm{~cm} \mathrm{~s}^{-1}$, was the most energetic single velocity event at $1500 \mathrm{~m}$. Later, the jet weakened and the correspondence with $1420-\mathrm{m}$ temperature patterns improved somewhat including the appearance of a cold cyclonic eddy in the final time period. At $4000 \mathrm{~m}$, mean spatial variations comparable to the fluctuations again appear-possibly real, possibly instrumental. Deviations from the mean are plotted, but it is difficult to trace specific features at $4000 \mathrm{~m}$. The patterns, which are somewhat smaller than in the upper levels, tend to appear and disappear as though aliased. Westward propagation is not convincingly demonstrated.

Maps of the time variation of temperature and stream function extrema along $28^{\circ} \mathrm{N}$ and $69^{\circ} 40^{\prime} \mathrm{W}$ were computed (Fig. 9) to quantify phase propagation (RICHMAN, 1976; FreEland and Gould, 1976). After day 94, i.e., after the deployment of sufficient instrumentation for accurate mapping, the 420-m level temperature shows variable western propagation at speeds from 1.2 to $3.3 \mathrm{~km}$ day $^{-1}$. At $1420 \mathrm{~m}$, a westward motion at 2 to $3 \mathrm{~km} \mathrm{day}^{-1}$ is noted in both total and fluctuating temperature fields, while the stream function field, about $100 \mathrm{~m}$ deeper, indicates more than $5 \mathrm{~km} \mathrm{day}^{-1}$. At $4000 \mathrm{~m}$, it is not possible to trace specific features convincingly in either the total or fluctuating temperature fields, although current meter-based stream functions indicate a believable $5 \mathrm{~km} \mathrm{day}^{-1}$ westward propagation. At no level and for no data was north-south phase propagation observed at these scales.

An alternative mapping scheme introduced by McWILLIAMs (1976b) uses SOFAR float data to map stream function at $1500 \mathrm{~m}$ as an absolute velocity base. Dynamic height relative to $1500 \mathrm{~m}$ from the MODE-1 density data is then used in an objective scheme to provide stream function at other levels from 30 to $5000 \mathrm{~m}$ in the water column. These maps suggest a more nearly close-packed eddy field with from four to eight eddy centers in the $400-\mathrm{km}$ square centered on $28^{\circ} \mathrm{N}, 69^{\circ} 40^{\prime} \mathrm{W}$. Dynamic topography mapping accuracy falls off toward the periphery of the region, but the eddy extremes are relatively well determined. Eddy centers can usually be traced from level to level downward through the water column, even though the deeper levels tend to have more extrema than shallow and thermocline levels. The eddy centerlines tilt irregularly in amount and direction with depth, but the eddy axes of elongation, scale, and other gross features are relatively constant with depth. McWilliams used the maps to evaluate various bulk characteristics 

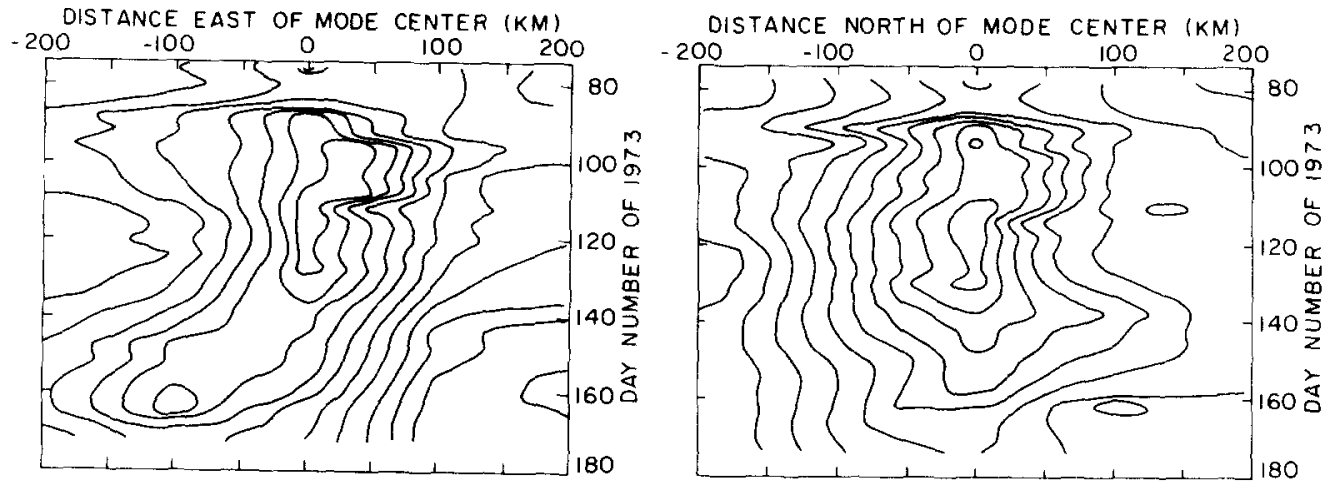

DISTANCE EAST OF MODE CENTER (KM)
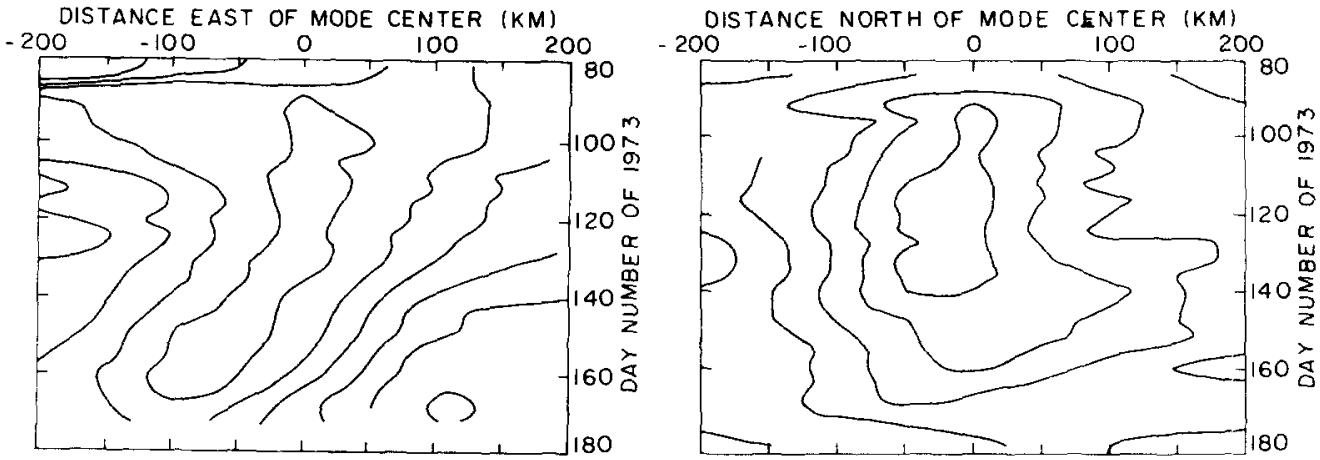

DISTANCE EAST OF MODE CENTER (KM)

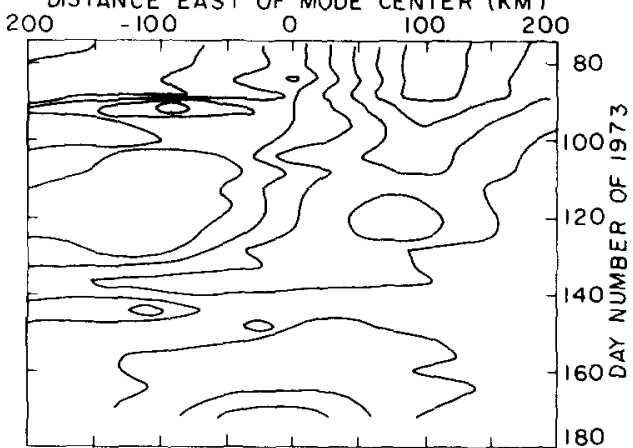

DISTANCE NORTH OF MODE CENTER (KM)

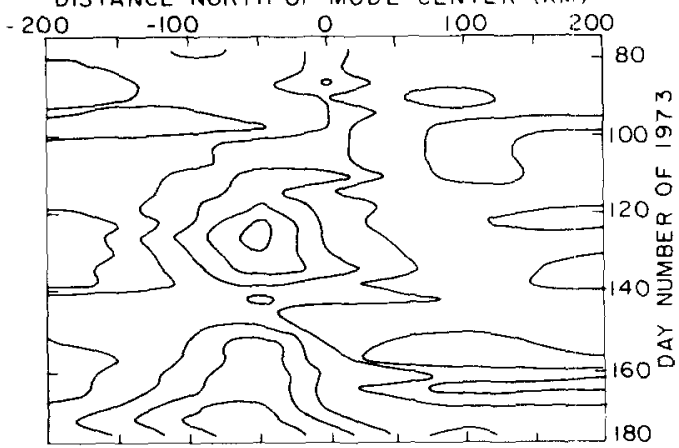

Fig. 9(a). Phase propagation plots of temperature patterns at 420 (top), 1420 (middle), and $1500 \mathrm{~m}$ (bottom) based on moored sensors (from RichmaN, 1976). 


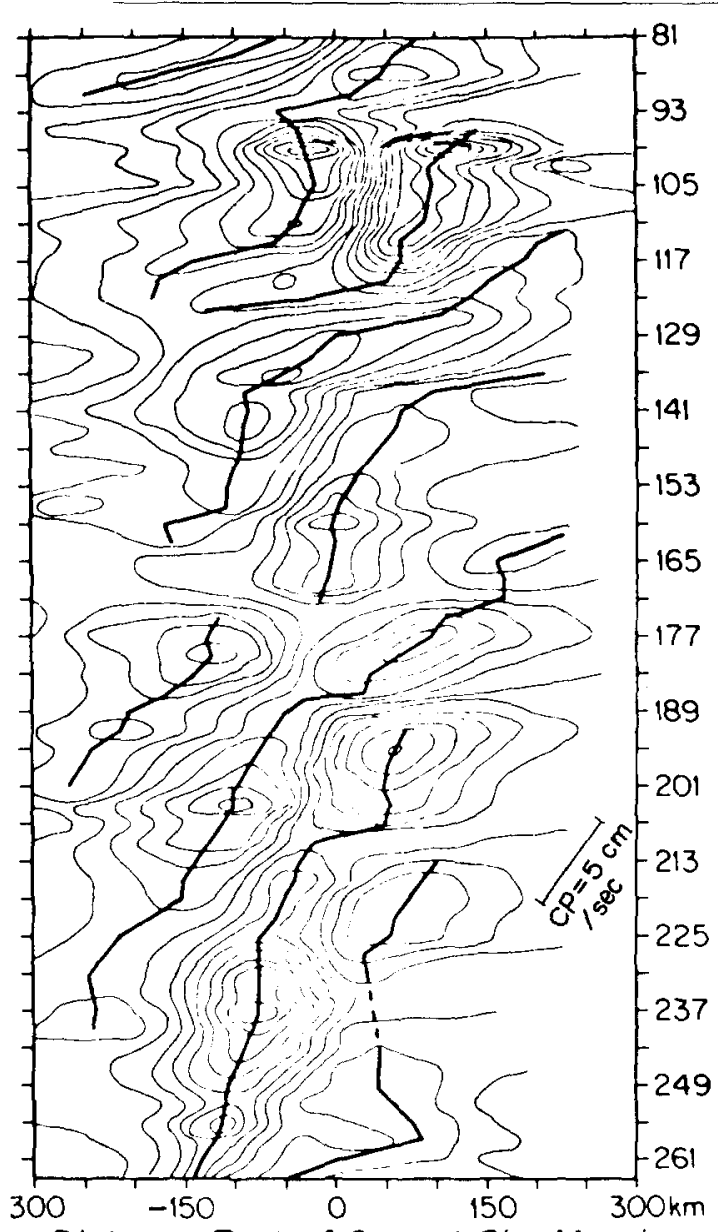

Distance East of Central Site Mooring

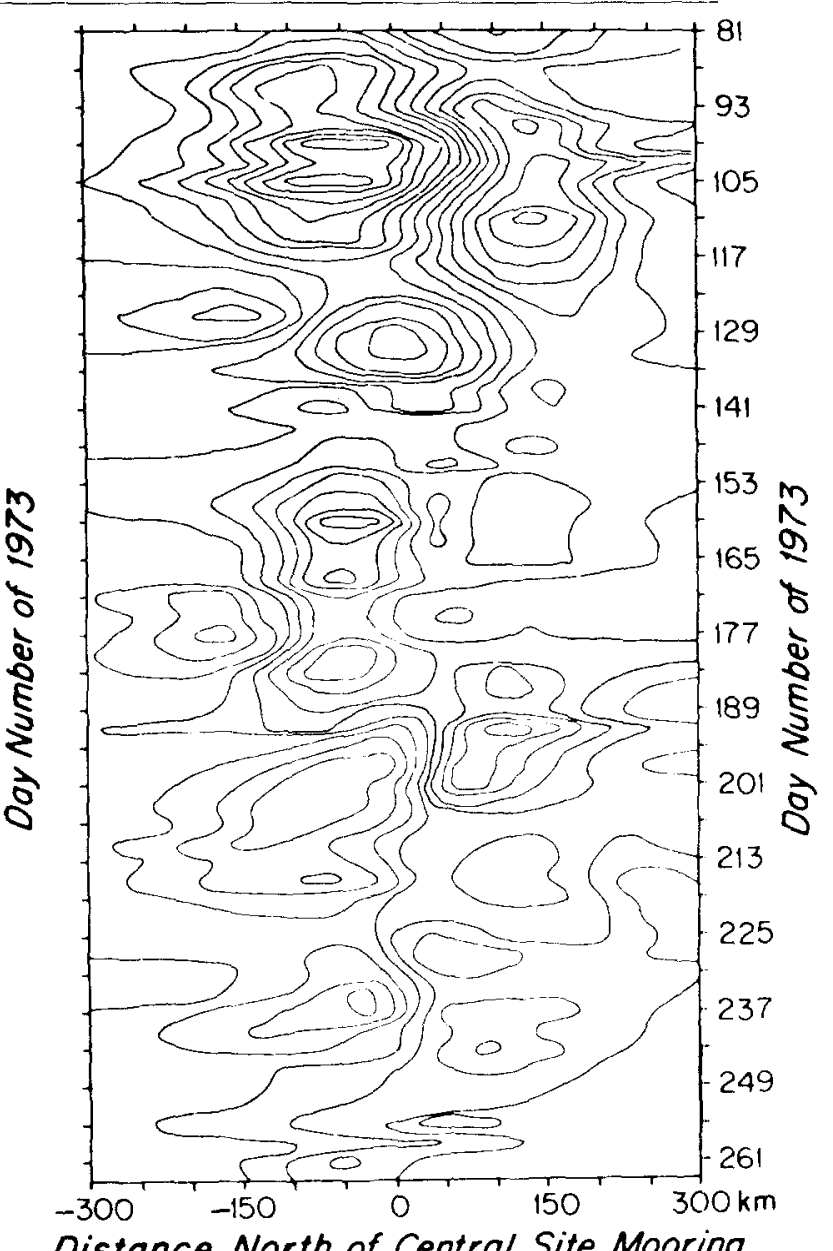

Distance North of Central Site Mooring

Fig. 9(b). Phase propagation plots of stream function patterns at $1500 \mathrm{~m}$ based on SOFAR float trajectories (from FreELAND et al., 1975).

predicted by the eddy dynamical theories and for his analysis of potential vorticity conservation (discussed in Section 4).

\subsection{Scales}

The intensive sampling period, 'MODE-1', was long enough to allow for accurate mapping of the variability field, and therefore scale and energy level, throughout the water column for roughly one realization, but it was too short to allow reliable quantitative statistical analysis of the low-frequency flows in the region. However, coverage during the post-MODE period was adequate for good estimates of kinematic temporal scales and energy levels at a number of depths to be gained from spectra, and some tests of dynamical processes to be carried out. The general picture of scale is one of decreasing length and time scales with depth and of an anisotropic nonuniform kinetic energy distribution.

The square integral correlation time scale, approximately the time required for 
observational independence within a long quasi-normal time series, is a reasonable indicator of relative time scales within the limited MODE data set (RICHMAN et al., 1977). Its values at representative depths in units of days for the three primary time series are as follows (RICHMAN et al., 1977):

\begin{tabular}{rccc} 
& Temperature & Zonal velocity & \multicolumn{1}{c}{ Meridional velocity } \\
\hline $500 \mathrm{~m}$ & 36.4 & 70.0 & 23.3 \\
$1500 \mathrm{~m}$ & 32.4 & 20.4 & 27.8 \\
$4000 \mathrm{~m}$ & 22.8 & 21.2 & 25.8 \\
\hline
\end{tabular}

The decrease with depth of the thermal time scale is notable, as is the strikingly long zonal flow time scale in the thermocline. The deep time scale in all these records and the meridional speed time scale at all depths is about 23 days. Temperature and zonal speed time scales increase toward the surface to 36 and 70 days, respectively, the longer value being statistically less reliable.

Absolute estimates of time scales can be made by the familiar method of locating the prominent peaks on the abscissas of the kinetic energy and temperature spectra (Fig. 10). The spectra are clearly 'red' at the 500-m level at MODE center and appear to be so at the other levels shown. The energy containing lower frequency bands are not resolvable using the limited duration MODE data set. Maximum entropy spectra have therefore been computed (RICHMAN, 1976) and were used to support some of the conclusions presented below. The maximum entropy spectra themselves will not be shown here (see Richman et al., 1977).

All of the kinetic energy spectra indicate an energy-containing band from 50 to about 150 days, the so-called eddy scale. A higher frequency band from $5^{-1}$ to $30^{-1} \mathrm{cpd}$ and a lower frequency band (unresolved) at periods greater than 200 days are clearly apparent. The 4000-m spectra are bimodal in the eddy band with a secondary peak at the higher frequency end, as suggested in the maps, while the MODE center eddy spectral peak at $1500 \mathrm{~m}$ stretches toward periods greater than 200 days.

Spatial scales may be inferred from zero crossings of the correlation functions of the spatially averaged temperature field over the MODE-1 array. The correlation function of a field having a dominant wavelength would cross zero at the quarter wavelength point. Zero crossings (Fig. 11) occur at $140 \mathrm{~km}$ at $500 \mathrm{~m}, 70 \mathrm{~km}$ at $1500 \mathrm{~m}$, and $55 \mathrm{~km}$ at $4000 \mathrm{~m}$, mirroring the behavior of time scale with depth. The working hypothesis for the MODE-1 array design was a $100-\mathrm{km}$ zero-crossing at $1500 \mathrm{~m}$ based on MODE- 0 moored array data (MODE-1 SCIENTIFIC CounCIL, 1973), a slight overestimate for the middle and deep water, occasionally accentuated by current meter failures.

Horizontal scales derived from low-passed bottom-mounted pressure gauge records were too large to be resolved by pairs of instruments set within the MODE region. They are estimated to be more than an order of magnitude larger than deep baroclinic scales (Brown et al., 1975).

Vertical structure in MODE-1 may be inferred from profiles of salinity and temperature determined by STD and CTD (LEETMAA, 1977c), by profiles of baroclinic and total velocity obtained by SANFORD (1975) and POCHAPSKY (1976) using, respectively, electromagnetic and acoustic profilers, and by modal analysis of the site mooring records (RICHMAN, 1976; RichMAN et al., 1977; DAVIS, 1975).

A MODE-center hydrographic profile (Fig. 12) shows the main thermocline centered 

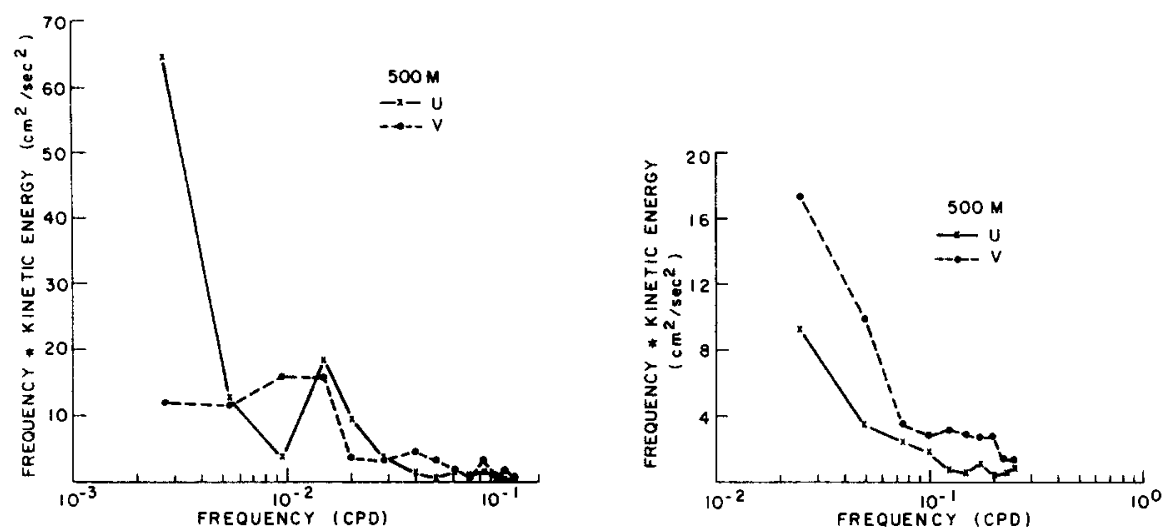

(a)
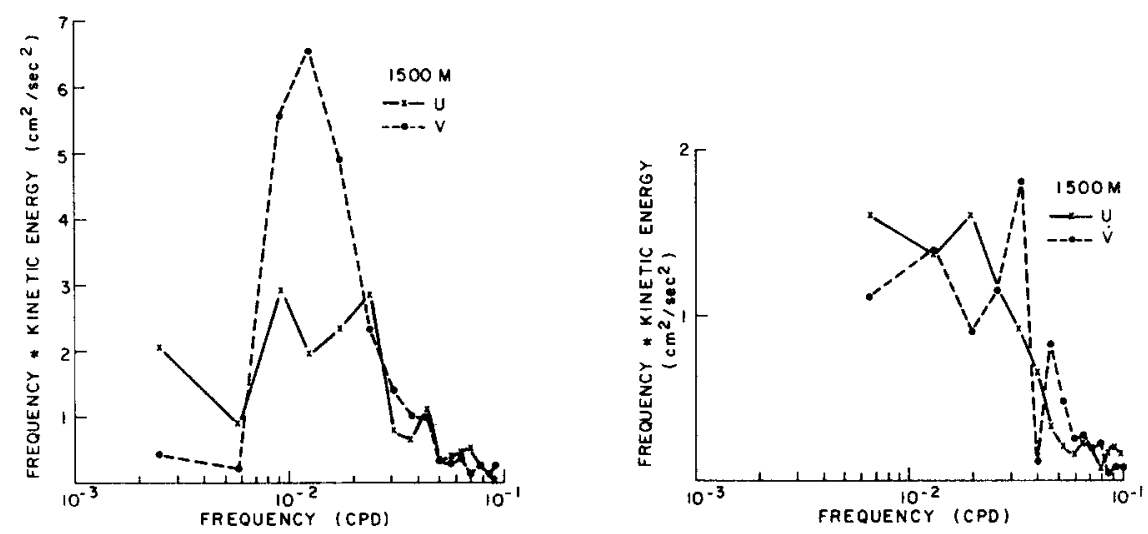

(b)
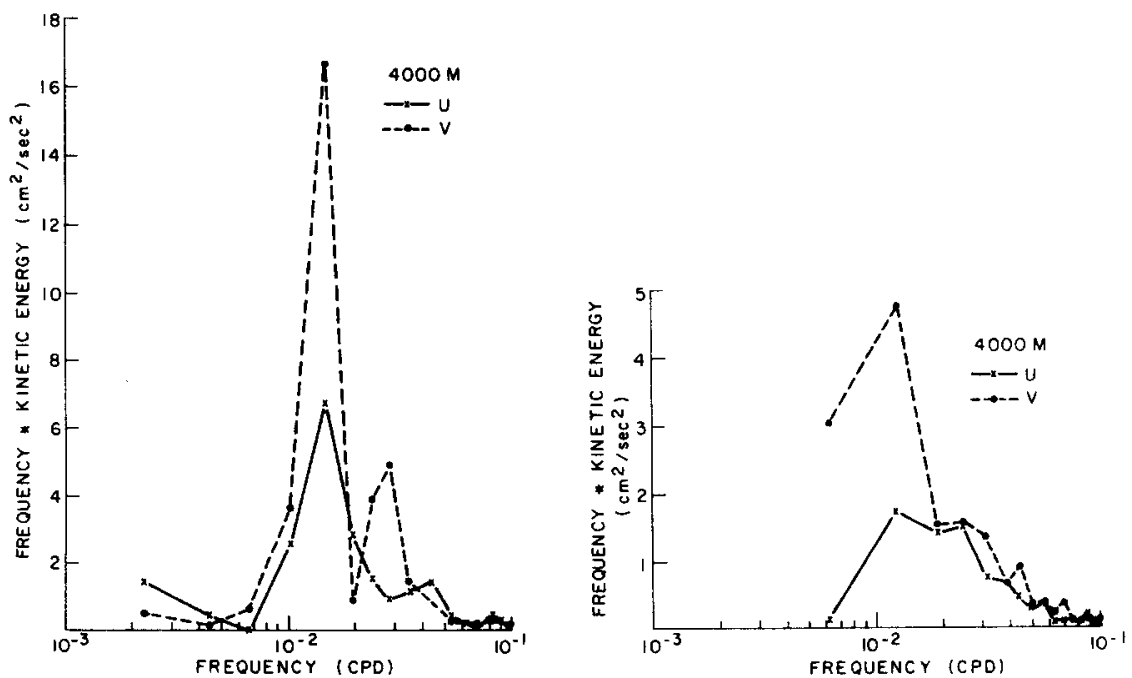

(c)

Fig. 10. Frequency spectra of moored current meter velocity records at MODE-center (left) and MODE-east (right) at (a) 500, (b) 1500 and (c) $4000 \mathrm{~m}$. Energy is in density units. [From RichmaN et al. (1977).] 


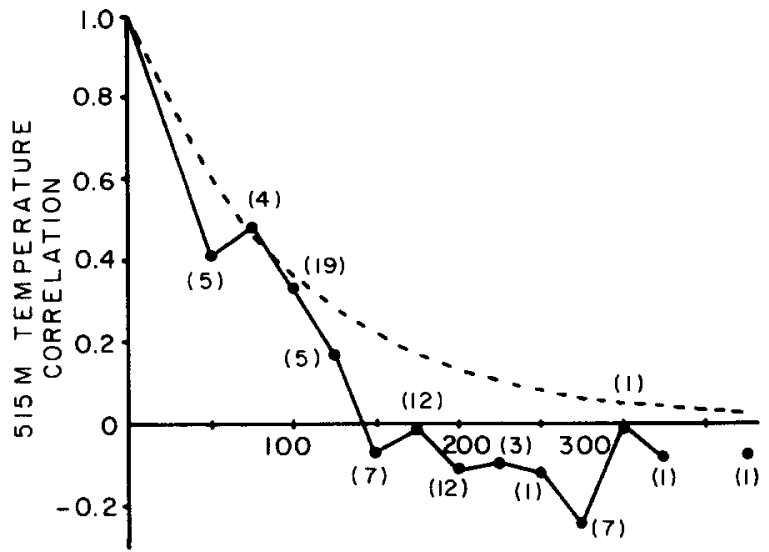

HORIZONTAL SEPARATION (KM)
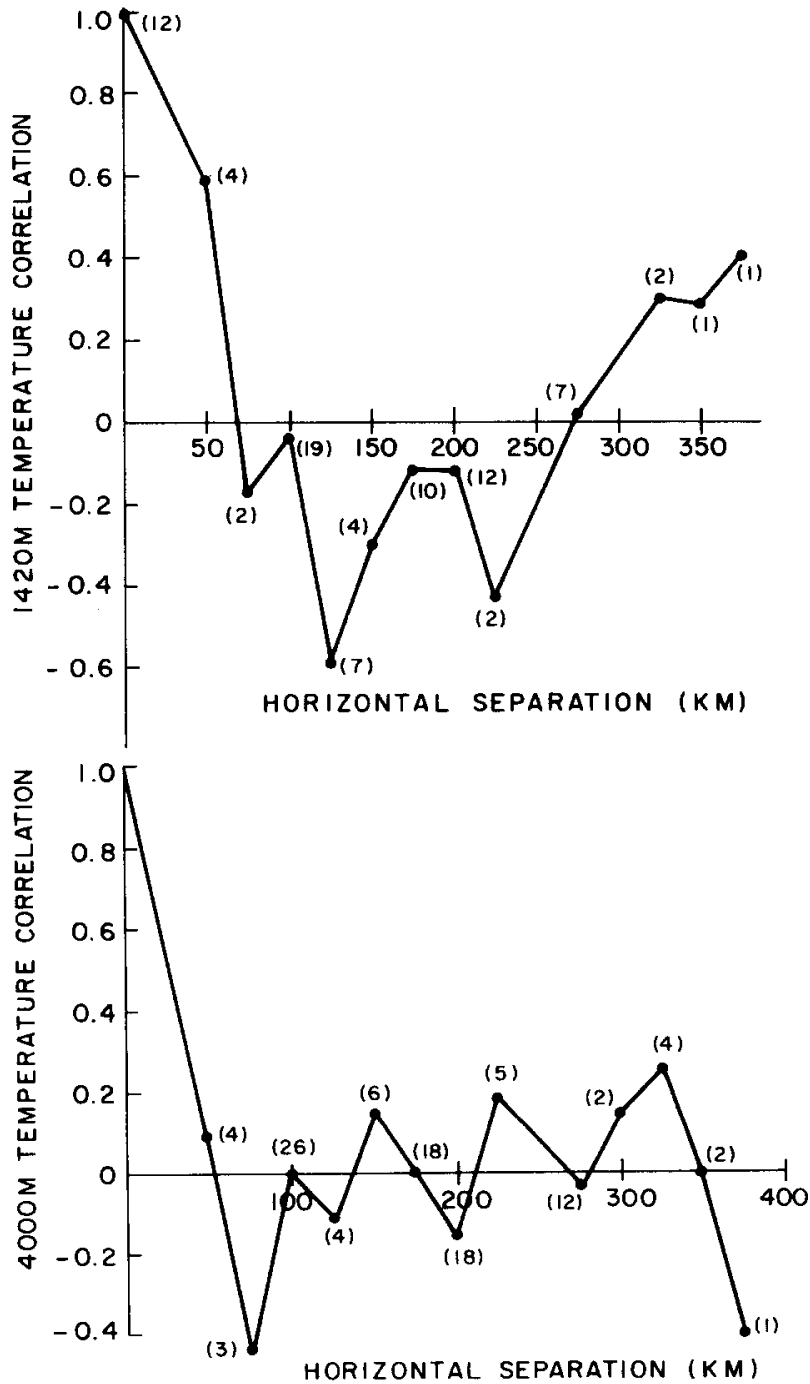

Fig. 11. Correlation functions of the spatially averaged temperature field over the MODE-1 array at 515,1420 , and $4000 \mathrm{~m}$ [From RichMAN (1976).] 


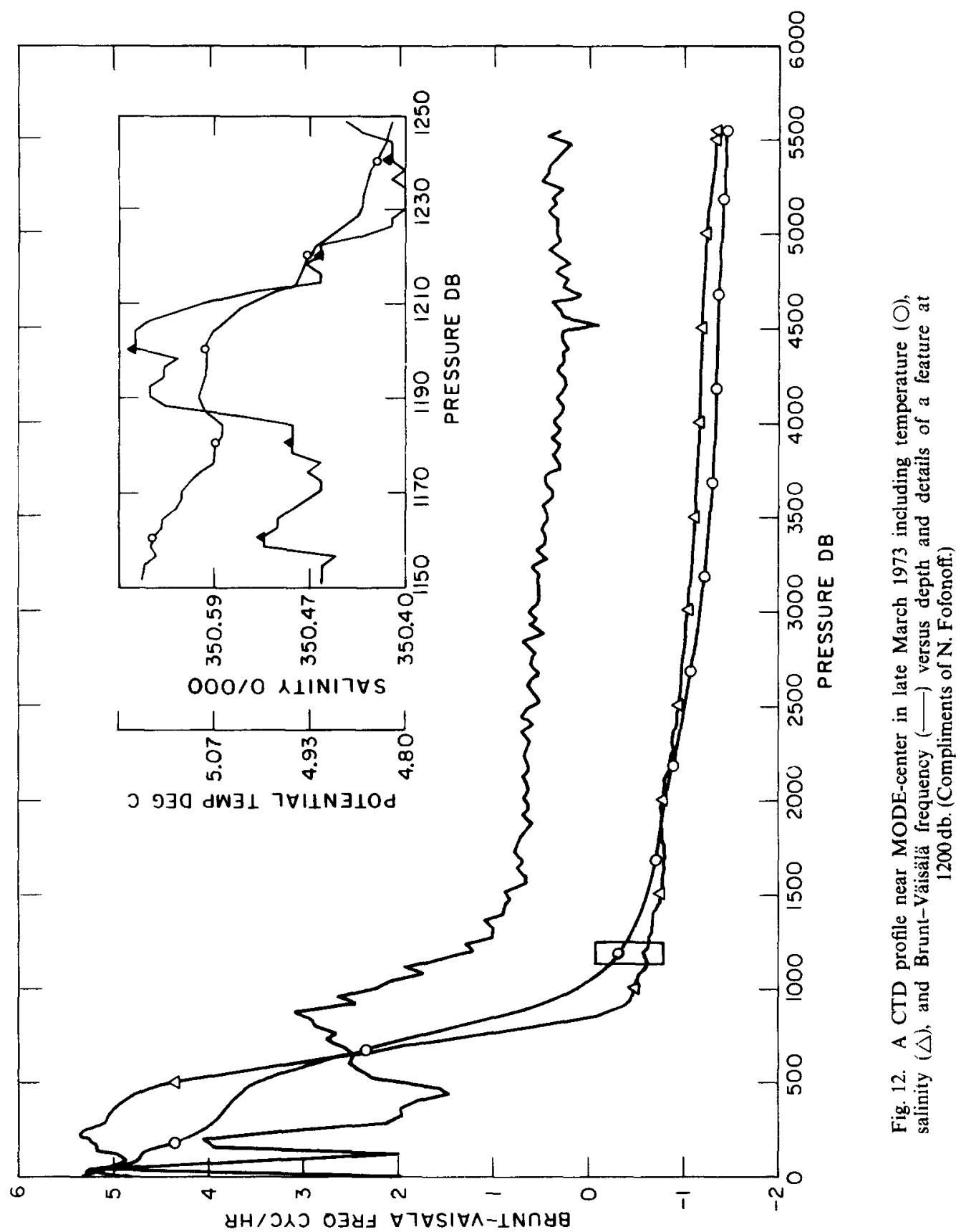

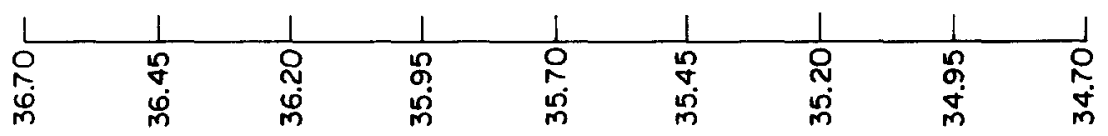

OO/O ג1INITVS

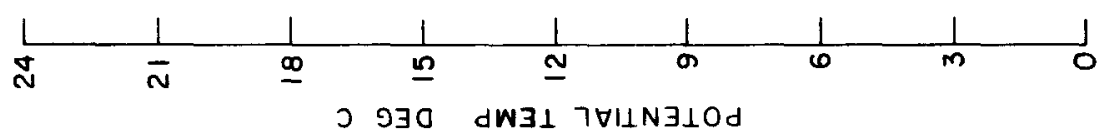


VELOCITY PROFILES $202 \mathrm{U}-206 \mathrm{U}$

ROTARY FIT AND SERIES MINUS FIT

24 MAY 1973

25 MAY

$0600 Z \quad 0737 \quad 1200 \quad 1454 \quad 1800 \quad 2034 \quad 0000 \quad 0310 \quad 0600 \quad 0915 \quad 1200$

EAST COMPONENT (CM/S)

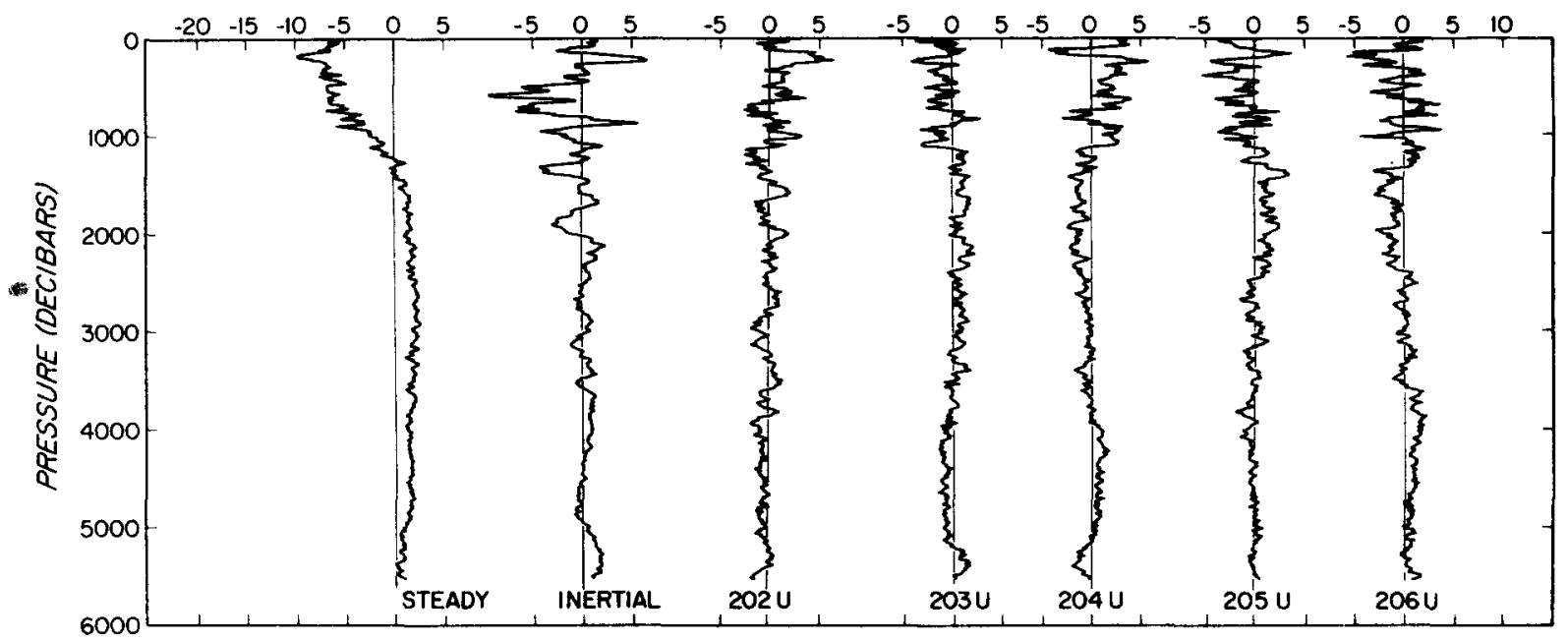

NORTH COMPONENT (CM/S)

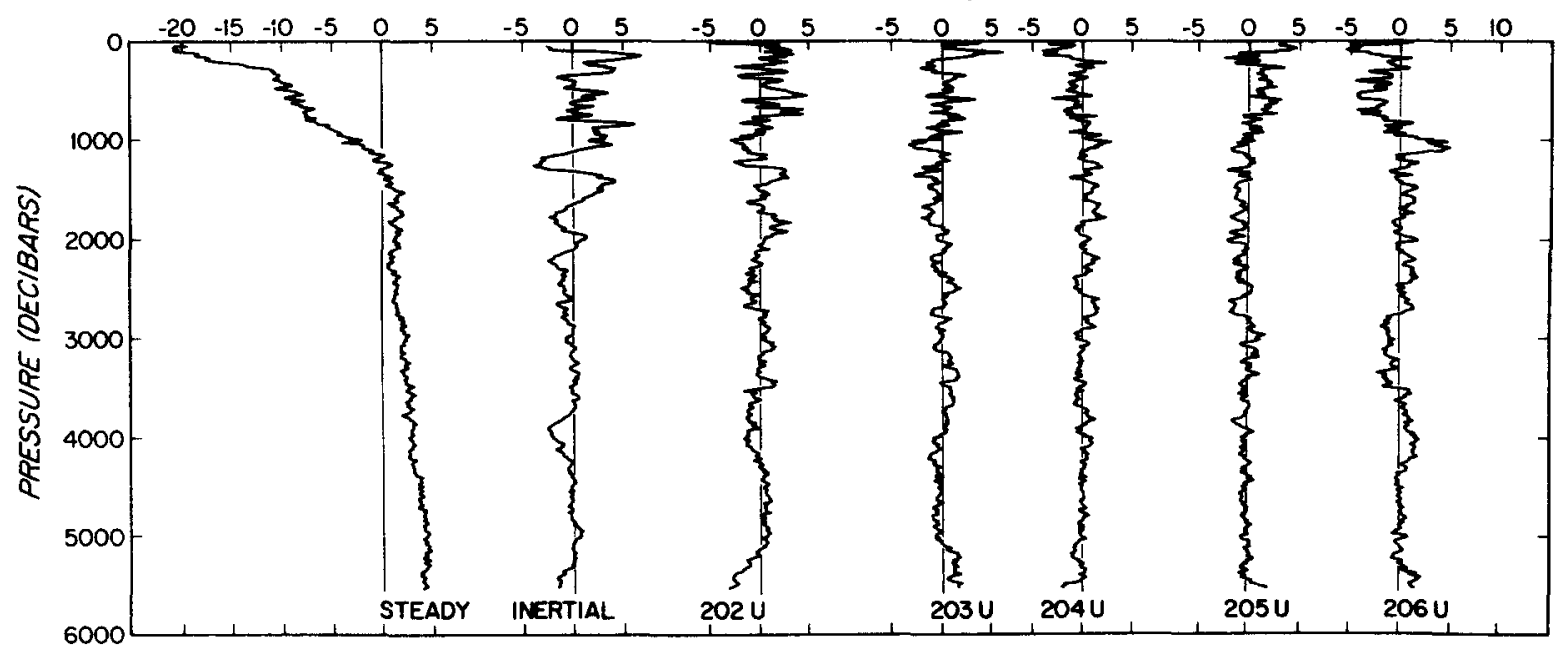

Fig. 13. Five electromagnetic velocity profiles observed over $30 \mathrm{~h}$, plotted as (i) mean component ('steady'), (ii) inertial component, and (iii) residuals. [From SANFORD (1975).]

near $750 \mathrm{~m}$ with a new seasonal thermocline in the upper $50 \mathrm{~m}$ and microstructure (JoYCE, 1976) typical of the area. The $T-S$ relationship is exceedingly tight except in the upper $200 \mathrm{~m}$ and in the 1500-m range because of the intrusion of Mediterranean water (HAYES, 1975).

SANFORD's (1975) estimate of the low-frequency shear profile near MODE-center, calculated by averaging five sequential profiles distributed uniformly over one inertial 
period (25.6h) on May 24 and 25, 1973, is described to within $5 \%$ of its energy by the first baroclinic mode alone (Fig. 13). This result is consistent with modal decompositions of records from moored arrays at MODE-center during the same period (DAVIS, 1975; RichmaN, 1976; see also McWiLliams, 1976b). Based on 11 drops near MODE-center during June 6 to 17, 1973, Pochapsky's profiles are similar and show 34\% of the lowfrequency kinetic energy in the barotropic mode and nearly all of the remaining baroclinic energy aligned meridionally.

Other low-frequency profiler shear estimates over the rougher topography to the east show strikingly different profiles with less thermocline shear, some bottom intensification, and velocity maxima at mid-depth (HoGG, 1976).

Low-frequency profiles from both velocity profilers show, superimposed, (i) large amplitude $\left(10 \mathrm{~cm} \mathrm{~s}^{-1}\right) 100-\mathrm{m}$ scale inertial oscillations throughout the water column, decreasing in amplitude below $2000 \mathrm{~m}$, and (ii) noninertial $3 \mathrm{~cm} \mathrm{~s}^{-1}$ oscillations of similar scale (Fig. 13).

Vertical coherence can be estimated for periods from 25 to 200 days from site mooring data (RICHMAN et al., 1977). In the eddy-containing band, the pattern of coherences is irregular but generally vertically coherent for meridional flow and not strongly so for zonal. Temperature is coherent in the thermocline and in the deep water, but not significantly so elsewhere. At the lower period extreme, no significant vertical coherence was observed.

At higher frequencies ( 5 to 30 day period) kinetic and potential energy scales with frequency as $\omega^{-2.5}$ (see Fig. 10), and with depth in the WKBJ sense. The energy is equally partitioned among zonal kinetic, meridional kinetic, and potential energy, and is homogeneous on scales of 100 km (RICHMAN, 1976).

\subsection{Second moments}

The most striking feature of the kinetic energy spectra shown in Fig. 10 is the dominance, by a factor of about four, of the lower frequency (periods greater than 200 days) zonal flows in the 500-m records at MODE center. The record at MODE-east is too short to resolve even the eddy-containing band completely, and therefore the very low-frequency MODE-center record stands alone as the single most energetic flow in the region. A distinct energetic mesoscale eddy band from 50 to 150 days is indicated with nearly an equipartition of zonal and meridional energy within the band. Energy levels in the eddy band at this level are not significantly different MODE-center to MODE-east, although the eastern site favors zonal eddy energy at all frequencies.

At $1500 \mathrm{~m}$ the overall eddy energy level is reduced (compared to $500 \mathrm{~m}$ ) by a factor of three at MODE-center and there is no clear evidence of dominant energy at the very low frequencies, although a tendency toward 'redness' and zonal domination is indicated. In the eddy band itself, meridional flow definitely dominates the zonal, far more so than at $500 \mathrm{~m}$, but only at MODE-center. There is a marked decrease in energy level of the eddy containing band at MODE-east by about 1/3 compared to MODE-center [as was noted earlier from the behavior of the MODE SOFAR float cluster (FREELAND et al., 1975)] and a slight tendency toward a secondary peak at the high-frequency limit of the eddy band.

The overall energy levels at $400 \mathrm{~m}$ are intermediate to those at 500 and $1500 \mathrm{~m}$. There is a scant tendency toward zonal dominance at very low frequencies, but it is really not resolved. Again, there is a marked dominance of the meridional flow over the zonal in the eddycontaining band, and, as suggested by the maps, a tendency toward energy at the highest 


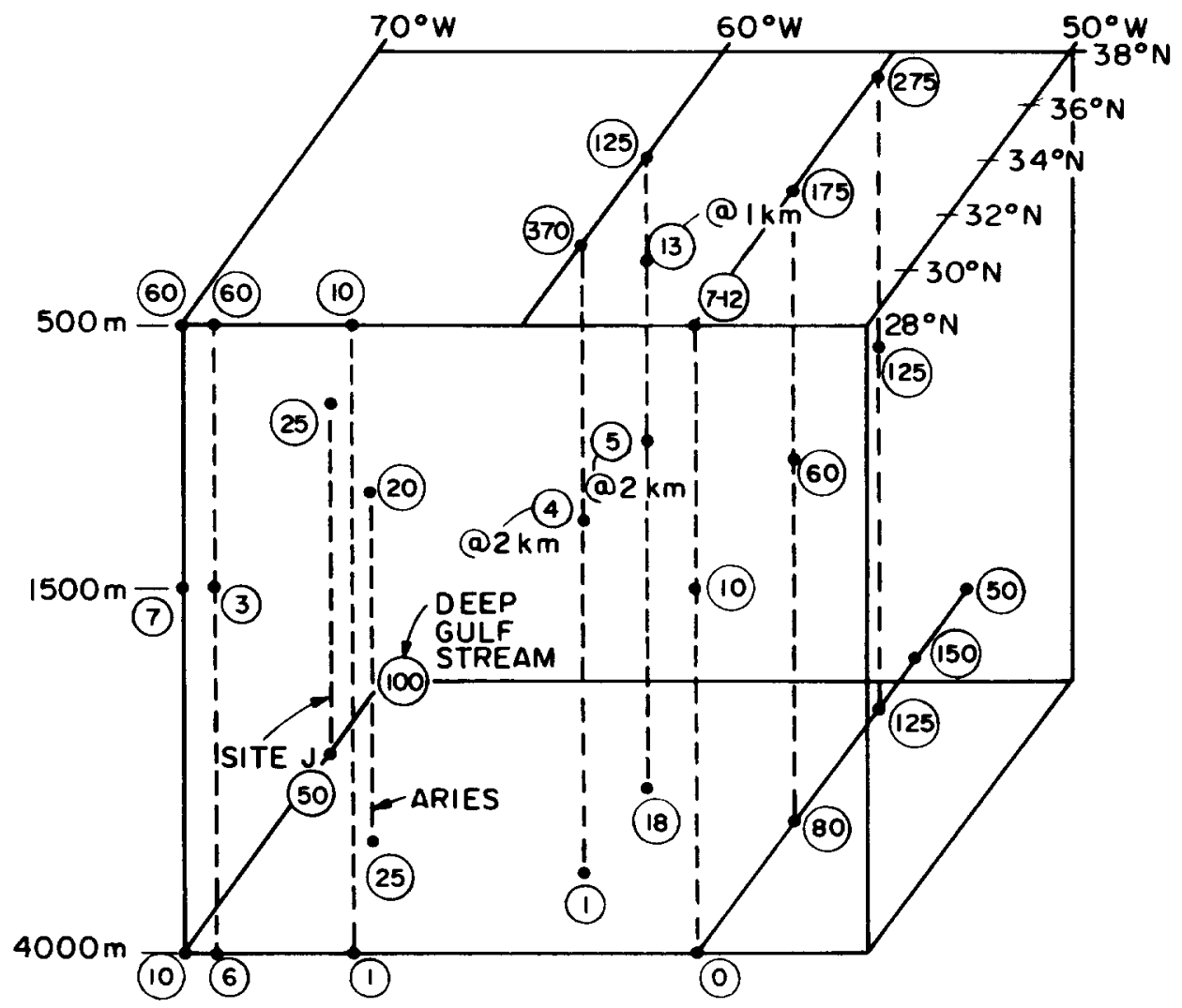

I. $28^{\circ} \mathrm{N} 55^{\circ} \mathrm{W}: 3$ CLOSELY-SPACED MOORINGS WITH 50OM. ENERGIES @ 7,9 AND 12

2. $34^{\circ} \mathrm{N} 60^{\circ} \mathrm{W}$ AND $31^{\circ} \mathrm{N} 60^{\circ} \mathrm{W}$ RECORD A LARGE-SCALE COLD EVENT

3. MEAN CURRENT IS BOTTOM INTENSIFIED@ $34^{\circ} \mathrm{N} 60^{\circ} \mathrm{W}$

4. ALL ENERGIES IN $\mathrm{CM}^{2} /$ SEC. $^{2}$

Fig. 14(a). Distribution, at various levels, of kinetic energy intensities from longest-term estimates available from 55 to $70^{\circ} \mathrm{W}, 28$ to $41^{\circ} \mathrm{N}$. (By W. Simmons, based primarily on data by the W.H.O.I. Moored Array Project).

eddy frequencies and, presumably, length scales. Energy decreases to the east by a factor of about three, but other spectral features are comparable to MODE-center.

The eastward spectral decline at 1500 and $4000 \mathrm{~m}$ does not seem to occur in the higher frequency bands, in either kinetic or potential energy (RICHMAN et al., 1977). The lowest frequencies are, of course, unresolved because of shorter records in the rougher terrain to the east.

The off-diagonal Reynolds stress term $\overline{u^{\prime} v^{\prime}}$ is significantly nonzero at 1500 and $4000 \mathrm{~m}$, though less than $\overline{u^{\prime 2}}$ and $\overline{v^{\prime 2}}$ by a factor of about three. $\overline{u^{\prime} v^{\prime}}$ decreases toward the east (RICHMAN, 1976) and increases toward the north (SCHMITZ, 1976b) as does the kinetic energy itself. ScHMITZ (1976b) has shown evidence for both positive and negative values of mesoscale eddy viscosities over the deep western recirculation gyre (WoRTHINGTON, 


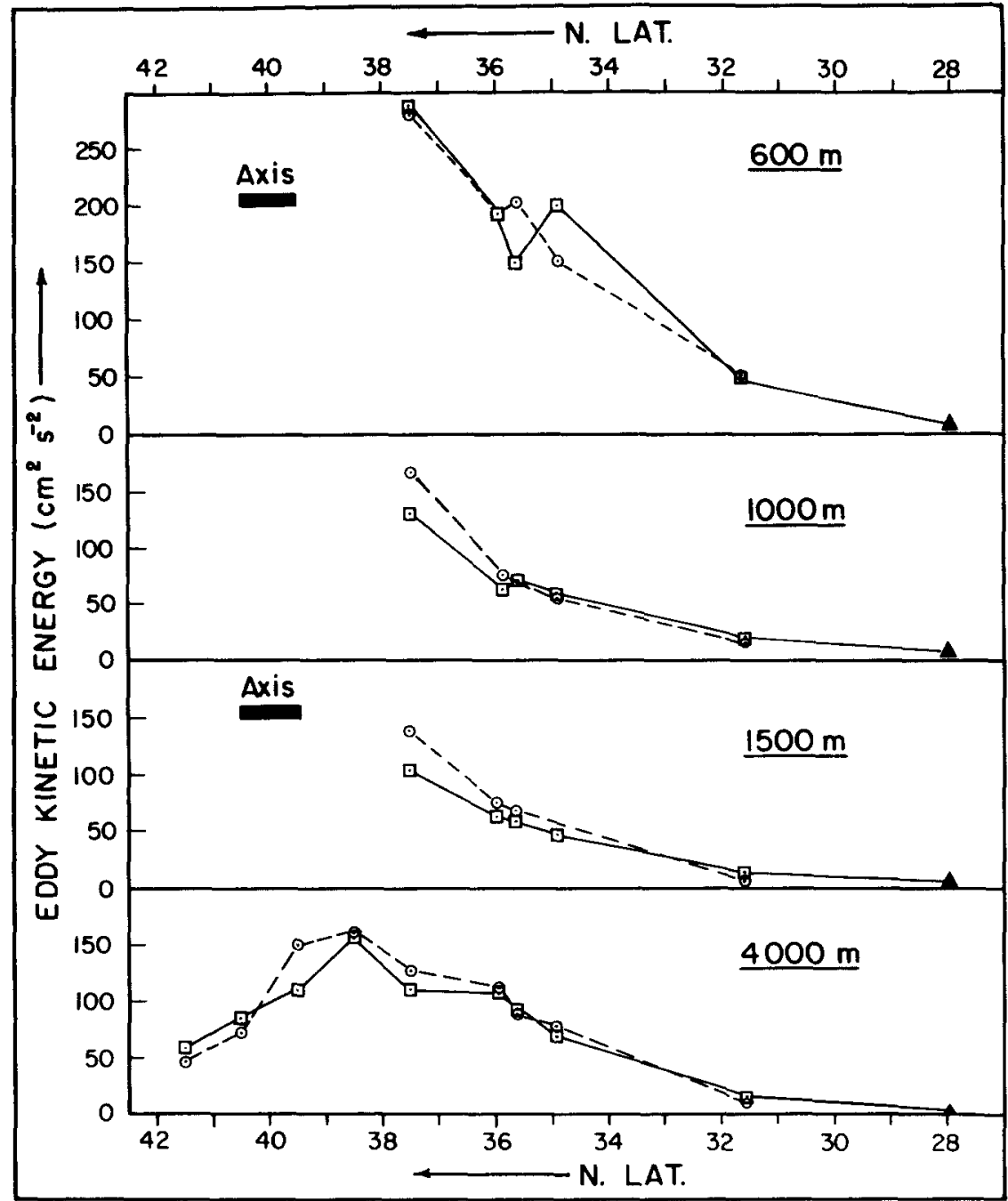

Fig. 14(b). Distribution of kinetic energy along $55^{\circ} \mathrm{W}$ from 18 months of continuous current meter records. [From SchmrTz (1978).] Note the wide range of intensities and the inhomogeneity.

1977) and has stressed the importance of eddies as a possible driving mechanism for the deep mean circulation. Error estimates are given by FlierL and MCWILLIAMS (1977).

The zonal eddy heat transport is also significantly nonzero in the deep water, with a value of $7 \times 10^{5} \mathrm{ergs} \mathrm{s}^{-1} \mathrm{~cm}^{-2}$. At shallower depths the eddy heat transports are greater by an order of magnitude, approximately $3.5 \times 10^{6} \mathrm{ergs} \mathrm{s}^{-1} \mathrm{~cm}^{-2}$ at $1500 \mathrm{~m}$, and $3 \times 10^{7}$ ergs $\mathrm{s}^{-1} \mathrm{~cm}^{-2}$ (to the east), and $4 \times 10^{6} \mathrm{ergs} \mathrm{s}^{-1} \mathrm{~cm}^{-2}$ (to the north) at $500 \mathrm{~m}$. However, at these depths, the eddy heat transports are not significantly different from zero, possibly because of the lack of simultaneous temperature and velocity data for time scales greater than the eddy scale. The average climatological meridional heat transport in the ocean is estimated at $6 \times 10^{7} \mathrm{ergs} \mathrm{s}^{-1} \mathrm{~cm}^{-2}$ (VONDER HAAR and OORT, 1973). Thus, although the eddies may be critical elements in the overall oceanic heat transport process, they were 
ineffectual as direct transporters of heat in the MODE-1 region during the time of the experiment. However, preliminary analysis suggests that the eddies play an important role in inducing much larger heat transports in the surface layers, as discussed in the next section.

It is now possible to begin to piece together a preliminary composite picture of eddy variability in the western North Atlantic. The pictorial elements include: (i) the Aries Swallow float measurements, (ii) moored current meter data from sites along $70^{\circ} \mathrm{W}$ maintained from time to time by the Woods Hole Oceanographic Institution Moored Array Project (Schmitz, 1977), (iii) the MODE current meter arrays, (iv) the MODE-1 extended SOFAR float array, which suggested increased eddy kinetic energy levels to the north and south of MODE-1, and a sharp decline to the east at $1500 \mathrm{~m}$ (FREELAND et al., 1975), (v) the first U.S. POLYMODE array east and north of the MODE-1 site set with large geographical separations to explore energy levels and vertical structure of the variability on the larger-than-eddy scale, and (vi) the results of the second U.S. POLYMODE array (SCHMITz, 1978) set primarily along $55^{\circ} \mathrm{W}$ from $30^{\circ} \mathrm{N}$ to the Gulf Stream (see Fig. 4).

The emerging picture is one of large (two orders of magnitude) variability in eddy kinetic energy on the gyre and sub-gyre scale, particularly in the deep water. Vertical structure near the Gulf Stream on $55^{\circ} \mathrm{W}$ resembles the $<100$-day period structure at MODE-center, but it is more energetic. Vertical distribution at $55^{\circ} \mathrm{W}, 28^{\circ} \mathrm{N}$ resembles the $>100$-day period structure at MODE-center but is less energetic. A complicated and inhomogeneous distribution of kinetic energy levels occurs between, as shown in Fig. 14(a). The distribution of kinetic energy along $55^{\circ} \mathrm{W}$ and in the vertical is particularly exemplary of the complicated variety of intensities (Fig. 14b). Other evidence supporting large geographical-scale variability has been provided by DANTZLER $(1976,1977)$ for the upper $750 \mathrm{~m}$ and by WYRTKI et al. (1976) for the surface water. Gyre scale variabilities in potential energy are also high though dissimilar to those of kinetic energy. In particular, potential energy does not fall off to the east in the deep water to the same extent that kinetic energy does (RICHMaN et al., 1977). Eddy time scales to the east appear to be as long as 9 months, possibly within the range necessary for interpretation as linear baroclinic Rossby waves. Additional evidence of longer scales to the east is provided in four repeated transatlantic XBT sections by LeETMAA (1977b). Because the upper 750-m layer oscillated coherently in the vertical, only the $12^{\circ} \mathrm{C}$ isotherms are shown (Fig. 15). Few MODE-1 scale features appear. Rather, the dominant east-west scale is 1000 to $2000 \mathrm{~km}$. A striking feature is the variability over months of the mean depth of the $12^{\circ} \mathrm{C}$ isotherm, possibly brought about by large-scale barotropic oscillations advecting the mean north-south stratification.

A major objective of the POLYMODE experiment is to explore, over sufficiently long time scales, the statistical properties of the eddy field in widely separated regions of the North Atlantic.

\subsection{Surface layer eddy phenomena}

MODE-1 was located in the North Atlantic Subtropical Convergence about mid-way between the prevailing westerlies to the north and the trade winds to the south. The surface temperature field is characterized by a mean meridional gradient at all times of year (SCHROEDER, 1966), which is usually reproduced in a surface thermal frontal zone (VoORHIS and HeRSEY, 1964; VoORHIS, 1969). The gradient is strongest during late winter and early 


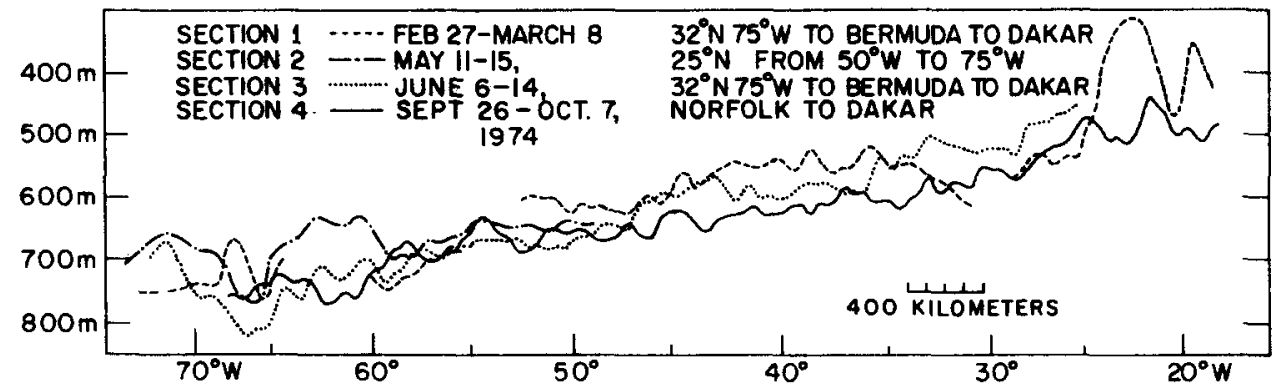

Fig. 15. Depth of the $12^{\circ} \mathrm{C}$ isotherm from four trans-Atlantic XBT sections within 8 months of one another. Note the irregular distribution of eddy intensity and scale and the large amplitude change in average depth of the $12^{\circ} \mathrm{C}$ isotherm. [From LeETMAA (1977b).]

spring, the season of MODE-1. Although the primary emphasis in MODE-1 was to measure the ocean's interior, some measurements were made in the surface layers, specifically, all CTD and STD casts, XBT drops, bucket temperatures, and engine intake temperatures on three of the six MODE-1 vessels. Using these data, VoORHIS, SCHROEDER and LEETMAA (1976) mapped 12-day average surface temperature patterns throughout MODE-1 and compared them to surface dynamic height maps relative to $1500 \mathrm{db}$. Their surface temperature maps very much resemble satellite radiometric imagery observed in succeeding years in the same region and season (satellite imagery was not available during MODE-1). The surface signatures are dominated by long filamentous tongues of warm (cold) water intruding into colder (warmer) ambient surroundings, with scales of 40 to $400 \mathrm{~km}$. Although the MODE-1 surface sampling scheme was somewhat haphazard, Voorhis, Schroeder and Leetmaa provide a strong case that the surface filaments are drawn out advectively by the eddy surface currents suggesting, for these scales, that the eddies drive the surface mixed layer from below far more efficiently than the winds drive it from above. The filaments do not swirl completely about a single eddy as in vortex mixing. Instead, they are drawn sporadically along the outer extremities of oppositely rotating eddy pairs, migrating from pair to pair so as to be drawn out primarily in a north-south direction. The available large-scale ambient meridional gradient is distorted by the eddies so as to form smaller-scale variabilities. It was not possible in MODE-1 to trace this cascade beyond about $40 \mathrm{~km}$. The authors estimate the mean meridional heat transport for typical MODE-1 parameters (i.e. mixed layer depth $=50 \mathrm{~m}$, filament width $=100 \mathrm{~km}$, temperature anomaly $=2^{\circ} \mathrm{C}$, advective speed $=20 \mathrm{~cm} \mathrm{~s}^{-1}$ ) and find a net northward heat exchange of $10^{18} \mathrm{ergs} \mathrm{s}^{-1}$ per east-west kilometer. By comparison, the Vonder Haar-Oort estimate is $4 \times 10^{18} \mathrm{erg} \mathrm{s}^{-1}$ per east-west kilometer. Thus, surface heat transport advectively induced by eddy forcing from below could account for a significant fraction of the net poleward ocean heat transport required for steady climatology. The global effect, of course, depends upon eddy strength and distribution on the geographical scale. Carefully planned local surface measurements and some geographical exploration will be incorporated into the POLYMODE experimental plan.

\subsection{High frequencies}

Most of the moored instrumentation sampled at intervals sufficiently short to measure the internal wave field as well as the mesoscale motions. While the main focus in MODE-1 was on the lower frequencies, the internal wave field and the associated smaller spatial 
scales were intrinsically interesting. Moreover, there have been suggestions (MỨLLeR, 1976, 1977; BOOKER and BRETHERTON, 1967) that internal waves may have a direct and important interaction with the mesoscale and mean fields. The towed instrumentation (KATZ, 1975; ZENK and KATZ, 1975) sampled all wavelengths between the tow length $[0(2000 \mathrm{~km})]$ and the smallest digitization scale [0 (meters) $]$. Distinguishing between the energy in internal waves and in the mesoscale becomes difficult because of overlap of the possible ranges in wave number space. WUNSCH (1976) reported an attempt to relate internal wave energy to the energy found in eddies as a whole, but no significant relationship was found. LEAMAN and SANFORD (1975) and LEAMAN (1976) described the inertial peak in the internal wave spectrum in some detail using the freefalling electromagnetic profiler.

It is also possible that the smallest scales of the ocean, 'fine structure' and 'microstructure', are related to the dissipation of eddies. JOYCE (1976) reported efforts to relate the gross structure of eddy motion to that of the finestructure field. Related measurements were studied by HAYES (1975).

\subsection{Tides}

As a by-product of the measurements with pressure gauges, the MODE- 1 experiment led to a good determination of the surface tide. Measurements have been reported by BAKER et al. (1973) from the MODE-0 period, and by ZETLER et al. (1975) for MODE-1. The tides were qualitatively similar to those at Bermuda and in reasonable agreement with both empirical and numerical charts of tidal elevation for the region.

HENDRY $(1975,1977)$ used the moored temperature and velocity measurements to study the semi-diurnal internal tides in the MODE-1 array. He found that the motion was dominated by a coherently propagating fundamental vertical mode moving toward the southeast across the area. $M_{2}$ tidal currents inferred from bottom pressure gauges (ZETLER et al., 1975) were in first order agreement with Hendry's observed barotropic values. Hendry's overall result is in accord with the theory that the internal tide is generated at the continental shelf to the northwest.

\subsection{Bottom boundary layers}

A bottom mixed layer, as first described by AMOs, GARDEN and SCHNEIDER (1971), was observed in all deep CTD stations in the MODE-1 region. As shown by ARMI and Millard (1976), the layer varied from a few meters to about $100 \mathrm{~m}$ thick, with larger values tending to occur over the flat Hatteras Abyssal Plain and smaller values near its borders with rougher terrain to the east and the rise to the west. The latter profiles were complicated by irregular micro-structure-like signatures in the bottom several hundred meters over the rough topography. The thicker layers over flat bottoms seem to be the result of thorough mixing of the uniform profiles which would be obtained by extrapolating the overlying profiles to the bottom. However, they are thicker than turbulent Ekman layers by as much as six-fold over the Hatteras Abyssal Plain and by lesser amounts in the bordering regions (ARMI, 1977). The thickness is locally correlated with 1-day mean current speeds from moored current meters at the $4000-\mathrm{m}$ level. Preliminary results suggest variability scales of $10 \mathrm{~km}$ and a few days.

4. DYNAMICAL AND NUMERICAL RESULTS

The first plausible theoretical explanations of eddy phenomena appeared little more than a decade ago. PHILlips (1966) analyzed the 1960 Swallow float data off Bermuda in 
terms of a linear two-layer Rossby wave model with direct wind curl driving. The resultant flow patterns were, kinematically, reasonably well-fitting, but the amplitudes were greatly underestimated. Baroclinicity, topography, nonlinearity, instability, and other dynamical effects could be shown by scale analysis to be of probable importance on hypothetical but realistic seeming model fields. Too little was known to focus and pinpoint theoretical inquiries, and therefore MODE-1 had dynamical, as well as kinematic and descriptive, scientific objectives. These included investigating the degree to which the local momentum balance is geostrophic, verifying as possible the next order of the quasi-geostrophic character of the motions, and attempting to probe eddy dynamics in the search for sources, sinks, and principal transformations. These objectives were approached in a variety of ways.

\section{DYNAMICAL RESULTS}

\subsection{Balance of terms: geostrophy and divergence}

The simplest approach to the direct balance of terms was to evaluate the leading terms of the momentum and continuity equations by finite difference methods applied to longterm time series from moored instrumentation (BRYDEN, 1977; BRYDEN and FOFONOFF, 1977), and to shorter duration spatially intensive measurements from moored instruments and CTD stations (HorTON and STURGES, 1977), from velocity profilers and CTD stations (SANFORD and BRYDEN, 1974), and from moorings and towed sensors (KATZ, 1975). All such evaluations are contaminated by higher frequency energy in the internal wave band ('noise' from the eddy point of view) as well as by instrumental errors. A second, less direct evaluation of balance of terms involves computing spatial correlation functions of transverse and longitudinal velocity components. For the field to be horizontally nondivergent, certain relations must be satisfied. Likewise geostrophy can be assessed by a comparison of dynamic height. A review of both approaches is given by HoGG (1974).

BRYDEN's (1977) comparison of directly measured vertical current shears to geostrophic estimates of vertical shear (thermal wind) confirm the underlying geostrophic balance to within expected instrumental errors for mooring separations of $60 \mathrm{~km}$. Errors increase at $100-\mathrm{km}$ separations. Thirty of 32 comparisons of 4-day averages agree within estimated two standard deviation errors and all agree within three. Swallow (1977) was able to verify geostrophy across the main thermocline at better than estimated error (about $\pm 0.8 \mathrm{~cm} \mathrm{~s}^{-1}$ or $10 \%$ ), and HORTON and STURGEs (1977) verified it to within $0.6 \mathrm{~cm} \mathrm{~s}^{-1}$ for the 426 - to $3550-\mathrm{m}$ level and $1.7 \mathrm{~cm} \mathrm{~s}^{-1}$ for the $420-$ to $720-\mathrm{m}$ level.

Horizontal nondivergence has been established to within similar error limits (BRYDEN and FoFONOFF, 1977).

Quantitative estimation of horizontal divergence by examining variations of $\partial \rho / \partial z$ along trajectories on surfaces of constant density was not possible, the data being inadequate for this purpose. However, qualitative estimates were possible and indicated that if potential vorticity is conserved, then relative vorticity changes can be as large as $30 \%$ of the Coriolis parameter in the near surface layers and $10 \%$ of the Coriolis parameter in the main thermocline and the deep water (LEETMAA, 1977a). These values are somewhat larger than would be expected from scale analysis but are comparable to independent estimates of vortex stretching in MODE-1 (McWiLliams, 1976c).

In every case, geostrophy and nondivergence are established to within $10 \%$, the expected instrumental error. Scale analysis usually sets quasigeostrophic departures from geostrophy at about $1 \%$. Because the very heart of variability dynamics is in that $1 \%$ departure, it is necessary, in the direct approach, to be able to establish deviations from geostrophy at least two 
additional orders of magnitude beyond present instrumental limits (i.e. to within $0.1 \%$ ). The inherent instrumental difficulties associated with these objectives (e.g. estimating in situ density to better than $1 \mathrm{ppm}$ ) have been appreciated and, in the face of the dilemma, a new approach has been suggested.

\subsection{Balance of terms: conservation of potential vorticity}

MCWILLIAMS (1976c) suggested as an alternative a balance of terms study of the quasigeostrophic potential vorticity equation, in which the underlying and dominating geostrophic terms are eliminated by cross differentiation. In the absence of dissipation and the limit of small Rossby number, potential vorticity is conserved along a particle path. Each term of the vorticity balance can be estimated in principle either by finite differencing time series data from a carefully designed array of current and temperature sensors, or by differentiating a sequence (at different levels and times) of objectively mapped total dynamic pressure fields computed, for example, on the basis of dense hydrographic data with a dense float array to provide absolute velocities at one level. The first method is not possible with MODE-1 data as the calculation requires a special one-purpose array design that was not incorporated in the MODE-1 field plan. (It is, however, planned as a component of POLYMODE.) The second method is applicable to MODE-1 data; however, the MODE-1 sampling scheme was designed primarily for a synoptic-descriptive experiment to explore space-time characteristics and the relationships among them, and is less refined than is required for these purposes. Therefore the calculation could be carried out only at special places and times (year days 95 to 110 and 125 to 165 of 1973). For these intervals McWilliams was able to make maps of relative vorticity, planetary vorticity, and vortex stretching components and explore, over the entire water column, the ways in which they combine (Fig. 16). In addition, unsteady and advective changes in potential vorticity were also estimated. The conservation was (i) highly nonlinear at $150 \mathrm{~m}$ over 10-day intervals centered on days 135 and 140 (the mid-point of the MODE-1 high) and on days 105 and 160 (toward the extremes of the MODE-1 high), and (ii) nearly linear (i.e. linearized advection) at the same depth over the 60-day interval between year days 105 to 165 (the duration of the MODE-1 high). The reliability of these results is high although other results, mainly at depth, are less firm because of sampling inadequacies. Overall, geostrophy, horizontal nondivergence, the appropriateness of small Rossby number perturbation theory, and the unimportant role in the interior of small-scale dissipation have all been further supported by this verification of their immediate consequence, the quasigeostrophic potential vorticity balance of terms. (A SOFAR float-CTD experiment designed specifically for this second method of quasigeostrophic potential vorticity balance of terms is planned as an element of POLYMODE.)

\subsection{Linearity versus nonlinearity}

Whether eddy dynamics are linear or not depends, of course, on which eddies, where, and when. Linear eddies doubtless exist somewhere, and all eddies may be represented linearly for at least some times. Indeed, a linear representation of 'the' MODE-1 eddy in terms of two pairs of flat-bottomed barotropic and baroclinic Rossby waves has been put forward by MCWILliams and FLIERL (1976). With this relatively crude decomposition, they can depict roughly the shape of the MODE-1 eddy and account for about half of its energy. Four waves may seem relatively crude as the sole ingredients for an eddy decomposition, but for comparison, SANFORD (1975) has shown that for short periods and 


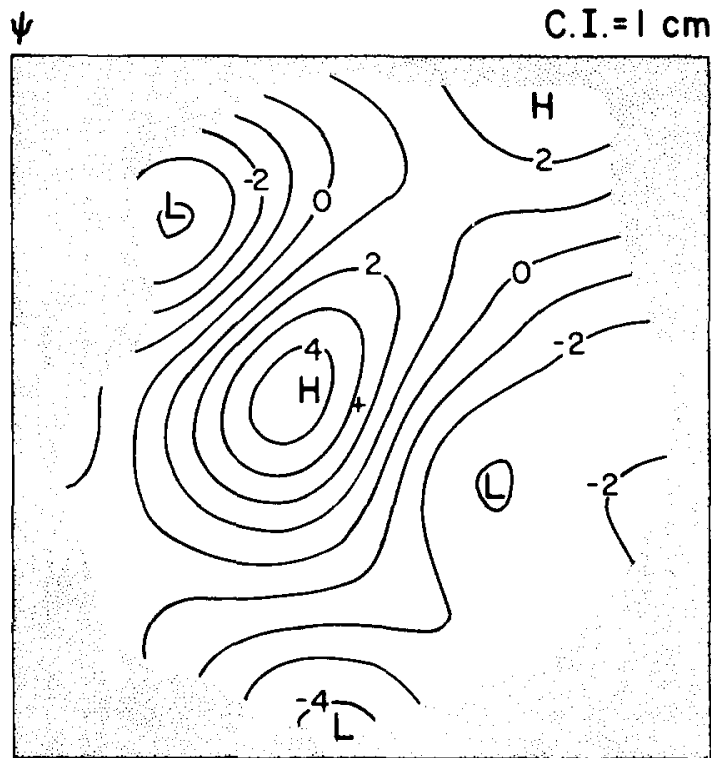

VORTEX STRETCHING C.I $=0.02$

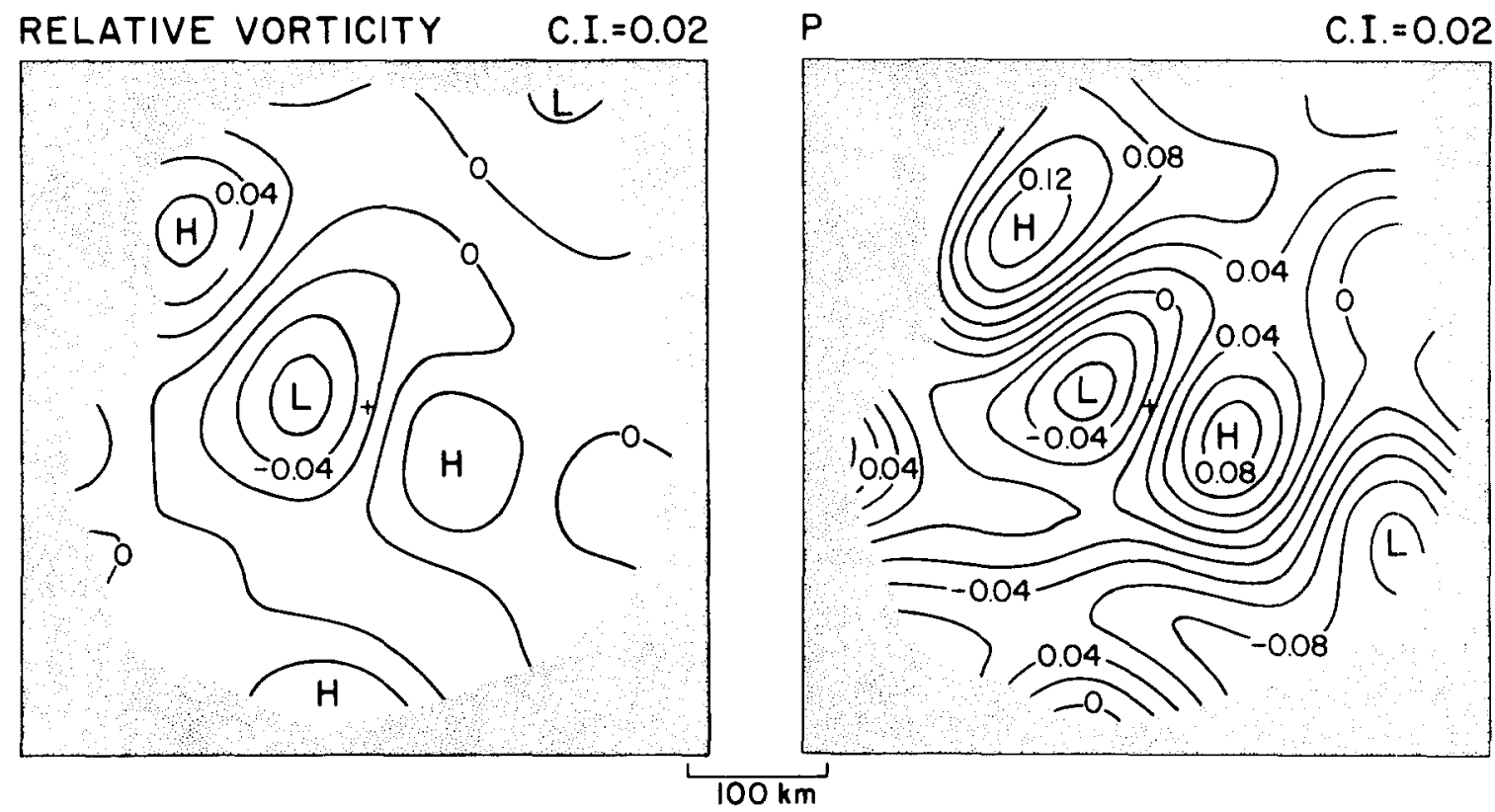

Fig. 16. Maps of stream function $(\psi)$, vortex stretching, relative vorticity, and potential vorticity at $750 \mathrm{~m}$ on day 140 centered at MODE-center. C.I. means contour interval. [From MCWILIIAMS (1976b).]

over a flat bottom up to $95 \%$ of the vertical distribution of baroclinic energy is describable in terms of the first baroclinic mode alone. Wave models such as these are conceptually and representationally useful, but overall they are not dynamically convincing in that they are not uniformly accurate in depth on the scale of one period, they are spatially regular and periodic while the eddies are not, they are somewhat large in baroclinic time scale 


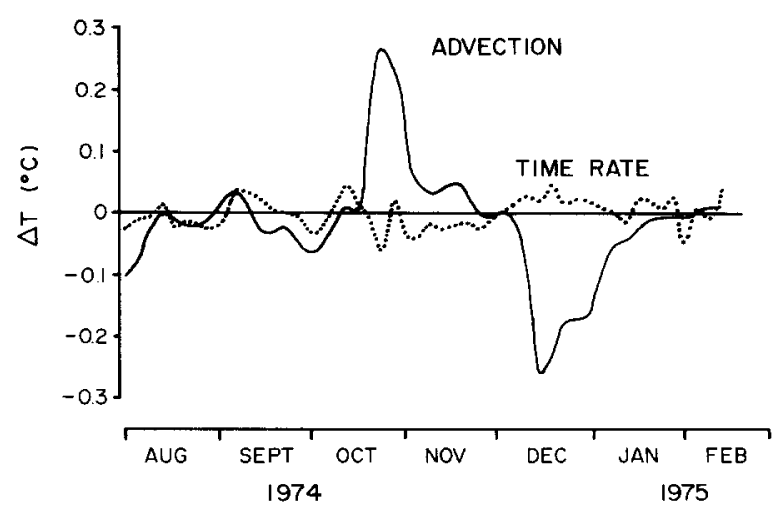

Fig. 17. Estimates of horizontal advection of temperature compared to time rate of change of temperature below the main thermocline at MODE-center. Note the large amplitude non-linear event in winter 1974 to 1975. [From RichmaN (1976).]

compared to MODE-1 data (i.e. 300-day periods), wholly linear, and have uniform distributions of horizontal scale in the vertical while current meter records suggest that eddies do not. Thus even the MODE-1 eddy, which is comparatively weak on the energy scale of eddies, appears to have been inherently nonlinear.

As was noted, the eddy kinetic energy density, and with it the tendency toward nonlinearity, appears to increase both northward and southward from the MODE-1 site, although latest historic XBT evidence suggests the southern increase is confined to the region near the Antillean topographic barrier (DANTZLER, 1977). The MODE-1 area itself provides evidence for the existence of nonlinear processes, through both MCWILLIAMS' (1976c) shorter term vorticity balances and BRYDEN's (1976) analysis of the heat balance in the International Waves Experiment (IWEX) moored array [0 (1 month) duration] near MODE center in November, 1973. Assuming geostrophy, hydrostatics, and a tight $T-S$ relationship, Bryden used the thermal wind equation to estimate horizontal advection of temperature in terms of speed and vertical turning of horizontal current, demonstrating that nonlinear advections are the same order of magnitude as temporal variability of temperature. RICHMAN (1976) carried out the same computation on the MODE-1 site mooring data and found (Fig. 17) advection and time variability to be about comparable throughout most of the record, except during an 80-day cold cyclonic event in late 1974 and early 1975, (possibly a ring) during which advection dominated temporal variations by a factor of five. [Most of thecurrent turning in this event, to which the advection estimate is sensitive, occurred between the thermocline and deep water, a characteristic also noted in a ring-like feature to the northeast of MODE-1 (MCCARTNEY et al., 1977).]

Three independent measures of the nonlinearity of the current field at $1500 \mathrm{~m}$ were given by FreELAND et al. (1975). The ratio of r.m.s. current speed to pattern propagation speed, 0.8 , suggests only marginally linear dynamics, as does the ratio of Eulerian to Lagrangian time scales. The ease with which mixing of fluid particles occurs, fully comparable to random walks of the same time and velocity scales, indicates a much stronger level of nonlinearity.

Thus, there is strong evidence, at least in the MODE area, in support of nonlinear eddy dynamics even though some well-verified properties such as westward phase propagation are temptingly reminiscent of linear wave dynamics. It must be borne in mind, however, 
that numerical models (e.g. RHINES, 1975) show such phase tendency well into the nonlinear range. Such pattern propagation could be unrelated to wave activity or quite different from phase velocity of constituent waves. Other areas, perhaps east of MODE-1, may have a greater tendency toward linearity while still others, to the north, are likely to be even more nonlinear.

\subsection{Direct wind forcing}

Phillips (1966) first modeled the eddy variability as wind-driven linear two-layer Rossby waves with bottom friction and fit his model to the Aries float measurements. Rough agreement was found, most of the energy being in the barotropic mode, but the wind driving was altogether too weak to account for the measured current strengths. Wind estimates in that region have recently been updated by BUNKER (1976), BUNKER and WORTHINGTON (1976) over rectangles of $2^{\circ}$ latitude and $5^{\circ}$ longitude. Moreover, a longer term larger scale record of eddy kinetic energy at $1500 \mathrm{~m}$ is now available from the MODESOFAR float data. LeETMAA (1978) re-examined the direct wind problem by applying Phillips' wind driving model to the new data and showed that $\left\{\left(v^{2}\right)_{\text {obs }} /\left(v^{2}\right)_{\text {predicted }}\right\}^{1 / 2}=1.4$ at the latitude of MODE-1, thus suggesting the wind could play a far more active role. Local estimates of wind stress during MODE-1 based on ambient noise levels as measured by the inverted echo sounder array suggest values even greater than those given by Bunker, which are averaged spatially over two-degree squares and temporally (SHAW, WATTS and RosSBY, 1977). The general latitudinal variation of $v^{2}$ predicted agrees well with that suggested by the SOFAR float energies in the band from 23 to $30^{\circ} \mathrm{N}$ (FrEELAND et al., 1975). LEETMAA (1978)also found strong evidence for direct wind forcing in long-term R.V. Panulirus time series, the vertical variability being induced by north-south advection of the ambient climatological temperat ure gradient by barotropic waves.

Philander (1978) has also suggested that direct wind driving can account, at least in part, for the low-frequency variability. He noted that in mid and high latitudes, surface wind variability is dominated by large-scale eastward propagating cyclones. Such disturbances force an oceanic response that penetrates to the ocean floor. Measurements in high latitudes [between Scotland and Iceland (MEINCKE, 1975), and in the Drake Passage (BAKer, Nowlin, Pillsbury and Bryden, 1977)] do show a correlation between fluctuations of the currents and variability of the surface winds. There is no clear evidence that this type of forcing is important in the MODE region.

\subsection{Topography}

Topographic generation mechanisms have been shown to be effective both for spectral redistribution of eddy energy in a developing numerical eddy field (OwENS and Bretherton, 1978) and as generators of isolated free vortices through mean current interactions with correspondingly isolated topographic features (HUPPERT and BRYAN, 1976). Nonlinear $\beta$-plane flat-bottom numerical process models tend toward barotropic flows with maximum length scales $\sim \sqrt{ }(U / \beta)$ (RHINES, 1977). Bottom topography, however, introduces smaller scale variability in the deep water and maintains the baroclinicity. (See Section 4.8 for additional discussion of scale transformation processes.) Both phenomena were observed in MODE-1, although the models underpredict the ratio of baroclinic to barotropic eddy energy for MODE-like parameters. Another numerical topographic mechanism noted by BRETHERTON (1975) is that a strong, deep large-scale 
barotropic current from the west (but not one from the east) can resonate with topographically induced Rossby waves to produce a remarkably energetic eddy field through form drag pressure work by the large-scale flow. For MODE-1 parameters, the required currents are very strong.

The HUPPERT and BRYAN (1976) mechanism induces an eddy by vortex stretching due to moderate flow over a bump. The advected eddies are cyclonic and warm, leaving anticyclonic cold eddies trapped over the perpetrating bump. Rather strong flows are required lest the current flow around the bump. Field evidence for this mechanism has been found only in strong Gulf Stream flows near large-scale topographic features.

Topographic effects, if anything, appear reversed in MODE-1. That is, small-scale topography seems to act as an energy sink, at least locally. Energy levels at $1500 \mathrm{~m}$ are lowest east of MODE-center over the rough terrain and the transition is most abrupt (FreEland et al., 1975). The role of rough topography in inducing the smaller scale deep variabilities in the MODE-1 maps remains equivocal, although the process models suggest a causal connection as does HoGG's (1976) mechanism. This effect of topography, which has been successfully modeled analytically, relates to the change induced in current profiles from first baroclinic mode-like structures over smooth bottoms to higher baroclinic modal structures with reduced upper layer shears and mid-depth maxima over rougher bottoms. Spatially growing (i.e. complex wave number) baroclinically unstable waves. bounded below in wave number, draw energy from an imposed mean shear field as it impinges upon a two-dimensional topographic feature. Comparison with a sequence of electromagnetic MODE-1 velocity profiles from smooth to rough topography is striking. The role of the larger scale topographic features such as the Mid-Atlantic Ridge in eddy generation and transformation is a subject for experimentation in POLYMODE.

The role of topography in inducing steady flows has been documented by the observations (SchmiTz, 1976b) of a new deep abyssal current moving southward along the western slope of the Bermuda Rise at $2 \mathrm{~cm} \mathrm{~s}^{-1}$ at $4000 \mathrm{~m}$ (compared to one-tenth that value over the Hatteras Abyssal Plain). The identification is based on 2 years' of moored current meter data at MODE-center and MODE-east. Preliminary estimates suggest the current intensifies toward the bottom and falls off with height up to about $1500 \mathrm{~m}$. Horizontal structure is unknown although the current seems to flow more nearly parallel to lines of constant depth than to constant Coriolis parameter over depth.

\subsection{Current related sources}

The case for open ocean baroclinic instability has been made (RoBINSON and MCWilliams, 1974), but the existing data base, limited though it is, and large-scale numerical models suggest such instability is an important source mechanism only in the near fields of energetic boundary current flows such as the Gulf Stream system or the North Equatorial Current in the North Atlantic. These regions are rich potential sources of eddy variability through both baroclinic (from available potential energy) and barotropic (from mean kinetic energy) instabilities, as well as through radiation from energetic Gulf Stream oscillations and meanders (HoLLAND and LiN, 1975a, b) and from detached and freely drifting Gulf Stream rings (FLIERL, 1977). Most indications implicate the intense boundary current regions as major probable source areas. The mechanisms are many and varied, but the relatively high available energy levels there, together with compatible matching of scales between the currents and the eddy variability, lend considerable support to this association. Explicit field documentation is another matter. Except for the North Equatorial 
Countercurrent (which will be a site for POLYMODE observations) these regions remain technologically inaccessible with present instrumental techniques.

\subsection{The role of internal waves}

The suggestion that internal waves may have a significant role in eddy dynamics and vertical mixing has sparked a renewed interest in deviations from the 'mean state' of stationarity, horizontal homogeneity and isotropy, and vertical symmetry. MülLER (1976) suggested that the modulation of the internal wave field by larger scale motions leads to a diffusion of mean flow momentum when relaxation processes are taken into account. For strong relaxation processes, as caused by nonlinear interaction among internal waves (Olbers, 1976; MCComas and Bretherton; 1977) the diffusion of momentum can be parameterized by diffusion coefficients. Müller predicts large values for the vertical viscosity $\left(\mu \sim 4 \times 10^{3} \mathrm{~cm}^{2} \mathrm{~s}^{-1}\right)$ in the main thermocline. By investigating the short-term variability of internal wave statistical properties on a portion of the MODE current meter data, FrANkigNoul $(1974,1976)$ observed the predicted correlation between internal wave horizontal anisotropy and mean horizontal shear. RUDDICK (1977) sought correlations between internal wave Reynolds stresses and the vertical shear of low-frequency currents using longer times series of POLYMODE current meter data. Because these stresses were calculated using temperature instead of vertical velocity, the estimates are very noisy. Nevertheless, the stresses were one order of magnitude smaller than Müller's prediction and uncorrelated with local shears in regions of low eddy activity. FRANKIGNOUL and JOYCE (1978) also could detect no large, positive viscosity during IWEX. This result is consistent with MCCOMAs (1977), who showed that the nonlinear processes controlling the vertical symmetry of the internal wave field have shorter characteristic time scales than interactions in a symmetric spectrum, thereby reducing Müller's predicted viscosity.

FRANKIGNOUL (1976) detected a correlation between the fluctuations in total internal wave energy* and mean square vertical shear, suggesting a local interaction with a somewhat smaller vertical viscosity than Müller's estimates. MüLLER (1977) predicted a large secular transfer of energy from the mean flow to the internal wave field. A comparable energy dissipation by wave breaking at near-inertial frequencies yielding a vertical diffusivity of mass of $0.3 \mathrm{~cm}^{2} \mathrm{~s}^{-1}$ in the main thermocline has been calculated by MüLLER and OLBERS (1975). To date, measurements of temperature microstructure dissipation have not been related to mesoscale variability. JOYCE (1976) observed a weak increase in temperat ure finestructure activity in the thermocline as the large shear of the Gulf Stream region is approached from the south. FRANKIGNOUL and JOYCE (1978) also observed finestructure modulation on the mesoscale. Whether these weak variations are related to internal waves or eddies is unknown. WUNSCH (1976) found only a weak increase (if any) in the internal wave continuum of energy as the Gulf Stream was approached in the deep water. A high energy increase was observed only in the immediate vicinity of seamounts, suggesting topographic generation and strong relaxation-dissipation.

Processes affecting the internal wave continuum may differ from those of near-inertial waves. For example, McComas (1977) found that vertical asymmetries at near-inertial frequencies are only weakly attenuated by relaxation processes. This is supported by LEAMAN and SANFORD (1975) and SANFORD (1975), who have shown that over smooth

\footnotetext{
* ZENK and KATZ (1975) found no heterogeneity in the high wavenumber part of towed spectra in the thermocline, but the tows were made in a short time-space interval ( $50 \mathrm{~km}$ radius, 3 days).
} 
topography the internal wave field at near-inertial periods is vertically asymmetric and energy propagates downward. LEAMAN (1976) estimated this net downward energy flux to be 0.2 to $0.4 \mathrm{ergs} \mathrm{cm}^{-2} \mathrm{~s}^{-1}$ and suggested that it is dissipated in the bottom boundary layer. Additional array data are needed to determine if these results can be connected to the eddy field.

\section{NUMERICAL RESULTS}

\subsection{Process models in eddy dynamics}

A process model is a numerical or theoretical model that attempts fully to resolve only a few of the important processes that occur in the real ocean. To achieve adequate numerical resolution, these models usually treat only a limited area, considered to be far from lateral boundaries. For convenience it is assumed that all fluctuating quantities can be constrained to be periodic over the length of the area considered. Interest attaches not so much to particular realizations of flows as to the statistical interpretation of presumed ensembles of such flows. In such models one may consider, for example, effects of stratification, of bottom topography, and of variable Coriolis parameter while retaining nonlinear advection terms. Although a considerable simplification over real ocean dynamics, these idealized models are complex. A beginning has been made, both qualitatively and quantitatively, in understanding this complexity. Present efforts focus on relating the growing understanding of process models to overall questions of ocean circulation.

The most complete discussion of what has been learned in process models is that of RHINES (1977). Here we summarize some of the more clear-cut results to date.

The most numerically ambitious process model has been that of BRETHERTON* and KARWEIT (1975), who resolved six layers in the vertical and $64 \times 64$ grid points horizontally. On a nominal cell of $1000 \times 1000 \mathrm{~km}$, this gives a horizontal resolution down to $15 \mathrm{~km}$. In each layer, evolution of a quasigeostrophic streamfunction is evaluated including effects of horizontal advection, of vortex stretching, and of $\beta$, the variation of Coriolis parameter. The uppermost layer is bounded by a horizontal, rigid, frictionless surface; the lowermost overlies realistic topography and includes a bottom Ekman layer. A particular innovation in this (B-K) model concerns the form of lateral vorticity diffusion. Some diffusion is required by the horizontal differencing to prevent an artificial accumulation of vorticity variance at the grid scale. Usually such diffusion is obtained ad hoc by providing a kinematic viscosity (i.e. $\nabla^{2}$ smoothing) several orders of magnitude larger than the physical viscosity, one consequence of which is a rapid unrealistic dissipation of kinetic energy. The B-K model assumes ad hoc a higher differencing $\left(\nabla^{4}\right)$ diffusion, which damps vorticity variance while only minimally damping energy or velocity variance.

Several experiments have been carried out on the B-K model, including (a) free decay of a random eddy field with energy density initially concentrated in the upper ocean, (b) baroclinic instability from an initial state of uniform shear across the main thermocline with the deeper fluid at rest, and (c) the spin-up of an eddy field from an impressed uniform barotropic flow either from the east or from the west. Other experiments have considered a single feature, e.g. the evolution of an isolated circular eddy or the breakup of a narrow jet.

\footnotetext{
* See also OWens and Bretherton (1978).
} 
One of the most satisfying results of these B-K experiments is the tendency of the model to redistribute energy among its vertical modes in a way rather like observed structures in the MODE area. Although this result appears to be sensitive to overall energy density in the model, it does suggest reassuringly that local eddy interactions are important to local statistical adjustments in contrast to a hypothesis that the basin circulation might directly determine the statistics of smaller scales of motion. Were the latter the case, the whole basis for limited area process modeling would be invalid.

Other results of B-K experiments include a tendency even in quite non-linear eddies to propagate westward as quasi-Rossby waves with some displacement northward (southward) for cyclonic (anti-cyclonic) eddies in their self-advection fields. A uniform barotropic current from the west across topography is found to shed a vigorous eddy field; from the east such a current is far less effective. This result appears to suggest resonant topographic forcing of steady Rossby waves-eddies. Baroclinic instability also is observed to proceed much in the way predicted by linear stability analysis (RoBINSON and MCWILliams, 1974). It is observed, however, that the inclusion of bottom topographic roughness generally inhibits baroclinic conversion and the subsequent tendency toward barotropicity.

The $\mathrm{B}-\mathrm{K}$ model is a relatively sophisticated calculation which appears to produce physically realistic local eddy dynamics. However, there remains the need for an analytical or, at least, conceptual account of the statistical tendencies observed in these calculations. For this we turn to the still simpler, more idealized models by RHINEs (1977).

Consider just a single layer with flat bottom. The physics consist only of vorticity advection and Rossby wave propagation. Advection alone constitutes the problem of twodimensional turbulence (2DT) which is broadly described by KRAICHNAN (1967) in terms of dual turbulent cascades. In higher wave numbers, vorticity variance or 'enstrophy' cascades into even finer scales of motion while in lower wave numbers energy grows upwards into even larger eddies in a so-called 'reverse cascade'. RHINEs (1975) observed that with $\beta$ present such larger eddies will begin to propagate at speeds faster than fluid advection speeds and so become decoupled from the turbulent cascade. Thus the reverse cascade will be arrested near a length scale $L_{\beta}=\sqrt{ }(2 U / \beta)$ where typical Rossby wave phase speeds equal typical fluid advection speeds $U$. Correspondingly an initially isotropic eddy field becomes anisotropic, preferring zonal motion, i.e. following contours of constant Coriolis parameter $f$.

Carrying further the idea of cascades, consider two-layer flow over a flat bottom. For length scales shorter than the deformation radius $L_{\rho}^{*}$ the layers are effectively decoupled. The 2DT reverse cascade in each layer causes eddies to grow in size toward $L_{\rho}$. For scales larger than $L_{\rho}$, baroclinic eddies are unstable and decay into eddies of scale $L_{\rho}$. Near $L_{\rho}$ layer coupling becomes important, eddies in the two layers become phase locked or barotropic and continue to grow in size but now as barotropic eddies. Finally this barotropic reverse cascade is arrested near $L_{\beta}$. If $L_{\beta}$ is not much larger than $L_{\rho}$, there is an effective mechanism for trapping energy.

Topography adds other complications. In the simplest case of one-layer flow with just advection and topography, it is observed numerically that an initially random eddy field becomes strongly correlated with topography (in the sense of anticyclonic circulation

${ }^{*} L_{\rho}=1 / \sqrt{ }\left(F_{1}+F_{2}\right), F_{i}=f^{2} / g^{\prime} H_{i}, g^{\prime}=g \Delta \rho / \rho$, where $H_{i}$ is the thickness of layer $i$ and $\Delta \rho$ the difference of density between layers. 
around hills) in the order of an eddy time scale. In the multilayer flow it has been noted that topography inhibits baroclinic conversion. Still, for scales smaller than $L_{\rho}$ deep layers become locked to topography while on larger scales topographic influence extends through the fluid column though not so effectively as in the one-layer models.

Combining solutions from linear dynamics with ideas of turbulent cascades and simple scale estimates, we form a coherent picture of much that is seen in numerical process models. Detailed quantitative interpretation still is missing as is a basic qualitative understanding of statistical tendencies. Why, for example, do cascades go one way rather than the other? Why is barotropic motion preferred in large eddies? Why do eddies lock to topography?

Salmon, Holloway and Hendershott (1976) suggest that statistical tendencies arise on account of the many interacting degrees of freedom in much the way that thermodynamic laws arise from many molecular collisions. Constructing the analogue of classical statistical mechanics, one obtains qualitatively many of the observed statistical tendencies: ratios of barotropic baroclinic energy, correlations with topography and cascade directions as disequilibrium tendencies combine toward classical equilibrium solutions. These results remain qualitative because they cannot account for dissipation, which has no classical analogue.

Quite another approach was taken by BRETHERTON and HAIDVOGEL (1976) who observed that quasi two-dimensional flows dissipate enstrophy preferentially over energy. The tendency thus is towards a state of minimum enstrophy for given energy. For the case of single-layer flow over topography, this variational solution yields a steady flow locked to the topography. The solution is like the solution of SALMON et al., (1976) and is qualitatively like simulated flows which are decaying toward such an asymptotic state.

The question of quantitative prediction of disequilibrium statistical evolution involves the closure problem of turbulence theory. However, recent advances in closure theory (e.g. Kraichnan, 1971) can be extended to problems of ocean dynamics. Holloway and HeNDERSHOTT (1977) observed that such closures accommodate interacting waves and, in the limit of weak waves, recover identically the more familiar resonant interaction approximation. Applied to nonlinear Rossby waves, this calculation obtains quantitatively both the cascade arrest and anisotropy discussed by Rhines. HERRING (1977) has given a closure for one-layer flow over topography, predicting evolution rates of energy spectra and of the vorticity topography correlation.

Numerically, conceptually and, in some part, analytically the statistical behavior of limited-area process models is coming to be understood. Now the focus changes toward integrating these building blocks into an overall dynamical model of ocean circulation, including realistic energetic sources and sinks. The computer will continue to play a central role through the construction of ocean basin circulation models with improved parameterization suggested by process models and with improved resolution as bigger and faster machines become available. Such high resolution ocean basin models are described in the following section, 4.9. Numerical investigation of limited area models with nonperiodic boundaries or partial lateral boundaries will be important. Extension of theoretical methods is suggested in the quasihomogeneous, quasilinear expansion by MCWILLIAMS (1976a) or in such spectral closures as those of KADOMTSEV (1965) or KraicHNAN (1972).

\subsection{Eddy-resolving oceanic general circulation models}

Numerical model studies of the general circulation which have sufficient horizontal resolution to describe explicitly the mesoscale eddy field within the larger-scale circulation 
are known as eddy resolving general circulation models (EGCMs). These fine horizontal resolution studies are carried out in closed basins and driven by simple large-scale forcing processes. Thus the eddies that occur do so spontaneously because of internal dynamical processes. The general approach is to integrate the equations of motion forward in time until a statistical equilibrium circulation is achieved, which is then analyzed to understand the dynamics of the model eddy flow, the processes responsible for the generation, transport. and dissipation of model eddy energy, and to examine the nature of the interaction between the eddy and the large-scale time mean flows. Although this type of work has only just begun the studies to date represent the initiation of a phase of numerical modeling necessary for the construction of a physically correct and credible general circulation model for the real oceans.

Eddy resolving general circulation experiments have been carried out with a range of model physical processes and numerical methods. Holland and LiN (1975a, b) used primitive equation dynamics with two layers in the vertical, flat-bottom basins, and single and double gyre steady zonal winds. Robinson, Harrison, Mintz and SEMTNER (1977) and SEMTNER and MinTz (1977) used primitive equation dynamics with five levels in the vertical, steady zonal winds, and thermal forcing. The RoBINson et al. (1977) experiment used a single gyre wind and a flat-bottom basin, while the Semtner and Mintz experiment used a multiple gyre wind and a basin with a coastline oriented to the northeast and with model continental shelf and slope topography. HoLland (1977b) has done further flat-bottom basin studies with quasigeostrophic dynamics and two levels. Subgrid-scale diffusive and dissipative processes have been modeled variously in the several studies including the traditional constant eddy viscosities (Laplacian friction), higher order eddy viscosity (biharmonic friction) and linear and nonlinear bottom friction. All of the above calculations used finite difference numerical methods, but HAIDvOGEL (1977) has introduced pseudo-spectral numerical methods with quasigeostrophic dynamics. Figure 18 provides examples of computed model flow fields.

Consider first the experiments with two layers in the vertical. HollaND and LIN (1975a, b) showed that mesoscale motions can appear spontaneously during the integration of the equations of motion for a baroclinic ocean from an initial state of rest. For some values of the model parameters (principally Ekman and Rossby numbers) the solutions come to a steady state with no eddies, while for other values finite amplitude eddies constitute a part of the final statistically steady state. In the eddying cases the flow can be described as a steady mean circulation co-existent with a set of eddies that propagate westward at a few kilometers per day. The eddies typically have periods of tens of days and horizontal wavelengths of a few hundred kilometers. Eddy motion is in some cases confined near the model Gulf Stream system but in other cases eddies populate the entire basin. Some combination of conversion of kinetic energy of the mean flow and of available potential energy into mean eddy kinetic energy maintains the eddies against dissipation. Eddy generation occurs in the eastward Gulf Stream or westward recirculation currents, or both, and the dominant energy conversion process depends on the particular parameters chosen for the model experiment. Many experiments show that the mean circulation of these eddying oceans can be significantly affected by the statistical nature of the eddy field.

The three quasigeostrophic two-layer experiments of Holland (1977b) examine the influence of geometries that produce free analog Gulf Stream jets in the center of a double gyre, as well as jets along the northern boundary of a single gyre. Additionally, the effects of a change in the model subgrid scale 'viscosity' parameterization, from Laplacian 

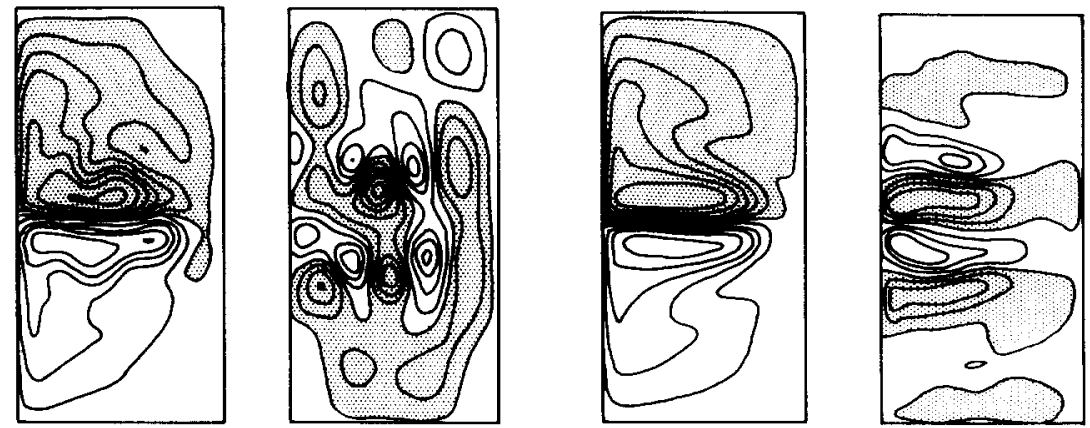

a
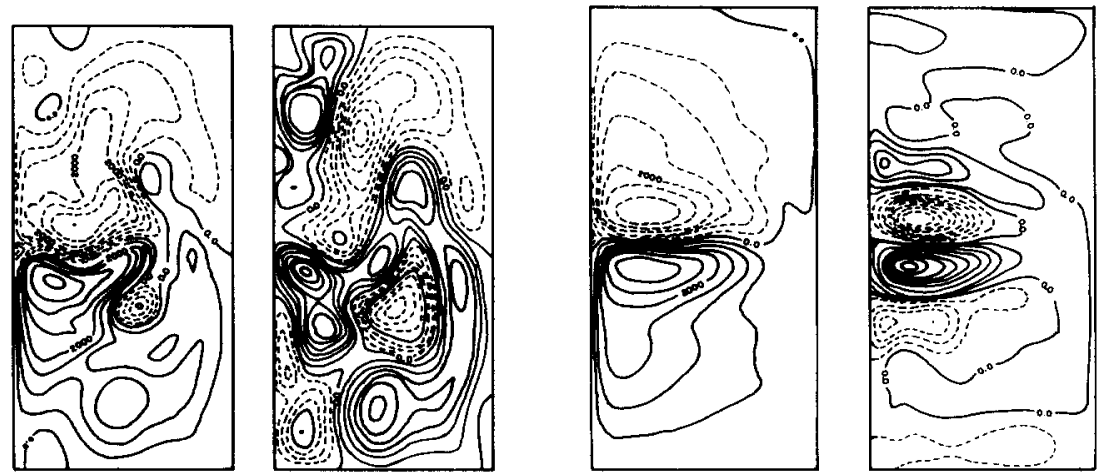

b
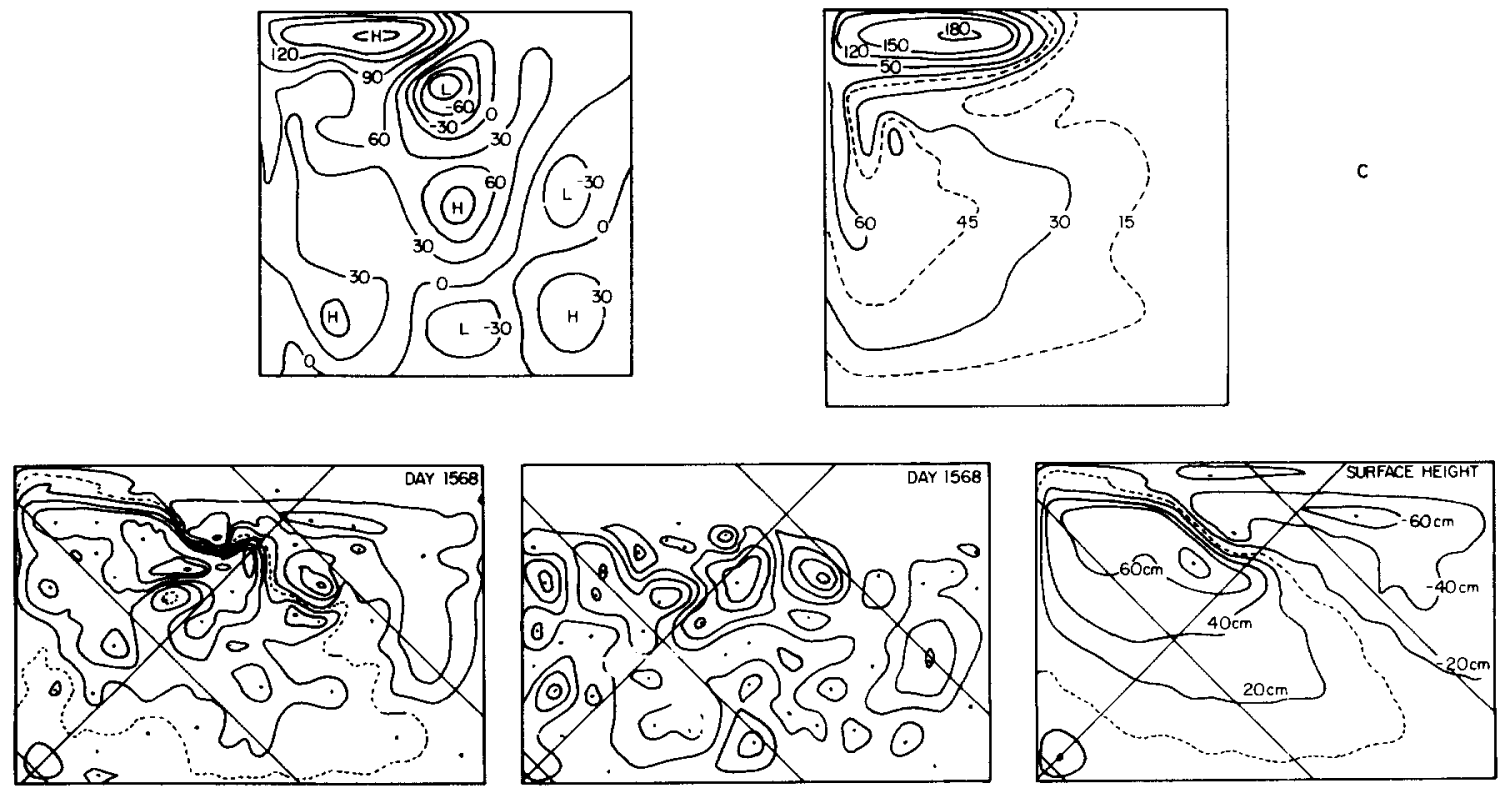

Fig. 18. Instantaneous and mean fields from several EGCM calculations: (a) upper and lower layer pressure from a two-layer primitive equation model (HoLLAND and LIN, 1975a, b); (b) upper and lower layer stream functions from a two-layer quasi-geostrophic model (HolLAND, 1977b); (c) transport function from the RoBINSON et al. (1977) five-layer primitive equation model; and (d) instantaneous surface, $2500-\mathrm{m}$ dynamic topography, and mean surface height from a five-layer primitive equation model (SEMTNER and MiNTZ, 1977). 
to biharmonic with linear bottom friction, were studied. These experiments show how wind energy put in at the sea surface is converted through mean kinetic energy into eddy kinetic energy, how eddy energy is transferred vertically downwards, and how deep mean abyssal gyres owe their existence to the model eddy fields.

The five-level primitive equation experiment of RoBINSON et al. (1977), which is wind and thermally driven, yielded a quasiequilibrium flow with an eddy field throughout the basin. The circulation is found to consist of several dynamically distinct regions. Conversion of the kinetic energy of the mean flow in the Gulf Stream recirculation is the primary energy source for the eddy flow, with a secondary source in the conversion of potential energy in the eastward flow along the western part of the southern boundary. Within the westward-flowing recirculation part of the Gulf Stream system and its adjacent near field, important eddy contributions to the mean heat and vorticity balances occur.

The flow that results in the five-level primitive equation experiment with certain largescale topographic features (SEMTNER and MinTZ, 1977) is also spatially complex. Its dominant feature is a strong meandering jet. Energy is removed from the mean flow (kinetic and potential) by eddy processes in the region where the model Gulf Stream is over the continental slope, but there is considerable input to the mean flow kinetic energy further offshore. Near the model Gulf Stream, eddy heat transports are comparable to mean flow transports, and local eddy effects can be strongly diffusive.

These numerical experiments provide for the first time complete, albeit model, data sets for ocean circulation systems including the low-frequency mesoscale variability. To understand the detailed dynamical information in these large data sets requires the construction of appropriate techniques of analysis that may ultimately influence the design of real ocean experiments and the analysis of oceanic observations. Dynamical analysis can serve not only to explain the results of particular experiments but also to explore the parameter dependencies and sensitivities indicated by the numerical results to date. Two such attempts are (i) local linear stability analysis and (ii) energy budget analysis for regions of the circulation with open boundaries.

HAIDvOGel and Holland (1978) apply two-dimensional linear instability theory to meridional profiles of EGCM-generated currents. They obtain linear predictions of the unstable regions of the currents, of the initial growth rates of the most unstable modes due to horizontal shear (barotropic) instability and vertical shear (baroclinic) instability, and of the characteristics of the unstable modes. They find that the stability analysis can correctly identify regions of instability best when the analysis is applied to instantaneous currents rather than time-mean ones and when the eddying flow is not too complicated or 'turbulent'. Many of the time-averaged solutions by Holland (1977b) show no sources of instability, a fact that may influence how best to apply simple stability theory to actual ocean currents.

HARRISON and RoBINSON (1978) developed an interpretation of the role of Reynolds stress-mean flow interaction work in open regions of a turbulent fluid flow, so that kinetic energy budgets over open regions can be studied. The concept of conversion between mean and eddy kinetic energies, which is central to the interpretation of this interaction integrated over a closed region, is not valid over an open region. These ideas have been applied to the different regions of the experimental flow of RoBINSON et al. (1977). Reynolds stress-mean flow interaction work converts kinetic energy of the mean flow into eddy energy in the recirculation and near field parts of the Gulf Stream, much of which is exported out of the production region by boundary pressure work to maintain the 
eddy field in the interior of the basin.

Intercomparison among different model results is an important method for evaluating the physical importance of and possibility of generalizing the results of particular experiments. This work has been initiated by several investigators. SEMTNER and HOLLAND (1978) have made an intercomparison between the experiment of SEMTNER and MINTZ (1977) and a two-layer wind and thermally-driven quasigeostrophic model designed to be as similar as possible to the Semtner and Mintz experiment. The results indicate that many aspects of the instantaneous and statistical mean behavior of both calculations are very similar. Much less computer time is needed to carry out quasigeostrophic experiments than for primitive equation calculations, and thus it is more efficient to investigate the parametric sensitivity of model EGCM systems under the assumption of quasigeostrophic rather than primitive equation dynamics whenever possible. Primitive equation dynamics are formally necessary, however, when model systems are sufficiently strongly forced to have intense boundary currents where the flow is not quasigeostrophic, when finite amplitude topographic effects are to be included, and when unrestricted thermal processes are to be modeled.

This EGCM work identifies the model Gulf Stream current system and its near field as the most important region for production of the energy of the eddy field. The details of the production process are strongly dependent on the model physical assumptions and parameter values. Much further work is needed to investigate the sensitivity of models similar to those discussed above and to determine if the same dynamical processes are responsible for the eddy field when other model physical processes (e.g. time-dependent wind and thermal forcing, linearized and finite amplitude mid-ocean topography, and different subgrid scale viscosity parameterizations) are included. Nonetheless an important general type of eddy production mechanism has been identified, one which may be expected to have its analogue in the real oceans, although whether or not this is the primary eddy production mechanism for the ocean cannot yet be surmised. These EGCMs represent a significant advance in general circulation modeling in that they explicitly resolve the momentum, heat, and vorticity transport properties of the eddy scale motion, rather than parameterizing them by the classical assumption of large constant diffusion coefficients. Future EGCM modeling results verified by field observations will provide, it is hoped, the basis of a physically accurate parameterization of the mesoscale, useful for coarse resolution large-scale computations.

\section{CONCLUSIONS}

Mid-ocean eddies, long known to mariners and hydrographers, are part of an energetic and structured variability field that is superimposed on the weaker gyre-scale mean circulation. Identifiable closed eddies are shown to be part of a continuum of scales up to gyre wide in length and (days) ${ }^{-1}$ in frequency. This variability is present in one form or another in all the World's oceans.

In the western North Atlantic, there is a persistent band of eddy variability of around 100 -day period and 70-km scale in which currents are horizontally nearly isotropic. Vertical scales are of the order of the depth and are observed to be principally the lowest mode over flat bottoms and higher mode over rough topography. Kinetic energy levels are up to several orders of magnitude above the mean and can vary markedly on the eddy $(\times 2)$, the sub-gyre $(\times 5)$, and gyre $(\times 100)$ scale. Kinetic energy levels at $1500 \mathrm{~m}$ over rough terrain appear to be less than those over nearby flat abyssal plains. 
One long record suggests that lower frequency variability $\left[<(200 \mathrm{day})^{-1}\right]$ is primarily zonal and strongly dominant in the main thermocline. Other records are too short for confirmation but not inconsistent with the result.

Eddy dynamics are consistent with geostrophy, nondivergence, and quasigeostrophic potential vorticity conservation. Different features are describable by balances varying from marginally to fully nonlinear.

The intensity of eddy and mean flow kinetic energy increases markedly northward of MODE-1 toward the Gulf Stream and to a lesser extent southward from MODE-1 toward the North Equatorial Current. The Gulf Stream is known to possess several intense varieties of variability on the eddy scale. Because the eddy and current fields are so intense in that region it is likely that the Gulf Stream (and possibly other free boundary currents in the gyre) is a source region for the variability. Numerical and analytical models support this conjecture and provide instability and radiative mechanisms, as well as details of the energy and scale transformation processes. Although all indicators implicate the boundary currents as at least one source of eddy energy, no conclusive field evidence has been put forward. Direct wind forcing has been shown to be a plausible and non-trivial potential source of eddy energy.

Reasonable analytical eddy-internal wave interaction mechanisms have been devised as eddy energy sinks. Large-scale numerical models suggest bottom dissipation, and process models provide various mechanisms for cascading to smaller scales. The issue remains equivocal.

Deep eddy momentum transports seem to vary directly in absolute magnitude with the mean large-scale flows north and east of MODE-1. The data are insufficient to resolve cause and effect. Deep eddy heat transports appear inadequate to account for the poleward climatological heat flux, but surface layer transports induced by eddy driving from below seem to be of the right magnitude and direction.

MODE-1 provided conclusive evidence for the existence of mid-ocean eddies and a fourdimensional densely-sampled data case history for analysis. As a direct result, successor and predecessor experiments have been interpreted with confidence in the context of a mesoscale eddy field. The results of MODE-1 and its successor experiments stand as the bases on which POLYMODE and future experiments to extend our understanding of eddies have and will be planned.

\footnotetext{
Acknowledgments ... In the U.S., principal support for MODE was jointly provided by the Office of Naval Research and the National Science Foundation through its Office of the International Decade of Ocean Exploration. Other support was derived from the National Center for Atmospheric Research (supported by NSF) and the National Oceanographic and Atmospheric Administration through their Atlantic Oceanographic and Meteorological Laboratory and the Geophysical Fluid Dynamics Laboratory at Princeton. The U.K. experiment was supported by the Natural Environment Research Council through the Institute of Oceanographic Sciences. This support is gratefully acknowledged. The paper was supported under NSF (IDOE) grant number OCE 7504215 A03, and is MODE Contribution Number 20.
} 


\section{The MODE Group}

BAKER D. J., JR.

Harvard University

BRETHERTON F. P.

Johns Hopkins University

Brown W.

Scripps Institution of

Oceanography

BRYAN K.

Geophysical Fluid Dynamics

Laboratory, Princeton University

BRYDEN $\mathrm{H}$.

Massachusetts Institute of

Technology/Woods Hole

Oceanographic Institution Joint

Program in Oceanography

Bush P. $\dagger$

Atlantic Oceanography and

Meteorology

Laboratory/N.O.A.A.

Cox C.S.

Scripps Institution of

Oceanography

Crease J.

Institute of Oceanographic

Sciences

DANTZLER H. L., JR.

Johns Hopkins University

DAvis R.

Scripps Institution of

Oceanography

FANDRY C.

Monash University

FILLOUX J. H.

Scripps Institution of

Oceanography

FlierL G.

Harvard University

FOFONOFF N.

Woods Hole Oceanographic

Institution

Frankignoul C. $\mathbf{J}$.

University of Hamburg

Freeland H. J.

Woods Hole Oceanographic

Institution

GoulD W. J.

Institute of Oceanographic

Sciences

HAidvogel D. B.

Massachusetts Institute of

Technology/Woods Hole

Oceanographic Institution Joint

Program in Oceanography
HANSEN D. V.

Atlantic Oceanography and

Meteorology

Laboratory/N.O.A.A.

HARRISON D. E.

Harvard University

HAR VEY R.

University of Hawaii

Hasselmann $\mathrm{K}$.

University of Hamburg

Hayes S. P.

Woods Hole Oceanographic

Institution

HENDERSHOTT M. C.

Scripps Institution of

Oceanography

HENDRY R.

Massachusetts Institute of

Technology/Woods Hole

Oceanographic Institution Joint

Program in Oceanography

HoGg N

Woods Hole Oceanographic

Institution

Holland W. R.

National Center for Atmospheric

Research

Holloway G.

Scripps Institution of

Oceanography

HUPPERT H. E.

University of Cambridge

JoYCE T. M.

Scripps Institution of

Oceanography

Katz E. J.

Scripps Institution of

Oceanography

LEAMan K. A.

Massachusetts Institute of

Technology/Woods Hole

Oceanographic Institution Joint

Program in Oceanography

Leetmaa A.

Atlantic Oceanography and

Meteorology

Laboratory/N.O.A.A.

MALONE F.

Lamont-Domfaty Geological

Observatory

MCWilliams J. C.

Harvard University
MiLlaRd R.

Woods Hole Oceanographic

Institution

MintZ Y.

University of California at Los

Angeles

MofJeld H.

Atlantic Oceanography and

Meteorology

Laboratory/N.O.A.A.

MOORE D. W

Massachusetts Institute of

Technology and Nova University

MÜLLER $P$.

University of Hamburg

Munk W.

Massachusetts Institute of

Technology/Woods Hole

Oceanographic Institution Joint

Program in Oceanography

Olbers D.

University of Hamburg

OWENS W. B.

Johns Hopkins University

POCHAPSKY T. E.

Lamont-Domerty Geological

Observatory

Rhines P. B.

Woods Hole Oceanographic

Institution

Richman J. G.

Massachusetts Institute of

Technology/Woods Hole

Oceanographic Institution Joint

Program in Oceanography

Richardson P. L.

University of Rhode Island

RICHARDSON W. S.

Nova University

RoBINSON A. R.

Harvard University

RossBy H. J.

Yale University

SALMON R. L.

Scripps Institution of

Oceanography

SANFORD T. B.

Woods Hole Oceanographic

Institution

SCARLET R.

Massachusetts Institute of

Technology

$\dagger$ Deceased. 
Schmitz W. J., JR.

Woods Hole Oceanographic Institution

SCHROEDER E. H.

Woods Hole Oceanographic Institution

SeAver G.

Massachusetts Institute of

Technology

Semtner A. J.

University of California at Los Angeles

Simmons W.

Massachusetts Institute of

Technology
SNODGRASS F.

Scripps Institution of

Oceanography

Stommel $\mathrm{H}$.

Massachusetts Institute of

Technology

Sturges W.

Florida State University

Swallow J. C.

Institute of Oceanographic

Sciences

VOORHIS A. D.

Woods Hole Oceanographic Institution

WaTtS R.

Yale University
WEARN R. B.

Harvard University

WEBB D.

Woods Hole Oceanographic

Institution

Webster F

Woods Hole Oceanographic

Institution

WuNSCH C.

Massachusetts Institute of

Technology

ZENK W.

Institut für Meereskunde an der

Universitat Kiel

ZETLER B

Scripps Institution of

Oceanography

\section{REFERENCES}

ACADEMY OF SCIENCES OF THE UKRANIAN S.S.R. (1977) Investigations of the synoptic variability of the ocean Materials of the Joint Soviet-American Theoretical Institute POLYMODE (Y ALTA 1976). MONIN A. S. and B. A NeLEPo editors. Marine Hydrophysical Institute, pp. 500.

Amos A. F., A. L. Gordon and E. D. Schneider (1971) Water masses and circulation patterns on the region of the Blake-Bahama outer ridge. Deep-Sea Research, 18, 145-165.

ANDREWS J.C. and P.SCULly-PowER (1976) The structure of an East Australian Current anticyclonic eddy.Journal of Physical Oceanography, 6, 756-765.

ARMi L. (1977) The dynamics of the bottom boundary layer of the deep ocean. In: Elsevier oceanography series, Vol. 19 Bottom Turbulence, JACQUES C. J. NIKoul, editor, Elsevier, pp. 306.

ARMI L. and R. C. MillaRD, JR. (1976) The bottom boundary layer of the deep ocean. Journal of Geophysical Research, 81, 4983-4990.

Baker, D. J., R. B. Wearn and W. Hill (1973) Pressure and temperature measurements at the bottom of the Sargasso Sea. Nature, 245, 25-26

Baker D. J., JR., W. D. Nowlin JR., R. D. Pillsbury and H. Bryden (1977) Antarctic circumpolar current : space and time scale fluctuations in the Drake Passage. Nature, 268, 696-698.

Bennett, D. and J. H. Filloux (1975) Magnetotelluric deep electrical sounding and resistivity. Reviews of Geophysics and Space Physics, 13, 147-239.

Bernstein R. L. and W. B. White (1974) Time and length scales of baroclinic eddies in the Central North Pacific Ocean. Journal of Physical Oceanography, 4, 613-623.

BoOKER J. R. and F. P. BRETHERToN (1967) The critical layer for internal gravity waves in a shear flow. Journal of Fluid Mechanics, 27, 513-539.

Brekhovskikh L. M., K. N. Fedorov, L. M. Fomin, M. N. Koshlyakov and A. D. Yampolsky (1971) Large-scale multi-buoy experiment in the tropical Atlantic. Deep-Sea Research, 18, 1189-1206.

BRETHERTON F. P. (1975) Recent developments in dynamical oceanography. Quarterly Journal of the Royal Meteorological Society, 101, 705-721.

Bretherton F. P. and D. B. Haidvogel (1976) Two-dimensional turbulence above topography. Journal of Fluid Mechanics, 78, 129-154.

BRETHERTON F. P. and M. KARWEIT (1975) Mid-ocean mesoscale modelling. Numerical Models of Ocean Circulation, pp. 237-249, National Academy of Science, Washington, DC, $364 \mathrm{pp}$.

Bretherton F. D., R. Davis and C. FANDRY (1976) A technique for objective analysis and design of oceanographic experiments. Deep-Sea Research, 23, 559-582.

Brown W., W. Munk, F. SNodgrass, H. Mofjeld and B. Zetler (1975) MODE bottom experiment. Journal of Physical Oceanography, 5, 75-85.

BryDEN H. (1976) Horizontal advection of temperature for low-frequency motions. Deep-Sea Research, 23, $1165-1174$

BRYDEN H. (1977) Geostrophic comparisons from moored measurements of current and temperature during the Mid-Ocean Dynamics Experiment. Deep-Sea Research, 24, 667-681.

BRYDEN H. and N. FOFONOFF (1977) Horizontal divergence and vorticity estimates from velocity and temperature measurements in the MODE region. Journal of Physical Oceanography, 7, 329-337.

Bunker A. F. (1976) Computations of surface energy flux and annual air-sea interaction cycles of the North Atlantic Ocean. Monthly Weather Review, 104, 1122-1140.

Bunker A. F. and L. V. Worthington (1976) Energy exchange charts of the North Atlantic Ocean. Bulletin 
of the American Meteorological Society, 57, 670-678.

Bush P. (1976) Bathymetry of the MODE-1 region. Deep-Sea Research, 23, 1105 1113.

Caston G. F. and J. C. Swallow (1972) N.I.O. Internal Reports D9 and D10 (reporting 41 short neutrally buoyant float trajectories at $1 \mathrm{~km}$ and $2 \mathrm{~km}$ depth in the N.W. Indian Ocean). (Unpublished document.)

Chausse D. and S. TARBell (1976) A compilation of moored current data and associated ocean observations, Volume XII, 1973, Mid-Ocean Dynamics Experiment (MODE). Woods Hole Oceanographic Institution. Ref. 76-101. (Unpublished manuscript.)

Cheney R. E. and P. L. Richardson (1976) Observed decay of a cyclonic Gulf Stream ring. Deep-Sea Research, 23, 143-155.

Cheney R. E., W. H. Gemmill, M. K. Shank, P. L. Richardson and D. WebB (1976) Tracking a Gulf Stream ring with SOFAR floats. Journal of Physical Oceanography, 6, 74I-749.

Cox C. S., J. H. Fillioux, D. I. Gough, J. C. Larsen, K. A. Poehls, R. P. Von Herzen and R. Winter (1978) Atlantic lithosphere sounding. The Geophysical Journal of the Royal Astronomical Society (to be submitted).

CREASE J. (1962) Velocity measurements in the deep water of the western North Atlantic, summary. Journal of Geophysical Research, 67, 3173-3176.

DANTZleR H. L.. JR. (1976) Geographic variations in intensity of the North Atlantic and North Pacific eddy fields. Deep-Sea Research, 23, 783-796.

Dantzler H. L., JR. (1977) Potential energy maxima in the tropical and subtropical North Atlantic. Journal of Physical Oceanography, 7, 512-519.

DaviS R. (1975) Statistical methods. In Dynamics and the analysis of MODE-1: a report to the MODE-1 Scientific Council by the MODE-1 Dynamics Group. Department of Meteorology, Massachusetts Institute of Technology. (Unpublished manuscript.)

Dexter S., J. Milliman and W. J. Schmit7. JR. (1975) Mineral deposition in current meter bearings. Deep-Sea Research, 22, 703-706.

Dow D. L., H. T. Rossby and S. R. Signorini (1977) SOFAR floats in MODE: final report of float trajectory data. University of Rhode Island, Technical reference number 77 3. (Unpublished manuscript.)

DuNCAN C. P. (1968) An eddy in the subtropical convergence southwest of South Africa. Journal of Geophysical Research, 73, 531-534.

EltaNin RePorts (1974) Lamont-Doherty Geological Observatory Technical Report CU-2-74 (ten near bottom current meter records near $125^{\circ} \mathrm{E}, 50^{\circ} \mathrm{S}$ ). (Unpublished document.)

Fifiri. G. (1977) The application of linear quasigeostrophic theory to Gulf Stream rings. Joumal of Phisical Oceanography, 7, 365-379.

Flifrl G. and J. C. MCWilliams (1977) On the sampling requirements for measuring moments of eddy variability. Journal of Marine Research, 35(4), 797-820.

Frankignoul C. J. (1974) Observed anisotropy of spectral characteristics of internal waves induced by low frequency currents. Journal of Physical Oceanography, 4, 625 634.

FrankigNoUl C. J. (1976) Observed interaction between oceanic internal waves and mesoscale eddies. Deep-Sea Research, 23, 805-820.

Frankignoul C. J. and T. M. Joyce (1978) On energy and momentum exchange of the internal wave field during IWEX. Journal of Geophysical Research. (In press.)

Freeland H. J. and J. Gould (1976) Objective analysis of mesoscale ocean circulation features. Deep-Sea Research, 23, 915.924.

Freeland H. J., P. B. Rhines and H. T. Rossby (1975) Statistical observations of the trajectories of neutrally buoyant floats in the North Atlantic. Journal of Marine Research, 33, 383-404.

FugLister F. C. (1960) Atlantic Ocean atlas of temperature and salinity profiles and data from the International Geophysical Year of 1957-1958. The Woods Hole Oceanographic Institution.

Fuglaster F. C. (1972) Cyclonic rings formed by the Gulf Stream, 1965-1966. Studies in physical oceanography Vol. 1. ARnOLD L. GoRdon, editor Gordon \& Breach, pp. 137-167.

GANDIN L. S. (1965) Objective analysis of meteorological fields. Israel Program for Scientific Translations, $242 \mathrm{p}$.

Gould W. J. (1976) A formation zone for Big Babies near the Mid-Atlantic Ridge? POLYMODE News No. 16, Woods Hole Oceanographic Institution. (Unpublished document.)

Gould W. J., W. J. Schmitz, JR. and C. Wunsch (1974) Preliminary field results for a Mid-Ocean Dynamics Experiment (MODE-0). Deep-Sea Research, 21, 911 -931.

HAIDVOGEL D. B. (1977) Quasi-geostrophic regional and general circulation modelling: an efficient pseudospectral approximation technique. Proceedings: ASME Symposium on Computing Methods in Geophysical Mechanics.

HAIDVOGEL D. B. and W. R. Holland (1978) The stability of ocean currents in eddy-resolving general circulation models. Journal of Physical Oceanography, 8(3), 393-413.

Hammond A. L. (1974) Undersea storms: experiment in the Atlantic. Science, 195, $244-247$.

HARRISON D. E. and A. R. RoBINSON (1978) Energy analysis of open regions of turbulent mean eddy energetics of a numerical ocean eddy experiment. Dynamics of Oceans and Atmosphores, 2, 185-211.

HAYES S. P. (1975) The temperature and salinity fine structure of the Mediterranean water in the western Atlantic. Deep-Sea Research, 22, 1-11. 
Hendry R. (1975) The generation, energetics, and propagation of internal tides in the western North Atlantic Ocean. Ph.D. Thesis, Massachusetts Institute of Technology and Woods Hole Oceanographic Institution.

Hendry R. (1977) Observations of the semidiurnal tide in the western North Atlantic Ocean. Philosophical Transactions of the Roval Society of London. A286, 1-24.

HerRING J. R. (1977) On the statistical theory of two-dimensional topographic turbulence. Journal of Atmospheric Science, 34, 1731-1750.

HogG N. (1974) Balance of terms. In Dynamics and the analysis of MODE-1: report of the MODE-1 dynamics group. Department of Meteorology, Massachusetts Institute of Technology. (Unpublished document.)

HoGG N. (1976) On spatially growing baroclinic waves in the ocean. Journal of Fluid Mechanics. 78, 217-236.

HoGg N. (1977) Temperature maps. In: Atlas of the Mid-Ocean Dynamics Experiment (MODE-1). V. LEE and C. WunsCH, editors, MODE-1 Atlas Group, Massachusetts Institute of Technology, pp. 274.

Holland W. R. (1977a) Oceanic general circulation models. In The Sea, Vol. 6: Marine Modeling. E. D. GoldBERG, I. N. McCave, J. J. O'Brien and J. H. Steele, editors, John Wiley, pp. 1048.

HOLLAND W. R. (1977b) The role of mesoscale eddies in the general circulation of the ocean : numerical experiments using a quasi-geostrophic model. Journal of Physical Oceanography, 8(3), 363-392.

HollaND W. R. and L. B. LiN (1975a) On the generation of mesoscale eddies and their contribution to the oceanic general circulation I. A preliminary numerical experiment. Journal of Physical Oceanography, 5, 642-657.

Holland W. R. and L. B. LIN (1975b) On the generation of mesoscale eddies and their contribution to the oceanic general circulation II. A parameter study. Journal of Physical Oceanography, 5, 658-669.

Holloway G. and M. C. Henderschott (1977) Stochastic closure for nonlinear Rossby waves. Journal of Fluid Mechanics, 82, 747-765

Hunkins K. L. (1974) Subsurface eddies in the Arctic Ocean. Deep-Sea Research, 21, 1017-1033.

Huppert H. E. and K. Bryan (1976) Topographically generated eddies. Deep-Sea Research, 23, 655-679.

JOYCE T. M. (1976) Large-scale variations in small-scale temperature/salinity fine structure in the main thermocline of the northwest Atlantic. Deep-Sea Research. 23, 1175-1186.

K adomtsev B. B. (1965) Plasma Turbulence. Academic Press, pp. 149.

KaTz E. J. (1975) Tow spectra from MODE. Journal of Geophysical Research, 80, 1163-1167.

Kraichnan R. H. (1967) Inertial ranges in two-dimensional turbulence. The Physics of Fluids, 10, $1417-1423$.

Kraichnan, R. H. (1971) An almost-Markovian Galilean-invariant turbulence model. Journal of Fluid Mechanics, 47, 513-524.

Kraichnan R. H. (1972) Test field model for inhomogeneous turbulence. Journal of Fluid Mechanics, 56, 287-304.

LaI D. Y. and P. L. Richardson (1977) Distribution and movement of Gulf Stream rings. Journal of Physical Oceanography, 7, 670-683.

LEAMAN K. D. (1976) Observations of the vertical polarization and energy flux of near-inertial waves. Journal of Physical Oceanography, 6, 894-908.

LeAmAn K. D. and T. B. SANFord (1975) Vertical energy propagation of inertial waves: a vector spectral analysis of velocity profiles. Journal of Geophysical Research, 180, 1975-1978.

LeETMAa A. (1977a) A study of MODE dynamics. Deep-Sea Research, 24, 733-742.

LeETMAa A. (1977b) Observations of large scale depth perturbations in the main thermocline. Journal of Physical Oceanography, 7, 746-748.

LeETMAA A. (1977) Maps. In: Atlas of the Mid-Ocean Dynamics Experiment (MODE-1). V. LeE and C. WUNSCH, editors, MODE-1 Atlas Group, Massachusetts Institute of Technology, pp. 274.

LFETMAA A. (1978) Fluctuating winds, an energy source for mesoscale motions. Journal of Geophysical Research, 83, $427-430$.

MCCartney M. S., L. V. Worthington and W. J. Schmitz, JR. (1977) Large cyclonic rings from the northeast Sargasso Sea. Journal of Geophysical Research, 83, 901-914.

McComas C. H. (1977) Equilibrium mechanisms within the oceanic internal wave field. Journal of Physical Oceanography, 7, 836-845.

MCCOMAs and F.P. BreTherton (1977) Resonant interaction of oceanic internal waves. Journal of Geophysical Research, 82, 1397-1412.

McWilliams J. C. (1976a) Large scale inhomogenieties and mesoscale ocean waves: a single stable wave field Journal of Marine Research, 34, 423-456.

MCWilliams J. C. (1976b) Maps from the Mid-Ocean Dynamics Experiment: Part I. Geostrophic streamfunction. Journal of Physical Oceanography, 6, 810-827.

MCWilliams J. C. (1976c) Maps from the Mid-Ocean Dynamics Experiment: Part II. Potential vorticity and its conservation. Journal of Physical Oceanography, 6, 828-846.

MCWILliams J. and G. Flierl (1976) Optimal quasigeostrophic wave analysis of MODE array data. Deep-Sea Research, 23, 285-300.

MeINCKE J. (1975) Overflow '73 - evidence for atmospheric forcing of Arctic water overflow events. Institüt für Meereskunde, Kiel. (Unpublished manuscript.)

MODE-1 Atlas Group (1977) Atlas of the Mid-Ocean Dynamics Experiment (MODE-1). V. LeE and C. WUNSCH, 
editors, Massachusetts Institute of Technology.

MODE-1 Dynamics Group (1975) Dynamics and the analysis of MODE-1: a report to the MODE-1 Scientific Council. Department of Meteorology, Massachusetts Institute of Technology. (Unpublished document.)

MODE-1 INTERCOMPARISON GROUP (1974) Instrument description and intercomparison report: a report to the MODE-1 Scientific Council. Department of Meteorology, Massachusetts Institute of Technology. (Unpublished document.)

MODE-1 SCIENTIFIC Council (1973) MODE-1: an overview of the program and detailed description of the field experiment. Department of Meteorology, Massachusetts Institute of Technology. (Unpublished document.)

MODE-1 Synoptic Atlas Group (1974) MODE-1 draft synoptic atlas, a report to the MODE-1 Scientific Council. Department of Meteorology, Massachusetts Institute of Technology. (Unpublished document.)

MUlller P. (1976) On the diffusion of momentum and mass by internal gravity waves. Journal of Fluid Mechanics, 77, 789-823.

MƯlLER P. (1977) Spectral features of the energy transfer between internal waves and a larger scale shear flow. Dynamics of Atmospheres and Oceans, 2, 49-72.

Müller P. and D. Olbers (1975) On the dynamics of internal waves in the deep ocean. Journal of Geophysical Research, 80, 3848-3860.

Oceanus (1976) Ocean eddies. W. H. MACLeISH, editor. Woods Hole Oceanographic Institution, Vol. 19, No. 3.

OLbers D. (1976) Nonlinear energy transfer and the energy balance of the internal wave field in the deep ocean. Journal of Fluid Mechanics, 74, 375-399.

OWens W. B. and F. P. Bretherton (1978) A numerical study of mid-ocean mesoscale eddies. Deep-Sea Research, 25, 1-14.

Patzert W. C. and R. L. Bernstein (1976) Eddy structure in the central South Pacific. Journal of Physical Oceanography, 6, 392-394.

Philander G. (1978) Forced oceanic waves. Reviews of Geophysics and Space Physics, 16, 15-46.

Phillips N. A. (1966) Large-scale eddy motion in the western Atlantic. Journal of Geophysical Research, 71, 3883-3891.

Pochapsky T. E. (1976) Vertical structure of currents and deep temperatures in the western Sargasso Sea. Journal of Physical Oceanography, 6, 45-56.

Poehls K. A. and R. P. VoN Herzen (1976) Electrical resistivity structure beneath the northwest Atlantic Ocean. Geophysical Journal of the Royal Astronomical Society, 47, 331-346.

Rhines P. B. (1975) Waves and turbulence in a $\beta$-plane. Journal of Fluid Mechanics, 69, 417.

RHINes P. B. (1977) The dynamics of unsteady currents. In: The Sea, Vol. 6: Marine Modeling, E. D. GoLDBERG, I. N. MCCAVE, J. J. O'Brien and J. H. SteEle, editors, John Wiley, pp. 1048.

Richardson, P. L., R. E. Cheney and L. A. Mantini (1977) Tracking a Gulf Stream ring with a free drifting surface buoy. Journal of Physical Oceanography, 7, 580-590.

Richardson, W. S., H. J. White, JR. and L. Nemeth (1972) A technique for the direct measurement of ocean currents from aircraft. Journal of Marine Research, 30, 259-268.

Richman, J. G. (1976) Kinematics and energetics of the mesoscale mid-ocean circulation: MODE. Ph.D. Thesis, Massachusetts Institute of Technology/Woods Hole Oceanographic Institution.

Richman J. G., C. Wunsch and N. G. Hogg (1977) Space and time scales of mesoscale motion in the sea. Reviews of Geophysics and Space Physics, 15, 385-420.

Riser S. C., H. FreElaND and H. T. Rossby (1978) Observations of mesoscale motions near the western boundary of the North Atlantic. Deep-Sea Research, (in press).

Robinson A. R. (1975) The variability of ocean currents. Reviews of Geophysics and Space Physics, 13, 598-601.

Robinson A. R., D. E. Harrison, Y. Mintz and A. J. Semtner (1977) Eddies and the general circulation of an idealized ocean gyre: a wind and thermally driven primitive equation numerical experiment. Journal of Physical Oceanography, 7, 182-207.

Robinson A. R., J. R. LuYten and F. C. Fuglister (1974) Transient Gulf Stream meandering. Part I: An observational experiment. Journal of Physical Oceanography, 4, 237-255.

Robinson A. R. and J. C. McWilliams (1974) The baroclinic instability of the open ocean. Journal of Physical Oceanography, 4, 281-294.

Rossby H. T., A. Voorhis and D. WeBs (1975) A quasi-Lagrangian study of mid-ocean variability using long range SOFAR floats. Journal of Marine Research, 33, 355-382.

RuDDICK B. R. (1977) Observations of interaction between the internal wave field and low frequency flows in the northern Atlantic. Ph.D. Thesis, Massachusetts Institute of Technology/Woods Hole Oceanographic Institution.

Salmon R. L., G. Holloway and M. C. Hendershott (1976) The equilibrium statistical mechanics of simple quasi-geostrophic models. Journal of Fluid Mechanics, 75, 691-703.

SANFORD T. B. (1974) Observations of strong current shears in the deep ocean and some implications on sound rays. Journal of the Acoustical Society of America, 56, 118-121. 
SANFORD T. B. (1975) Observations of the vertical structure of internal waves. Journal of Geophysical Research, 80, 3861-3871.

SANFORD T, and H. BRYden (1974) Velocity profiles. Dynamics and the Analysis of MODE-1. Report of the MODE-1 Dynamics Group. Department of Meteorology, Massachusetts Institute of Technology. (Unpublished document.)

Sanford T. B., R. G. Drever and J. H. Dunlap (1978) A velocity profiler based on the principles of geomagnetic induction. Deep-Sea Research, 25, 183-210.

SChMitz W. J., JR. (1976a) Eddy kinetic energy in the deep western North Atlantic. Journal of Geophysical Research, 81, 4981-4982.

Schmitz W. J., JR. (1976b) Observation of a new abyssal current. Geophysical Research Letters, 3, $373-374$.

SCHMitz W. J., JR. (1977) On the deep general circulation of the western North Atlantic. Journal of Marine Research, 35, 21-28.

SCHMitz W. J., JR. (1978) Observations of the vertical distribution oflow frequency kinetic energy in the western North Atlantic. Journal of Marine Research, 36, 295-310.

SCHROEDER E. H. (1966) Average surface temperatures of the western North Atlantic. Bulletin of Marine Science, $16,302-323$.

SCOR WORKING Group 21 (1974) An intercomparison of some current meters. II : Report on an experiment carried out from the Research Vessel Akademik Kurchatov, March-April, 1970, by the Working Group on continuous current velocity measurements. UNESCO Technical Papers in Marine Sciences, No. 17, 16 pp.

Seaver G. (1975) Two XBT sections in the North Atlantic. MODE Hot Line News, 84. F. Webster, editor, Woods Hole Oceanographic Institution. (Unpublished manuscript.)

SEMTNER A. J. and W. R. Holland (1978) Intercomparison of quasi-geostrophic ocean models with primitive equation models. Journal of Physical Oceanography, (in press).

SemtNer A. J. and Y. Mintz (1977) Numerical simulation of the Gulf Stream and ocean eddies. Journal of Physical Oceanography, 7, 208-230.

Shaw P. T., D. R. WATts and H. T. Rossby (1978) On the estimation of ocean wind speed from ambient noise measurements. Deep-Sea Research (in press).

SNodgrass F., W. Brown and W. MUNK (1975) MODE: IGPP measurements of bottom pressure and temperature. Journal of Physical Oceanography, 5, 63-74.

Swallow M. (1961) Deep current in the open ocean. Oceanus, 7, 2-8.

Swallow J. C. (1971) The Aries current measurement in the western North Atlantic. Philosophical Transactions of the Royal Society of London, A, 270, 451-460.

SWALlow J. C. (1976) Variable currents in mid-ocean. Oceanus, 19, 19-25.

SWALlow J. C. (1977) An attempt to test the geostrophic balance using MINIMODE current measurements. Deep-Sea Research (Supplement).

Swallow J. C., B. S. MCCarTney and N. W. Millard (1974) The MINIMODE float tracking system. Deep-Sea Research, 21, 573-595.

U.S. POLYMODE ORganizing Committee (1976) U.S. POLYMODE program and plan. Department of Meteorology, Massachusetts Institute of Technology. (Unpublished manuscript.)

VONDER HAar, T. H. and A. M. OORT (1973) New estimate of the annual poleward energy transport by northern hemisphere oceans. Journal of Physical Oceanography, 2, 169-172.

Voorhis, A. D. (1969) The horizontal extent and persistence of thermal fronts in the Sargasso Sea. Deep-Sea Research, 16 (Suppl.), 331-337.

Voorhis A. D. and J. B. Hersey (1964) Oceanic thermal fronts in the Sargasso Sea. Journal of Geophysical Research, 69, 3809-3814.

Voorhis A. D., E. H. Schroeder and A. LeetmaA (1976) The influence of deep mesoscale eddies on sea surface temperature in the North Atlantic subtropical convergence. Journal of Physical Oceanography, 6 , 953-961.

Watts R. and H. T. RossBy (1977) Measuring dynamic heights with inverted echo sounders: results from MODE. Journal of Physical Oceanography, 7, 345-358.

WiLson W. S. and J. P. DUGAN (1977) Mesoscale thermal variability in the vicinity of the Kuroshio Extension. Journal of Physical Oceanography, 8, 537-540.

Worthington L. V. (1976) On the North Atlantic circulations. The Johns Hopkins Oceanographic Studies, The Johns Hopkins University press, pp. 110.

WuNSCH C. (1976) Geographical variability of the internal wave field: a search for sources and sinks. Journal of Physical Oceanography, 6, 471-485.

Wyrtki K., L. MAGAard and J. HAGer (1976) Eddy energy in the oceans. Journal of Geophysical Research, 81, 2641-2646.

ZENK W. and E. J. KATZ (1975) On the stationarity of temperature spectra at high horizontal wave numbers. Journal of Geophysical Research, 80, 3885-3891.

Zetler B., W. Munk, H. Mofjeld, W. Brown and F. Dormer (1975) MODE tides. Journal of Physical Oceanography, 5, 430-441. 


\section{NOTE ADDED IN PROOF}

Several MODE contributions not referenced in the text have appeared during the production of the paper. They are listed below for completeness:

Frankignoul C. and P. Müller (1978) Quasi-geostrophic response of an infinite $\beta$-plane ocean to stocastic forcing by the atmosphere. Journal of Physical Oceanography (in press).

FLIERL G. R. and A. R. RoBINSON (1978) XBT measurements of thermal gradients in the MODE eddy. Journal of Physical Oceanography, 7, 300-302.

Richardson P. L., R. E. ChENEY and L. V. WORTHINGTON (1978)GulfStream rings: a quasi-synoptic census. Journal of Geophysical Research (submitted).

Robinson A. R., D. E. HARRison and D. B. Haidvogel (1978) Mesoscale eddies and general circulation models. Dynamics of Oceans and Atmospheres (submitted).

WaTts R. (1978) Gulf Stream ring coalescence with the Gulf Stream off Cape Hatteras. Science (in press).

WEBB D. (1977) SOF AR floats for POLYMODE. Oceans 77 Conference Record, Proceedings of Oceans 77 Conference, Vol. 2, p. 44b1-44b5, Los Angeles, CA.

WunsCH C. (1978) The North Atlantic general circulation west of 50 degrees west determined by inverse methods. Reviews of Geophysics and Space Physics (in press). 